\title{
Antibacterial effects of New Zealand plant extracts against mycobacteria
}

\author{
A thesis \\ submitted in partial fulfilment \\ of the requirements \\ for the degree of \\ Master of Science in Molecular Microbiology \\ At \\ Victoria University of Wellington \\ By

\section{Emma Anne Earl}

School of Biological Sciences

Victoria University of Wellington

New Zealand

2010 


\begin{abstract}
Mycobacterium tuberculosis, the causative agent of tuberculosis (TB) has infected approximately $1 / 3$ of the world population, with 9.4 million new TB cases in 2008. In addition to increased cases of drug-resistant strains it is vital that novel antitubercular compounds are discovered in order to treat infections and reduce the time of current TB therapy courses. Natural resources such as plants are now being considered as the focus for discovering new compounds. Plants have long been investigated as a source of antibiotics for the treatment of human disease. New Zealand (NZ) contains a unique and diverse flora; however, to current knowledge no native plants have been examined for antimycobacterial activity. Using ethnobotany as a basis for selection, a total of 58 native plant samples were collected and tested for direct antimycobacterial activity. Samples were extracted with sterile distilled water (SDW), ethanol (EtOH) or methanol $(\mathrm{MeOH})$ and screened for inhibition against the surrogate species, Mycobacterium smegmatis. Active plant samples were then validated for bacteriostatic activity towards $M$. bovis BCG and $M$. tuberculosis H37Ra as well as other clinically-important species. Nine extracts from the species Laurelia novae-zelandiae, Lophomyrtus bullata, Metrosideros excelsa, Myoporum laetum, Pittosporum tenuifolium, Pseudopanax crassifolius and Pseudowintera colorata were found to be active against $M$. smegmatis. Two active extracts were the bark and cambium extracts of Laurelia novae-zelandiae (Pukatea), which were reportedly used by indigenous Māori for the treatment of tubercular lesions. Upon further investigation these extracts also demonstrated
\end{abstract}


bactericidal activity towards $M$. smegmatis as well as bacteriostatic activity towards the slow-growing species $M$. bovis BCG and $M$. tuberculosis. Purification techniques were then performed to improve the efficiency of activity and initial exploration of delivery systems was also examined. The bioactive extracts determined in this research offer a starting point for identifying their chemical basis of antimycobacterial activity with the objective of potentially discovering new anti-tubercular drugs. 


\section{ACKNOWLEDGEMENTS}

There are a number of people I wish to acknowledge who were significant to this research. First and foremost I would like to thank my supervisor Dr Ronan O'Toole for his advice, guidance and support in this research. It was his concept and supervision that allowed this research to occur.

I would like to thank Rewi Elliot and the Otari-Wilton Bush Reserve, Kaitoke Regional Park and Karori Wildlife Sanctuary (Zelandia) for their generous donation of native plant samples. Special thanks to Kathryn O'Toole and Rodney Lewington for their help with collection and identification. Thank you to Peter Butler and Sandra Crone of Forest Herbs Research Ltd, for their donation of Horopito. From FHR I would also like to thank Carol Hulse for her donation of samples from the South Island as well as her friendly emails and advice.

There was a number of people form KK817 and KK816 who were a great help with this research. You guys fantastic company to work alongside, with great music and not-so-great jokes. Thank you to Mudassar Altaf, for your work on the slow-growing species as well as spending time and feedback on my writing and research. Thank you Rekha Murikoli, for your cytotoxicity work and friendly chats. Thank you Chris Miller, Nathaniel Dasyam and lan Bassett for your help when I was developing my protocols. Thanks also to Shahista Nisa and Richard Campen for any assistance or advice I needed while in the lab. Special thanks to Sandi Dempsey, for her plasmid pSHIGH, to Simon Swift for his Staphylococcus aureus strain and to the Chemical Genetics lab for the use of their plate reader.

Numerous SBS staff have been valuable assets to me, from fixing equipment, to offering their expertise and assistance. Thank you to the SBS technicians Cameron Jack, Neville Higgison and Craig Doney, as well as the admin staff for their support and friendly encouragement. 
Special thanks go to Patricia Stein, for being there to calm me down when things went wrong.

I also wish to thank my office mates Praneta, Surrey and Kirsty (Kirsty you may have as well been in our office). Thanks guys for the encouragement and procrastination, from Friday afternoon treats to funny quotes and crosswords to entertain ourselves. I wish to especially thank Miles; you were my computer saviour in terms of showing me how to use Word and Endnote. Without you I would have spent another 6 months just trying to learn the neat tricks you showed me!

I wish to thank my family; Mum, Dad, Mark and Emma for your love and support, pep talks, hot meals and for generally putting up with me and my erratic hours. I also wish to thank my friends, for their general support and for still wanting to be friends when I bailed so many times. Also for Sunday soccer, you guys helped keep me sane when I needed a break and run around the field.

Lastly, but in no way the least, thank you Glen. You have been there when I needed you most and knew what to do to make me smile. You believed in me and without you I could not have done this. I will forever be grateful. 


\section{CONTENTS}

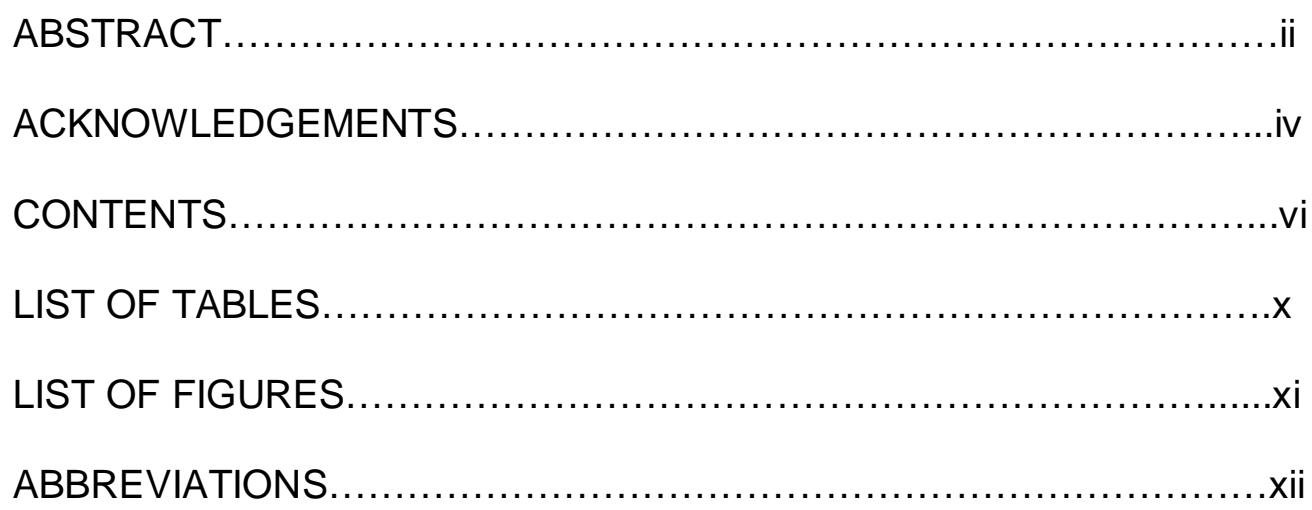

1. CHAPTER ONE: General Introduction.............................

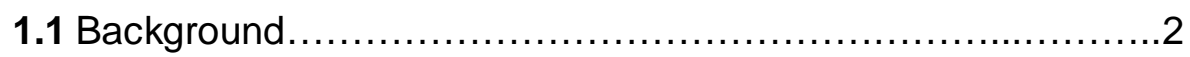

1.1.1 Pathogenesis of Tuberculosis.............................2

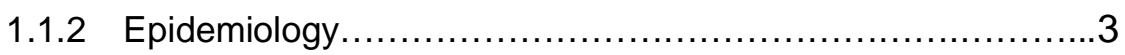

1.1.2.1 Epidemiology in New Zealand...........................4

1.1.3 Drug development and treatment..........................5

1.1 .4 Drug resistance..........................................

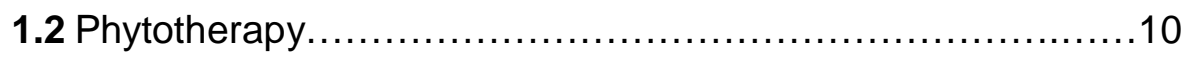

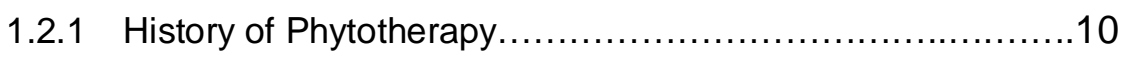

1.2.2 Medicinal value of Phytotherapy...........................11

1.2.3 Plant-derived drugs..........................................

1.2 .4 Secondary metabolites.................................... 15

1.3 New Zealand Flora.........................................16

1.3.1 Development of our flora................................16

1.3.2 Rongoa Māori..................................................... 17

1.3.3 Antibiotic activity of native New Zealand plants...............19

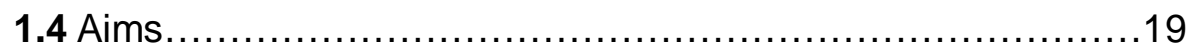

2. CHAPTER TWO: Materials and Methods.........................21

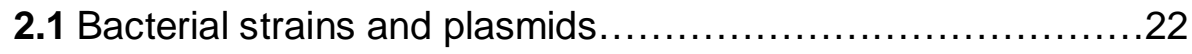

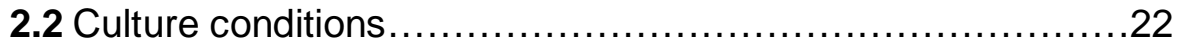




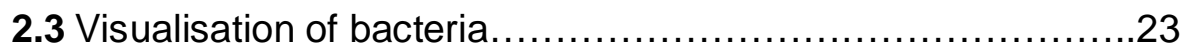

2.4 Sample collection...........................................

2.5 Solvent extraction............................................

2.5.1 Evaporation of solvents.................................24

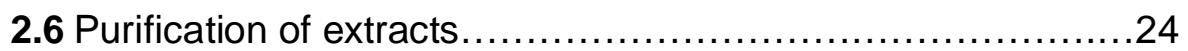

2.6.1 Size exclusion filtration of extracts.........................24

2.6.2 Solvent Phase Separation of extracts......................25

2.6.3 Size exclusion filtration and SPS..........................26

2.7 Assay Conditions ........................................27

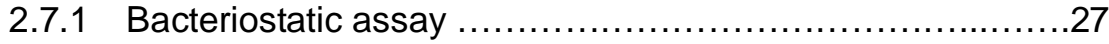

2.7.2 Resazurin reduction assay .................................

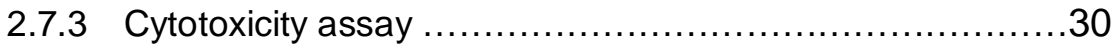

$2.7 .4 \quad$ Bactericidal assay.........................................

2.8 Data collection and analysis ................................. 32

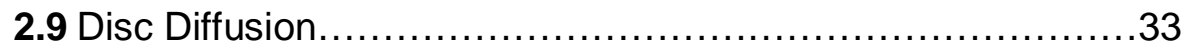

\section{CHAPTER THREE: Development of the Plant Extract}

Library...............................................................34

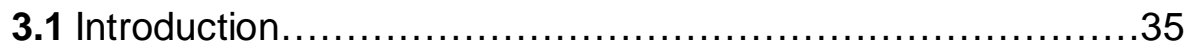

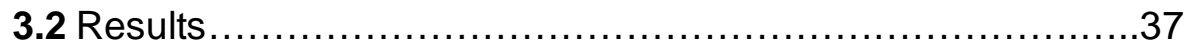

3.2.1 Medicinal information on native New Zealand plants collected for antimycobacterial screening........................... 37

3.2.2 Location of collection sites.................................39

3.2.3 Conditional information of the samples collected..............41

3.2.4 Development of Solvent Extraction.........................42

3.2.5 Initial Screening of Native Plants against M. smegmatis......43

3.2.6 Summary of Native Plant Extracts active against $M$. smegmatis

3.2.7 Comparison of GFP and OD results of active extracts against M. smegmatis

3.2.7.1 Bacteriostatic inhibition curves of extracts with activity against $M$. smegmatis................................48

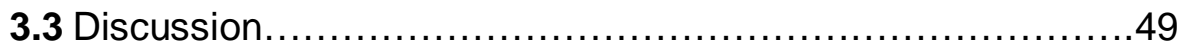

3.3.1 Construction of Plant Extract Library........................49 
3.3.2 Method Validation.......................................49

3.3.3 Initial screening of extracts against M. smegmatis............52

4. CHAPTER FOUR: Validation of Active Plant Extracts.............53

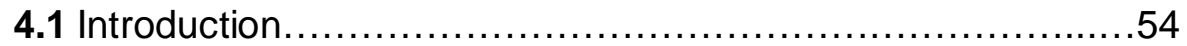

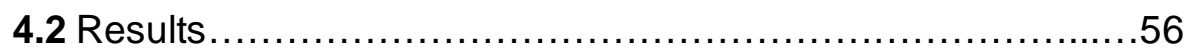

4.2.1 Summary of initial screening of active extracts against clinically-relevant species.....................................56

4.2.2 Bactericidal screening of active extracts....................60

4.2.3 Cytotoxicity of active plant extracts.......................61

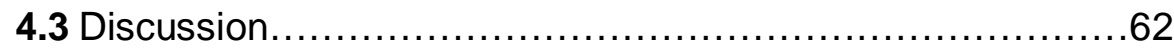

4.3.1 Screening of active samples against clinically-relevant

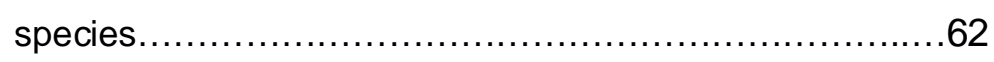

4.3.1.1 Antimycobacterial activity of Laurelia novaezelandiae..........................................64

4.3.2 Potential bioactive compounds present...................65

\section{CHAPTER FIVE: Efficiency and delivery of Plant Extract}

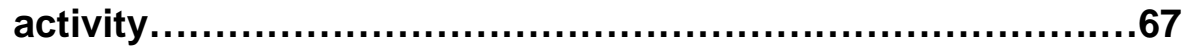

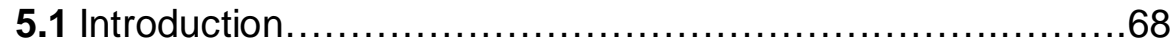

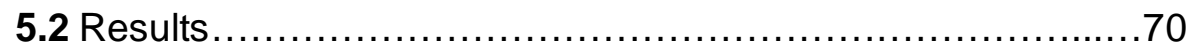

5.2.1 Activity of aqueous extracts tested against $M$. smegmatis...70

5.2.2 Size exclusion frationation of active extracts..................72

5.2.3 Solvent Phase Separation of active extracts.................74

5.2.3.1 SPS of active extracts with Ethyl Acetate.................74

5.2.3.2 SPS of active extracts with Chloroform..................76

5.2.3.3 Combination of Purification techniques....................78

5.2.4 Practical application of L. novae-zelandiae and other extracts........................................................ 80

5.3 Discussion...................................................

5.3.1 Purification techniques.................................... 83

5.3.2 Practical Application.................................... 85

6. CHAPTER SIX: Summary and Conclusions.....................87

6.1 Summary of Research.................................. 88 


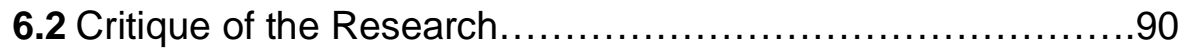

6.3 Future Directions .................................................

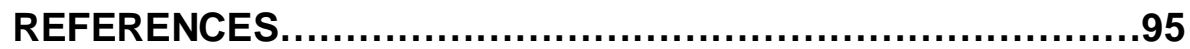

APPENDICES......................................................

Appendix 1: Research article in BMC Complementary and Alternative

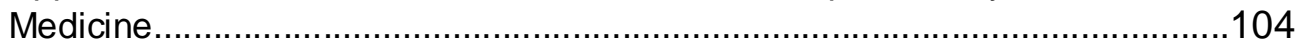

Appendix 2: Bacteriostatic inhibition curves of extracts with activity against $M$. smegmatis........................................................................ 


\section{LIST OF TABLES}

Table 1.1.3. List of current TB drugs used......................................

Table 3.2.1. Medicinal information on native New Zealand plants selected for

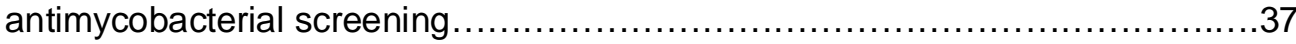

Table 3.2.3. Information of the samples collected...............................4 41

Table 3.2.4. Yield and MIC of M. excelsa methanol leaf extract in various

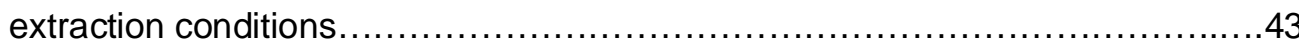

Table 3.2.5. Inhibition levels of native New Zealand plants with respect to $M$. smegmatis .44

Table 3.2.6. Antimycobacterial activity of plant extracts against $M$.

smegmatis

Table 3.2.7. MIC and $\mathrm{IC}_{50}$ values for GFP and OD of active crude plant extracts with respect to $M$. smegmatis.

Table 4.2.1. Comparison of $\mathrm{MIC}$ and $\mathrm{IC}_{50}$ values of active plant extracts with respect to M. smegmatis, M. bovis, M. tuberculosis, S. aureus and E. coli.......58 Table 4.2.3. Cytotoxicity of active extracts against J774 and HL-60 cell-lines....61 Table 5.2.1. Comparison of MIC and $\mathrm{IC}_{50}$ values of crude and aqueous plant extracts with respect to $M$. smegmatis. .71

Table 5.2.4. Inhibitory activity of extracts in a cream-based solution. 82 


\section{LIST OF FIGURES}

Figure 2.7.1. Outline of $96 \mathrm{wp}$ set-up for bacteriostatic assay..................29

Figure 2.7.4. Outline of $96 \mathrm{wp}$ set-up for cytotoxity assay........................32

Figure 3.2.2. Plant sample collection sites in New Zealand....................40

Figure 3.2.7.1. Bacteriostatic inhibition curves for bark and cambium extracts of

L. novae-zelandiae against M. smegmatis.

.48

Figure 4.2.1. Bacteriostatic inhibition curves for bark and cambium extracts of $L$. novae-zelandiae against $M$. bovis and $M$. tuberculosis.

Figure 4.2.2. Bactericidal activity of crude plant extracts with respect to $M$.

smegmatis

Figure 4.3.1.1. Laurelia novae-zelandiae (Pukatea) from Otari-Wilton Bush

Reserve.

Figure 4.3.2. Identified compounds in some native plants 65

Figure 5.2.2. Comparison of different size fractions of active plant extracts.....73

Figure 5.2.3.1. Comparison of crude and $A Q$ extracts activity when purified with

EtOAc through SPS. .75

Figure 5.2.3.2. Comparison of SPS with Chloroform $\left(\mathrm{CHCl}_{3}\right)$ purified plant

extracts.

Figure 5.2.3.3. Bacteriostatic activity of purified plant extracts with respect to $M$.

smegmatis.

Figure 5.2.4. Disc Diffusion of active extracts in an aqueous cream against $M$.

smegmatis and $S$. aureus.

Figure A.2. Bacteriostatic inhibition curves of active extracts against $M$.

smegmatis. 


\section{ABBREVIATIONS}

\begin{tabular}{|c|c|}
\hline $\mathbf{A Q}$ & Aqueous \\
\hline CAP & Capreomycin \\
\hline $\mathrm{CHCl}_{3}$ & Chloroform \\
\hline CYS & Cycloserine \\
\hline DNA & Deoxyribonucleic acid \\
\hline EpoA & Epothilone A \\
\hline ETH & Ethambutol \\
\hline EtOAc & Ethyl Acetate \\
\hline EtOH & Ethanol \\
\hline FCS & Fetal Calf Serum \\
\hline FDA & Food and Drug Administration \\
\hline FITC & Fluorescein Isothiocyanate \\
\hline GFP & Green Fluorescent Protein \\
\hline HIV & Human Immunodeficiency Virus \\
\hline HPLC & High-performance-liquid-chromatography \\
\hline $\mathrm{IC}_{50}$ & $50 \%$ inhibitory concentration \\
\hline INH & Isoniazid \\
\hline IPTG & Isopropyl $\beta$-D-1-thiogalactopyranoside \\
\hline KAN & Kanamycin \\
\hline KatG & Catalase-Peroxidase \\
\hline LA & Luria Agar \\
\hline LB & Luria Broth \\
\hline OADC & Oleic Acid, Albumin, Dextrose, Catalase \\
\hline OD & Optical Density \\
\hline
\end{tabular}




\begin{tabular}{ll} 
MDR-TB & Multi-drug resistant TB \\
MeOH & Methanol \\
MIC & Minimum Inhibitory Concentration \\
MOA & Mechanism of Action \\
MS & Mass Spectrometry \\
MRSA & Methicillin-resistant Staphylococcus aureus \\
NMR & Nuclear magnetic resonance \\
NZ & New Zealand \\
PZA & Pyrazinamide \\
RIF & Rifampin \\
SARs & Structural Activity Relationships \\
SDW & Sterile Distilled Water \\
SPS & Solvent Phase Separation \\
STR & Streptomycin \\
TB & Tuberculosis \\
TET & Tetrandrine \\
TMP & Tetramethylpyrazine \\
USA & United States of America \\
WHO & World Health Organization \\
XDR-TB & Extensively drug-resistant TB \\
\hline
\end{tabular}




\section{CHAPTER ONE:}

\section{General Introduction}




\subsection{Background}

Tuberculosis (TB) is an infectious disease that primarily affects the lungs and is caused by the slow-growing acid-fast bacillus Mycobacterium tuberculosis [1]. Tuberculosis and bacilli infection has afflicted humans for thousands of years [2, 3]. Egyptian mummies have been discovered with signs of TB infection [4] and even 9000 year old human remains had indications of a tubercule contagion [5]. Around the $17^{\text {th }}$ Century there was a notable rise in the incidence of TB in England, which was thought to be due to the expansion of cities and general population growth [2, 6]. The increase in close-contact, poor living conditions and inferior quality healthcare was thought to have exacerbated the spread of TB $[2,6,7]$.

It was not until 1882 that physician Robert Koch identified M. tuberculosis as the causative agent of tuberculosis, using his postulates to isolate the bacillus [8].

\subsubsection{Pathogenesis of Tuberculosis}

The primary mechanism of TB infection is by aerosol transmission [1, 9] and can only be spread by people that have contracted the active, not latent form of TB [10]. Approximately $90 \%$ of $M$. tuberculosis infections will be latent, when the mycobacteria are considered 'dormant' and do not cause disease [10]. When the bacterium has become active, the disease can be fatal if left untreated. When the microorganisms are inhaled into the lungs, the immune system responds by activation of T-lymphocytes [9]. This causes an accumulation of macrophages which leads to the formation of granulomas, or 'tubercules' [4, 9]. This lesion is a 
characteristic feature of TB and in most cases will not cause disease, leading to a latent state of TB [10]. However, up to $5 \%$ of infected individuals will progress to an active state of TB within a year of infection and up to another $5 \%$ will acquire active TB at some point in their life [10]. The infected tissue undergoes necrosis and leads to irreversible lung damage [9]. Typical symptoms indicative of TB include a chronic cough with blood-tinged sputum, fever, night sweats, loss of appetite, fatigue, weight loss and tubercular ulcers [9]. TB primarily infects lung tissue which is classed as pulmonary TB; though the bacilli can affect other tissues such as the lymph nodes, the circulatory system, the central nervous system, skin and the gastrointestinal tract. This is then classed as extrapulmonary TB [9]. Around $10-15 \%$ of active cases are extrapulmonary TB; however, this form of disease is increased up to $50 \%$ if the patient is HIV positive $[11,12]$.

\subsubsection{Epidemiology}

An estimated one third of the world population is infected with TB bacilli [13]. In 2008 the World Health Organization (WHO) reported 9.4 million cases of TB, including 500,000 cases of multi-drug resistant TB (MDR-TB) $[14,15]$. In 2008 approximately 1.8 million people died as a result of TB infection [14]. TB has killed more adults than any other single infectious agent, including AIDS and malaria [16]. TB is responsible for more than a quarter of unnecessary deaths in adults [16].

One of the main problems in the persistence and severity of TB is drug resistance. Co-infection of TB with Human Immunodeficiency Virus (HIV) 
is also a major issue, especially in less developed countries where TB is most prevalent [17]. An immunocompromised system can affect the severity of TB onset. Those that are HIV-positive have an increased chance of up to 30 times of progressing to an active state of TB [18]. It is approximated that 1.4 million people infected with TB are HIV-positive [17], with an estimated 500,000 deaths due to TB among HIV patients recorded in 2008 [18]. TB is considered to be the main cause of adult deaths with HIV $[13,17]$.

In 1993, TB was declared a global emergency by the WHO [19]. The tuberculosis incidence has worsened with the rise in drug-resistant strains of M. tuberculosis, increased HIV infections, use of different healthcare schemes among countries and the lack of care in regards to TB control programs [17]. In $2006 \mathrm{WHO}$, in conjunction with the Stop TB Partnership developed a 'Stop Tuberculosis' strategy, with the aim to "dramatically reduce the global burden of tuberculosis by 2015 " and thereby eliminating TB as a global health problem by $2050[1,17]$.

\subsubsection{Epidemiology in New Zealand}

Tuberculosis is not just an overseas issue. In New Zealand (NZ) there were approximately 7 cases per 100,000 of TB [20] and in central Auckland there was an incident rate of 12.3 cases per 100,000 in 2007 [20]. This is higher than the average number of cases in other developed countries such as Australia, United States of America (USA) and Canada, which have around 4-6 cases per 100,000 [17]. However, this is still lower than the incidence rate of 15 cases per 100,000 in the United Kingdom 
[17]. A possible factor for the high incidence of TB cases in NZ is due to high migration rates, with $65 \%$ of TB cases due to foreign-born individuals [21].

\subsubsection{Drug development and treatment}

With the continued existence of TB disease in humans there have been a variety of treatments investigated. However, it was not until the $20^{\text {th }}$ century that significant events occurred in the development of TB treatment.

In 1912 Bacillus subtilis and Bacillus mesentericus cultures were shown to inhibit M. tuberculosis growth [22]. In 1943 streptomycin was isolated from Streptomyces griseus. It had such a high efficacy against a broad range of organisms that it was quickly manufactured on a large-scale by 1944 [23]. There was a sharp decrease in the occurrence of TB after the discovery of streptomycin and it was thought that TB could be controlled if not eradicated [24].

In terms of prevention, Albert Calmette and Camille Guérin were the first to successfully develop a vaccine against tuberculosis using an attenuated bovine-strain labelled 'BCG' between 1905 and 1921 [25, 26]. It was then put into production, immunizing thousands of children in the United Kingdom. It was one of the first major vaccine trials in the United Kingdom and a noticeable decrease in the incidence of TB was observed from 1954 to 1965 [27].

The discovery and production of rifampin (RIF), isoniazid (INH) and pyrazinamide (PZA) soon followed, which are current TB drugs used 
today. RIF binds to the $\beta$-subunit of the DNA-dependent RNA polymerase enzyme, effectively inhibiting transcription [28]. INH is a powerful pro-drug that inhibits fatty acid synthesis once activated by the enzyme catalaseperoxidase (KatG) [29]. PZA still has a poorly understand mode of action, but it is thought that PZA is also a pro-drug that inhibits fatty acid synthesis [30]. The efficacy and structure of RIF, INH and PZA as well as other major first- and second-line drugs used are shown in Table 1.1.3.

Production of these drugs was significant as they enabled the foundation of combined drug therapy in order to alleviate the levels of TB as well as help avoid the formation of resistant strains [31]. There are now two types of drug regimens currently used for the treatment of tuberculosis. There are first-line drugs, such as ethambutol (ETH), INH, PZA, RIF and streptomycin (STR), as shown in Table 1.1.3. These drugs are first used to combat TB. There are also second-line drugs available such as capreomycin (CAP), cycloserine (CYS) and kanamycin (KAN) that are used when first-line drugs are no longer effective. However, second-line drugs tend to be less potent or more toxic than standard first-line drugs [32]. 


\begin{tabular}{|c|c|c|c|}
\hline TB drug & Line & $\begin{array}{l}\text { MIC against } \\
\text { MTB (H37Rv) }\end{array}$ & Mode of action \\
\hline Capreomycin (CAP) & Second & $2 \mu \mathrm{g} / \mathrm{ml}$ & $\begin{array}{l}\text { Inhibits protein } \\
\text { synthesis }{ }^{[33]}\end{array}$ \\
\hline Cycloserine (CYS) & Second & $25 \mu \mathrm{g} / \mathrm{ml}$. & $\begin{array}{l}\text { Inhibits cell-wall } \\
\text { biosynthesis and } \\
\text { maintenance }^{[34]}\end{array}$ \\
\hline Ethambutol (ETH) & First & $0.5 \mu \mathrm{g} / \mathrm{ml}$. & $\begin{array}{l}\text { Inhibits cell-wall } \\
\text { biosynthesis }\end{array}$ \\
\hline Isoniazid (INH) & First & $0.025 \mu \mathrm{g} / \mathrm{ml}$ & $\begin{array}{l}\text { Pro-drug that inhibits } \\
\text { fatty acid synthesis }\end{array}$ \\
\hline Kanamycin (KAN) & Second & $2 \mu \mathrm{g} / \mathrm{ml}$ & $\begin{array}{l}\text { Inhibits protein } \\
\text { synthesis }^{[36]}\end{array}$ \\
\hline Pyrazinamide (PZA) & First & $\begin{array}{l}6-50 \mu \mathrm{g} / \mathrm{ml} \\
\text { at } \mathrm{pH} 5.5\end{array}$ & $\begin{array}{l}\text { Prodrug that leads to } \\
\text { the inhibition of fatty } \\
\text { acid synthesis }^{[30]}\end{array}$ \\
\hline Rifampin (RIF) & First & $0.4 \mu \mathrm{g} / \mathrm{ml}$ & $\begin{array}{l}\text { Inhibits protein } \\
\text { synthesis }^{[28]}\end{array}$ \\
\hline Streptomycin (STR) & First & $1 \mu \mathrm{g} / \mathrm{ml}$ & $\begin{array}{l}\text { Inhibits protein } \\
\text { synthesis }^{[37]}\end{array}$ \\
\hline
\end{tabular}

Table 1.1.3. List of current TB drugs used. First- and second-line TB drugs currently employed with activity against $M$. tuberculosis H37Rv and general mode of action. 
Tuberculosis is difficult to treat and requires multiple drugs combined with long courses [1]. The course of treatment currently used is a Directly Observed Treatment Short-course (DOTS) program, involving different combinations of first- and second-line drugs. This course has a period of treatment time of usually 6 to 12 months, longer than most antibiotic treatments [1]. The epidemiological approach for DOTS therapy involves 5 major steps, which the WHO states are [38]:

1. Sustained political and financial commitment.

2. Diagnosis by quality ensured sputum-smear microscopy.

3. Standardized short-course anti-TB treatment (SCC) given under direct and supportive observation (DOT).

4. A regular, uninterrupted supply of high quality anti-TB drugs.

5. Standardized recording and reporting.

This program is applied with the intention of eradicating tuberculosis and to avoid the creation of drug-resistant strains.

\subsubsection{Drug resistance}

Although the discovery of streptomycin was hailed as a miracle antibiotic it was not long before resistant-strains appeared [22]. Isolates resistant to RIF, INH and PZA also began to surface not long after their production [39]. Nevertheless the production of these drugs combined with improved health-care standards was thought to be sufficient for controlling the spread of TB [40]. Consequently, there was little appeal in continuing 
research in discovering new TB drugs. As a result, for 40 years no new TB drugs were approved by the Food and Drug Administration (FDA) for clinical use [40]. A resurgence of TB in the 1980's, including drug-resistant cases and immunocompromised patients lead to renewed interest in developing novel drugs [40].

There are now two types of drug-resistant TB that have emerged, multidrug-resistant tuberculosis (MDR-TB) and extensively drug-resistant tuberculosis (XDR-TB). MDR-TB is resistant to first line drugs RIF and $\mathrm{INH}$, whereas XDR-TB is resistant to second-line drugs such as KAN or CAP as well as first-line drugs [15]. These strains of TB can be up to 250 times more expensive to treat than standard TB as they do not respond to the regular treatment courses provided [41]. MDR-TB and XDR-TB can take years to be treated with more toxic and less effective drugs [41].

There are multiple reasons for the development of drug-resistant strains. In terms of the nature of the bacteria, mycobacteria have highly sensitive drug-efflux systems and can produce enzymes that modify anti-tubercular drugs, for example aminoglycoside acetyl transferases [42]. A distinctive property of mycobacteria which is likely to contribute to its drug resistance is its cell wall, rich in lipids (e.g. mycolic acid), glycolipids, and polysaccharides [43]. This highly hydrophobic cell wall acts as a protective barrier [42]. A particular feature of TB however, is its ability to survive in an active or dormant state, which can provoke resistance [44]. It is these welldeveloped evasion systems that can provide mycobacteria with the ability to develop resistance. Random mutations within the gene sequence can also occur such as single nucleotide polymorphisms, leading to 
development of resistance [45]. HIV can also play a factor with the perseverance of resistant $\mathrm{TB}$, as it has been shown that a patient has a much higher chance of developing MDR- or XDR-TB if they are HIV positive [17]. Other factors for the emergence of resistant strains can be due to circumstances such as poor diagnosis, use of broad-range or poor quality drugs and patients not completing their course of drug treatment [46]. TB therapy is particularly problematic with patients not finishing their course of treatment. This is due to the long treatment time as well as toxic TB drugs. As a result, the patient is more likely to have an aversion to completing the course of medication [17].

With the presence of drug-resistant strains of bacteria, WHO has advised that new drugs are required to treat TB $[47,48]$. Natural resources are now being considered as the focus for discovering new compounds with novel modes of activity $[49,50]$.

\subsection{Phytotherapy}

Phytotherapy is the study of natural product extracts such as plants that have medicinal uses. Plants have been used for the treatment of human diseases well before antibiotics were discovered.

\subsubsection{History of Phytotherapy}

Indigenous peoples have known for generations the medicinal value of plants. The earliest discovery of plants thought to be used medicinally were found on the remains of a Neanderthal man (designated as Shanidar IV) from 60,000 B.C.E., from the archaeological site Shanidar Cave in Iraq 
[51, 52]. The Sumerians, one of the earliest known civilizations had written records of the study of herbal medicines from over 5000 years ago [51]. Around 2700 B.C.E., during the Han Dynasty the Chinese created a herbal book labelled the Shennong Bencao Jing, listing over 300 plants and their medicinal application [51]. One of the plants listed was Ephedra sinica that was used for the treatment of asthma and colds. E. sinica is still used today for traditional treatment and is the source of the alkaloid ephedrine, one of the active components used in common decongestants today [53]. Around 1500 B.C.E., Egyptians were known to use plants like garlic, wormwood, aloe, coriander, saffron, linseed and opium for medicinal purposes $[51,54]$. This information was recorded on the Ebers Papyrus, a document containing approximately 700 descriptions of plants and their medicinal purpose [51, 54]. In ancient Greece, Hippocrates recorded the medicinal practices of the Greeks (around 460 B.C.E.) in the Corpus Hippocraticum, detailing the use of herbs, as well as other beneficial medicinal practices such as fresh air and rest $[55,56]$. Then around 1025 C.E., a pharmacopoeia titled 'The Canon of Medicine' was written by Avicenna, cataloguing the uses of 800 different plants, drugs and minerals and their preparations $[57,58]$. Avicenna was also the first physician to develop a quarantine system after identifying TB as a contagious disease and its possible mode of spread $[57,59]$.

\subsubsection{Medicinal value of Phytotherapy}

South Africa is home to about $10 \%$ of tracheophyte plant species (plants containing a vascular system) on the planet, yet less than $5 \%$ of these 
species have been scientifically assessed for pharmacological activity [60]. However, around $70 \%$ of all South Africans utilize their endemic plants for medicinal purposes [60]. Bamuamba et al. (2008) found that extracts from the South African plant Buddleja sligna and Leyssera gnaphaloides had significant antibacterial activity, similar to that of the first-line drug RIF [61]. Tabuti et al (2010) recently determined that more than 80 plant species have been used by traditional medical practitioners in Uganda to treat tuberculosis [62]. Another study characterised leaf, bark and root material from trees used as traditional anti-tubercular medicines in South Africa [63].

The people of Papua New Guinea used bark from the plant Evodia elleryana for the treatment of coughs and fevers [64]. An ethyl acetate extract of this plant revealed that it had significant inhibitory activity against M. tuberculosis [64]. It was hypothesized that the inhibitory activity was due to the presence of alkaloid quinoline metabolites in the plant species [65], therefore presenting a potential class of compounds for drug development against M. tuberculosis [64].

There is much biodiversity in the Amazonian forest, but few plants have been tested for antibacterial activity [66]. Carneiro et al (2008) discovered 12 Amazonian plant extracts to have antibacterial activity against different strains of Mycobacterium smegmatis, Escherichia coli, Streptococcus sanguis, Streptococcus oralis, Staphylococcus aureus and Candida albicans [66, 67]. Methanol and chloroform extractions displayed high antimicrobial activity $[66,67]$. 
A number of plants native to Mexico were used in traditional medicine for the treatment of various respiratory diseases and were tested for antimycobacterial activity [68-71]. Jimenez-Arellanes et al (2003) screened Mexican plants that were used to treat respiratory diseases to investigate if they had antitubercular activity against drug resistant strains [68]. It was found that five plants (Artemisia Iudoviciana, Chamaedora tepejilote, Juniperus communis, Lantana hispida and Malva parviflora) had antimycobacterial activity against $M$. tuberculosis H37Rv [68]. A. ludoviciana was a particularly important resource in traditional Mexican medicine; used to treat coughs, asthma, bronchitis and other ailments [68, 69]. It was found that the plant $A$. Iudoviciana produced sesquiterpene lactones, which were thought to give the plant its antibacterial activity [68, 69]. Extracts of Citrus aurantifolia, C. sinensis and Olea europaea, also from Mexico were found to be active against both drug-susceptible and drug-resistant strains of virulent $M$. tuberculosis [71].

It is estimated that less than $10 \%$ of the Earth's higher plant species have been analysed for any kind of bioactivity [18]. Thus, there is a need for more research to be conducted on plants that have been traditionally used by indigenous peoples for the identification of new anti-tubercular drugs.

\subsubsection{Plant-derived drugs}

While today much of the focus has been on screening libraries of synthetic compounds for new lead drugs, plants have often provided a source of anti-bacterial compounds. One of the first drugs created was derived from the compound salicin, found in the bark of Salix alba $[72,73]$. 
Salicin was converted into salicylic acid which created aspirin, an effective painkiller and antipyretic [49, 74].

The compound aegicerin was isolated from Clavija procera and has been shown to have activity against Mycobacterium tuberculosis $\mathrm{H} 37 \mathrm{Rv}$ and MDR-TB strains [75]. Rhodomyrtone, a compound from the Southeast Asian plant Rhodomyrtus tomentosa was found to have potent antibacterial activity against a number of clinically-important gram-positive species including Enterococcus faecalis, Streptococcus pneumoniae and methicillin-resistant Staphylococcus aureus (MRSA) [76]. The drugs tetramethylpyrazine (TMP) and tetrandrine (TET) were derived from Chinese herbal plants and are used for the treatment of cardiovascular disease [77].

Nowadays it is estimated that more than $50 \%$ of the principal prescription drugs in the United States of America (USA) are derived from natural plant extracts [78]. Some of the more well-known drugs include the anticancer drugs Paclitaxel (Taxo|®), derived from Taxus brevifolia [79], Vincristine (Oncovin) derived from Catharanthus roseus [80] and Camptothecin (Hycamtin $\AA$ ) which is derived from Camptotheca acuminata [81]. In terms of new plant-derived TB drugs there are some promising lead compounds, especially from the class of alkaloids. The alkaloid tryptanthrin, derived from Strobilanthes cusia, could lead to a potential TB drug with its considerable activity against the drug sensitive strain $M$. tuberculosis H37Rv [82]. The indole alkaloids ibogaine and voacangine, which were isolated from Tabernaemontana citrifolia, displayed promising activity against $M$. tuberculosis, both with a minimum inhibitory concentration 
(MIC) of $50 \mu \mathrm{g} / \mathrm{ml}$ [83]. Finally the alkaloid cepharanone B, was isolated from Piper sanctum and has potential activity against $M$. tuberculosis $\mathrm{H} 37 \mathrm{Rv}$ with an MIC of $12 \mu \mathrm{g} / \mathrm{ml}$ [84]. It is possible that native NZ plants will provide anti-tubercular compounds that could lead to new TB drugs.

\subsubsection{Secondary Metabolites in plants}

Secondary metabolites are compounds usually present in plants that are not involved in any primary functions of the plant's requirements, for example, growth, development and reproduction [85]. Secondary metabolites tend to be diverse in size, structure and distribution both within plants and between species, yet appear to have no evident metabolic purpose even though they persist in all flora [85]. Secondary metabolites are likely to have a significant function if the plant expends metabolic energy to produce them [85]. It is proposed that plants have developed complex systems involving secondary metabolites in order to survive the ecological complexity surrounding them. This can include the production of chemicals that facilitate protection against predators, whether it be a deterrent or poison [49]. Hence, although secondary metabolites do not support the essential roles of cell development, the energy spent in the production of them is favourable for the plants overall growth and spread $[49,86]$.

It is proposed that secondary metabolites could be the source of a plant's antibacterial properties [87]. If these compounds are utilized in the plants vascular system to ward off predators (e.g. as an irritant or poison) or used 
to ward off infection from fungi and bacteria then it is likely that these secondary metabolites are a source of antibacterial activity [49].

There are a number of different types of secondary metabolites. The classes found to contain the majority of antibacterial compounds are alkaloids, flavonoids, terpernoids and phenols [88]. Extracts from the South African plant Buddleja sligna and Leyssera gnaphaloides were thought to have antibacterial activity due to the presence of triterpenoids [61]. The flowers of Chrysanthemum morifolium were used in Chinese natural medicine in the treatment of inflammation and fever and it was found that different types of triterpenoids from these flowers demonstrated antitubercular activity [89]. The isoquinoline alkaloid berberine was isolated from Hydrastis canadensis and was found to demonstrate antitubercular activity [90]. The leaves of Galenia africana also exhibited antimycobacterial activity against $M$. tuberculosis of which the activity was isolated to three flavonoids; (2S)-5,7,2'-trihydroxyflavanone, (E)-3,2',4'trihydroxychalcone and (E)-2',4'-dihydroxychalcone [91].

Therefore, as plants produce thousands of secondary metabolites there is much potential for investigating flora as a source for antitubercular activity.

\subsection{New Zealand flora}

NZ has a somewhat diverse range of flora and therefore it is possible that a wide range of novel compounds are present and unique to NZ flora.

\subsubsection{Development of our flora}


The biodiversity of NZ's flora can be attributed to the remoteness of its land. The land that was to become NZ was separated from the ancient supercontinent Gondwana around 65 million years ago, allowing the native fauna and flora to evolve in isolation [92]. Consequently, NZ has a distinctive range of plants, with approximately $80 \%$ of trees and shrubs and $40 \%$ of ferns that are endemic to the country [92]. The genus Podocarpus (e.g. Tōtara) and Nothofagus (e.g. Beeches) show similarities to biota linked back to the landmass Gondwana [92], suggesting NZ plants are similar to that of ancient flora. Thus, NZ has some of the highest rates of endemic species, which implies that diverse and conserved selection of plants are more likely to contain novel compounds due to greater chemodiversity of secondary metabolites [93]. The diversity is also due to the mild temperate climate and general lack of animal predators that has allowed the fauna and flora to evolve and adapt unimpeded [92]. Despite the years of forestry clearance through the expansion of human settlements, there is still plenty of natural vegetation. Around $18 \%$ of NZ is protected conservation land [94] like that of Otari-Wilton bush or Karori Wildlife Sanctuary (Zealandia), therefore providing a wide variety of native plants for selection.

\subsubsection{Rongoa Māori}

Arrival of the Māori population from Polynesia occurred sometime around 1300 A.D. [95]. With the appearance and settlement of a human population in NZ, the Māori soon became familiar with the native flora, finding uses for it such as tools, building, clothing and medicine [96]. They 
employed 'Rongoa Māori', the traditional practice of using native flora for medicinal purposes [96]. This would include the use of leaves, roots, bark and flowers. Faith was also considered an important role in Rongoa medicine. A 'Tohunga' was a form of doctor that had the power of 'tapu' (meaning sacredness) who knew the medicinal uses of plants and was the dispenser of treatments [96]. When European explorers made contact, they found the Māori to be vigorous and strong inhabitants with little sickness present in the community [96]. In fact, it was recorded that the European medicine practitioners were known to rely on the Māori remedies when their own stock of drugs was limited [97].

Many plants were considered important in Rongoa. The NZ flax Phormium tenax was utilized in Rongoa Māori for many remedies. The leaves were boiled for the treatment of cuts by applying it as a disinfectant [98]. Flax roots were used for treating abscesses and the gum used for burns and ringworm [96]. Macropiper excelsum (Kawakawa) was also considered a principal plant in Māori medicine, as the leaves were used for several remedies. They were applied to wounds as well as used in the treatment of rheumatism, arthritis, bruises, bladder problems and chest difficulties [96, 99, 100]. The leaf of $P$. colorata (Horopito) was used to treat toothache, skin irritations as well as a painkiller [96, 101]. Overall though most of the remedies treated common problems such as pain, toothache, wounds, skin irritations and stomach aches [98].

Rongoa Māori is relevant to this research as it the main basis of selection of native plants for analysis. If activity is identified then it reinforces the 
implication that plants used in traditional medicine are likely to contain antibacterial compound(s) [49].

\subsubsection{Antibiotic activity of native New Zealand plants}

Some of the native flora of NZ has already been investigated for various bioactivities. The shrub Lophomyrtus bullata (Ramarama) has been identified as having activity towards Bacillus subtilis [102]. P. colorata is known to have significant activity against Candida albicans [103]. Its activity has been isolated to the sesquiterpene dialdehyde polygodial [103]. Liverworts have been investigated for bioactivity. The tea trees Manuka (Leptospermum scoparium) and Kanuka (Kunzea ericoides) have been shown to have antibacterial properties in their honey [104]. The liverwort Plagiochila stephensoniana was found to have antifungal activity, of which its active component was identified as bibenzyl 4-hydroxy-3'methoxybibenzyl [105]. However, to current knowledge NZ plants have not been assayed for activity against mycobacteria. Thus, there is a potential resource for novel antimycobacterial compounds in NZ flora.

\subsection{Aims of Research}

The aim of this research was to investigate the potential antimycobacterial activity of native plant extracts. This required the following objectives:

- Collect native plant samples with potential bioactivity 
This will be achieved by compiling a list of native plants with medicinal activity and then collecting the samples from local bush reserves in order to build the plant extract library.

- Identify native plant extracts with antimycobacterial activity

The plant samples will be extracted with various solvents and initially screened against surrogate species $M$. smegmatis for the detection of antimycobacterial activity.

- Validate plant extracts with antimycobacterial and antibacterial activity Positive hits will be tested for bacteriostatic activity against species $M$. bovis BCG, M. tuberculosis H37Ra, S. aureus and E. coli. Bactericidal activity will also be determined against $M$. smegmatis.

- Improve efficiency of extraction and deliver the bioactive extracts in a practical application

Positive hits will be purified and investigated for improved activity by means of size exclusion fractionation and solvent phase separation. Active plant extracts will also be applied to an aqueous cream for the purpose of delivery of the bioactive extract and assessed for inhibitory activity in a disc diffusion assay. 


\section{CHAPTER TWO:}

Materials and Methods 


\subsection{Bacterial strains and plasmids}

The mycobacterial strains used were $M$. smegmatis $\mathrm{mc}^{2} 155, M$. bovis BCG (Pasteur) and M. tuberculosis H37Ra. M. smegmatis and M. bovis BCG were labelled with a Green Fluorescent Protein (GFP) marker through the introduction of the plasmid pSHIGH + hsp60 by electroporation and selection on media containing kanamycin $(50 \mu \mathrm{g} / \mathrm{ml})$ as described by Miller et al (2009) [106]. Staphylococcus aureus Newman strain was GFP-labelled as previously described [107, 108] and selected on media containing erythromycin $(30 \mu \mathrm{g} / \mathrm{ml})$ (Sigma). See Appendix 1 Section 'Bacterial strains and plasmids' for more detail [109]. Escherichia coli DH5a was labelled with GFP using POT11 and selected on media containing chloramphenicol $(25 \mu \mathrm{g} / \mathrm{ml})$ (Sigma) as previously described [110].

\subsection{Culture conditions}

M. smegmatis $\mathrm{mc}^{2} 155$ was cultured on a Luria agar (LA) plate with kanamycin $(50 \mu \mathrm{g} / \mathrm{ml})($ Sigma $)$ at $37^{\circ} \mathrm{C}$. Colonies sele cted were inoculated in Luria Broth (LB) media containing kanamycin $(50 \mu \mathrm{g} / \mathrm{ml})$, Tween 80 $(0.1 \% \mathrm{v} / \mathrm{v})($ Sigma $)$ and D-arabinose $(250 \mu \mathrm{g} / \mathrm{ml})($ Sigma $)$.

Both $M$. bovis and M. tuberculosis cultures were grown in Middlebrook 7H9 broth supplemented with $10 \%(\mathrm{v} / \mathrm{v})$ OADC $(0.06 \%$ Oleic acid, $5 \%$ BSA, $2 \%$ Dextrose, $0.85 \% \mathrm{NaCl}$ ) (Becton, Dickinson and Company), glycerol $(0.5 \% \mathrm{v} / \mathrm{v})$ (British Drug Houses) and Tween 80 (0.05\% v/v).

GFP-labelled $S$. aureus Newman was cultured on LA containing erythromycin $(30 \mu \mathrm{g} / \mathrm{ml})$. When inoculated into media, S. aureus was 
grown in LB with the addition of erythromycin $(30 \mu \mathrm{g} / \mathrm{ml})$ and xylose $(0.5 \%$ w/v) (British Drug Houses).

E. coli DH5a/pOT11 was cultured on LA containing chloramphenicol (25 $\mu \mathrm{g} / \mathrm{ml})$. Innoculation into LB media involved the addition of chloramphenicol $(25 \mu \mathrm{g} / \mathrm{ml})$ and Isopropyl $\beta$-D-1-thiogalactopyranoside (IPTG) $(100 \mu \mathrm{g} / \mathrm{ml})$. IPTG was added to induce GFP expression.

\subsection{Visualisation of bacteria}

Slides of Mycobacteria smegmatis were prepared by removing $5 \mu$ from overnight cultures. The bacteria were viewed under a 1000 x (oil immersion) Olympus Provis AX 70TRF Fluorescent Microscope (Olympus America Inc) with a Fluorescein Isothiocyanate (FITC) filter used to visualise the fluorescent cells.

\subsection{Sample collection}

Plant samples were primarily collected from the Karori Wildlife Sanctuary (Zealandia) and Otari-Wilton Bush Reserve. Other samples were also obtained from Wellington; Kaitoke Regional Park, Upper Hutt and the central Wellington area with permission. Samples were also collected from the Canterbury and Nelson areas with permission. Leaf, flower, seed or bark tissues were collected fresh and stored in plastic bags. Leaves were chosen from the same apical node from each branch with similar size and colouring. Location, date of collection and details of the species were noted. 


\subsection{Solvent extraction}

Approximately $5-10 \mathrm{~g}$ of each plant sample was macerated using a blender (Breville) and then dried in roughly $20 \mathrm{~g}$ of the granular desiccate calcium sulphate (British Drug Houses). The dried sample was placed in a $50 \mathrm{ml}$ conical tube and sterile distilled water (SDW), ethanol (EtOH) or methanol $(\mathrm{MeOH})$ were added to give a final concentration of $100 \mathrm{mg} / \mathrm{ml}$. Samples were then incubated in a water bath at $55^{\circ} \mathrm{C}$ for 1 hour before being stored at $-80^{\circ} \mathrm{C}$ for 24 hours. The incubation was performed in order to imitate the preparations used in traditional Māori medicine. The resulting extract was then centrifuged (Alphatech) at $5000 \times \mathrm{g}$ for 15 minutes before being sterilized through a $0.22 \mu \mathrm{m}$ filter (Millipore). The final extract was stored at $-80^{\circ} \mathrm{C}$.

\subsubsection{Evaporation of extracts}

Plant samples to be evaporated had $500 \mu$ of extract aliquoted into 1.5 $\mathrm{ml}$ eppendorf tubes and were centrifuged (Labconco centrivap concentrator) under vacuum at $-100 \mathrm{kPa}$ with $30 \mathrm{bar} \mathrm{Hg}$, at $35^{\circ} \mathrm{C}$ for 2 hours. The resulting plant material was then resuspended in the desired solvent and sterilized through a $0.22 \mu \mathrm{m}$ filter.

\subsection{Purification of extracts}

\subsubsection{Size exclusion filtration of extracts}

Approximately $2 \mathrm{ml}$ of plant extract in $50 \% \mathrm{EtOH}$ or $\mathrm{MeOH}$ (or $100 \%$ SDW if aqueous (AQ) extract) was aliquoted into a $30 \mathrm{kDa}$ filter (Millipore) and 
centrifuged at $5000 \times \mathrm{g}$ for 20 minutes. The filtrate was then aliquoted into a $3 \mathrm{kDa}$ filter and centrifuged again at $5000 \times \mathrm{g}$ for 20 minutes. About $1 \mathrm{ml}$ of SDW was added to each of the filters and sonicated for 10 minutes to remove any extract present (retentate). The resulting filtrate and retentate were then pipetted into fresh eppendorf tubes and evaporated under speed-vacuum, weighed and resuspended in SDW to the desired concentration. The final extract was then sterilized through a $0.22 \mu \mathrm{m}$ filter and stored at $-80^{\circ} \mathrm{C}$ until required.

\subsubsection{Solvent Phase Separation of extracts}

\section{Ethyl Acetate}

Extracts were evaporated and resuspended in SDW to a concentration of $100 \mathrm{mg} / \mathrm{ml}$. Approximately $2 \mathrm{ml}$ of extract was added to a glass test tube and $2 \mathrm{ml}$ of $99 \%$ ethyl acetate (EtOAc) was added. The test tubes were then sealed with cotton and parafilm and refrigerated at $-80^{\circ} \mathrm{C}$ for 24 hours. The $A Q$ (extract) layer was removed and aliquoted into fresh eppendorf tubes, which were then evaporated and resuspended in SDW again to a final concentration of $10 \mathrm{mg} / \mathrm{ml}$. The extracts were then sterilized through a $0.22 \mu \mathrm{m}$ filter prior to analysis.

\section{Chloroform}

The extracts were evaporated and resuspended in SDW to a concentration of $100 \mathrm{mg} / \mathrm{ml}$. Approximately $2 \mathrm{ml}$ of extract was added to a glass test tube and $2 \mathrm{ml}$ of $99 \%$ chloroform $\left(\mathrm{CHCl}_{3}\right)$ was added. The test tubes were then sealed with cotton and parafilm and refrigerated at $-80^{\circ} \mathrm{C}$ for 24 hours. The AQ (extract) layer was removed and aliquoted into fresh 
eppendorf tubes, which were then evaporated and resuspended in SDW again to a final concentration of $25 \mathrm{mg} / \mathrm{ml}$. The $\mathrm{CHCl}_{3}$ layer was also removed and placed into a fresh test tube and evaporated at room temperature. Approximately $2 \mathrm{ml}$ of $99 \%$ DMSO (Sigma) was added and sonicated to dissolve the extract. The extracts were then transferred to fresh eppendorf tubes, evaporated and resuspended again in DMSO to a final concentration of $10 \mathrm{mg} / \mathrm{ml}$. Extracts were then sterilized through a $0.22 \mu \mathrm{m}$ filter prior to analysis.

\subsubsection{Size exlusion filtration and SPS}

Approximately $2 \mathrm{ml}$ of plant extract in $50 \% \mathrm{EtOH}$ or $\mathrm{MeOH}$ (or $100 \%$ SDW if $\mathrm{AQ}$ extract) was aliquoted into a $30 \mathrm{kDa}$ filter (Millipore) and centrifuged at $5000 \times \mathrm{g}$ for 20 minutes. The filtrate was then aliquoted into fresh eppendorf tubes $(500 \mu l)$, evaporated under speed-vacuum and resuspended in SDW to a concentration of $100 \mathrm{mg} / \mathrm{ml}$. Approximately $1 \mathrm{ml}$ of the filtrate was then aliquoted into a fresh glass test tube. Approximately $1 \mathrm{ml}$ of $99 \%$ EtOAc was then added to the filtrate. The test tubes were then sealed with cotton and parafilm and frozen at $-80^{\circ} \mathrm{C}$ for 24 hours. The $A Q$ (extract) layer was then removed and aliquoted into fresh eppendorf tubes, which were then evaporated and resuspended in SDW to a final concentration of $10 \mathrm{mg} / \mathrm{ml}$. The final extracts were sterilized through a $0.22 \mu \mathrm{m}$ filter prior to analysis. 


\subsection{Assay Conditions}

\subsubsection{Bacteriostatic assay}

Solvent-extracted and fractionated plant samples were examined in a 96well microtitre plate (96wp) bacteriostatic assay against $M$. smegmatis, $M$. bovis, M. tuberculosis, E. coli and S. aureus. Figure 2.7.1 illustrates the layout of the bacteriostatic assay. SDW $(150 \mu l)$ was added to the outer lanes of the 96wps to reduce evaporation. The remaining wells were filled with $50 \mu \mathrm{l}$ of liquid media. Plant extracts $(10 \mu \mathrm{l})$ were pipetted into columns 2 and 3 of the microtitre plates with a starting concentration of $2 \mathrm{mg} / \mathrm{ml}$. A two-fold serial dilution was then performed on each extract starting at column 3 , aliquoting $30 \mu$ from column 3 into column 4 and so on until column 11. Bacterial cells $(40 \mu \mathrm{l})$ were added to rows B-D at a final OD at $600 \mathrm{~nm}\left(\mathrm{OD}_{600}\right)$ of 0.2 . Rows $\mathrm{E}-\mathrm{G}$ contained media and extract alone, to measure any background optical density or fluorescence associated with the extract and media. A number of controls were added to ensure assay reliability. Bacterial cells were grown in media alone to allow for comparison of bacteriostatic activity against normal growth for each extract tested. Standard anti-tubercular drugs RIF and STR were used as positive controls, with starting concentrations of $0.1 \mathrm{mg} / \mathrm{ml}$. Solvent controls were also used, as some inhibition of bacterial growth could be exhibited by some solvents. Inhibition of growth due to the ethanol solvent was observed at concentrations of greater than $5 \%(\mathrm{v} / \mathrm{v})$ for all species tested. M. smegmatis, E. coli and S. aureus also had inhibition due to the methanol solvent at concentrations greater than $5 \%(\mathrm{v} / \mathrm{v})$, whereas $M$. 
bovis and $M$. tuberculosis only exhibited inhibition of growth at concentrations greater than $10 \%(\mathrm{v} / \mathrm{v})$. Thus, extracts tested in ethanol or methanol had a starting solvent concentration of $2 \%(\mathrm{v} / \mathrm{v})$ corresponding to the final concentration of plant extract. All extracts and controls were tested in triplicate. Plates were sealed with nitrocelluose film (Excel Scientific) and incubated at $3^{\circ} \mathrm{C}$ with $200 \mathrm{rpm}$ shaking. After 24 hours plates containing $E$. coli or $S$. aureus cultures were read for OD and GFP fluorescence. For the Mycobacterium species, M. smegmatis cultures were read after 96 hours, $M$. bovis and $M$. tuberculosis cultures were read after 14 days. Only OD was measured for M. tuberculosis as this organism did not contain a plasmid with a GFP insert. 

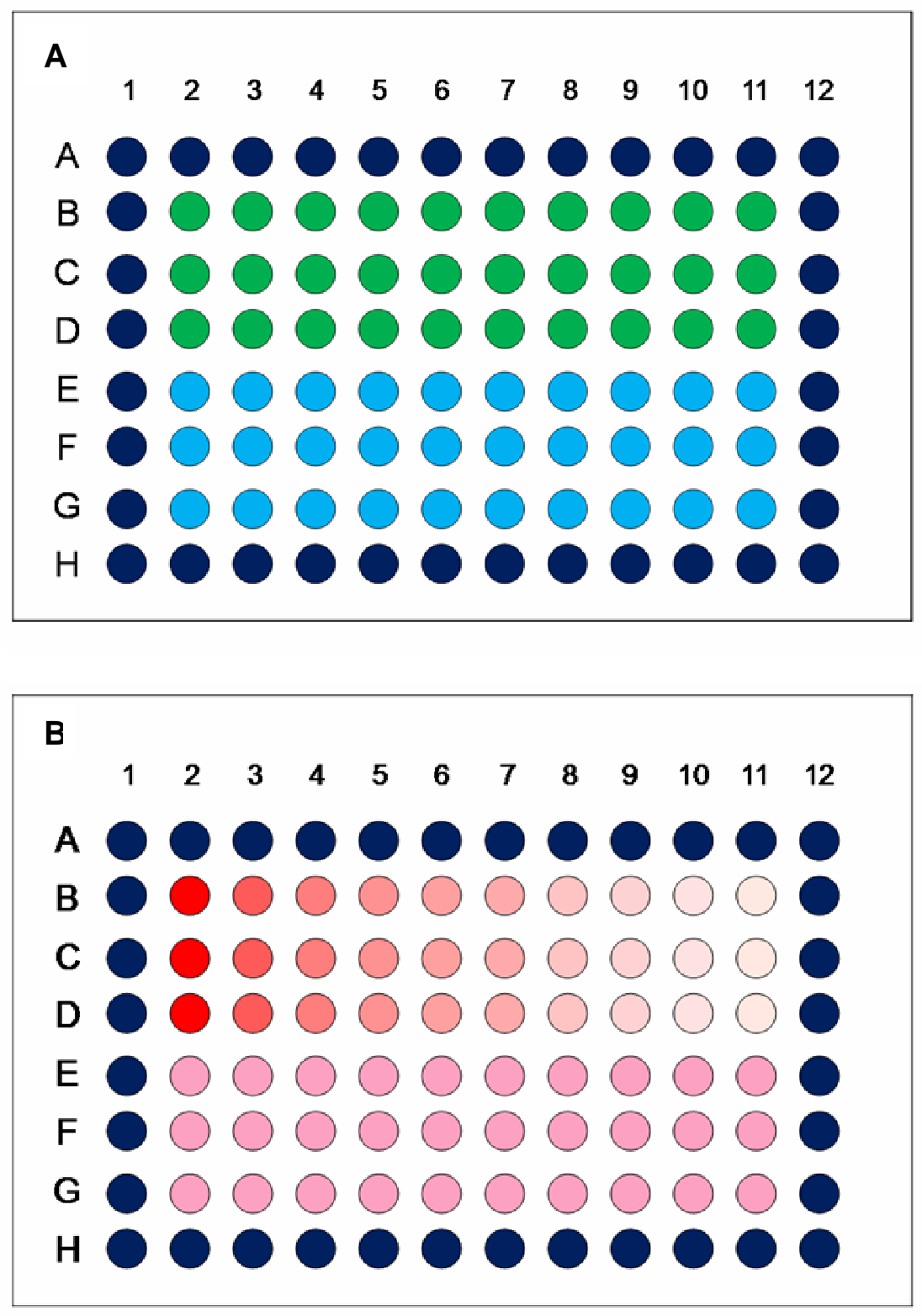

Figure 2.7.1. Outline of 96wp set-up for bacteriostatic assay. The outer wells are filled with SDW indicated by the dark blue wells (0). A) The green wells (0) indicate cells + media in triplicate and the blue wells $(O)$ indicate media alone in triplicate. B) The red wells $(0)$ indicate the $2: 1$ serial dilution of extract + cells + media in triplicate. The remaining pink wells $(\odot)$ indicate extract alone in media in triplicate to account for any background absorbance of the extract tested. Drug controls were tested in the same format. 


\subsubsection{Resazurin reduction assay}

An aliquot of $30 \mu \mathrm{l}$ of resazurin dye $(0.02 \% \mathrm{w} / \mathrm{v})$ (Sigma) was added to each well at the end-point of the bacteriostatic assay and incubated at $37^{\circ} \mathrm{C}$ for 2 hours. The plates were then read using the Wallac EnVision ${ }^{\circledR}$ Manager 1.12 software program with a General top mirror and wavelengths of $530 \mathrm{~nm}$ excitation and $590 \mathrm{~nm}$ emission.

\subsubsection{Bactericidal assay}

M. smegmatis was cultured for 8 days in LB containing kanamycin (50 $\mu \mathrm{g} / \mathrm{ml}$ ) until stationary growth phase was reached. The culture was then diluted to an $\mathrm{OD}_{600}$ of 1.0 with PBS (1x v/v). A 96-wp assay was then setup as previously described in the bacteriostatic assay protocol, with the exception of LB media being replaced with PBS $1 \times(\mathrm{v} / \mathrm{v})$. After 96 hours drug exposure, $30 \mu \mathrm{l}$ of resazurin dye $(0.02 \% \mathrm{w} / \mathrm{v})$ was added and the plates read for any bactericidal activity with wavelengths of $530 \mathrm{~nm}$ excitation and $590 \mathrm{~nm}$ emission.

\subsubsection{Cytotoxicity assay}

Murine macrophage cell-line J774 cells (ATCC) and human blood cell-line HL-60 (ATCC) were cultured in RPMI 1640 medium (Invitrogen) supplemented with $10 \%(\mathrm{v} / \mathrm{v})$ fetal calf serum (FCS) (Invitrogen) and PenStrep (Pencillin 50 units $/ \mathrm{ml}$ and Streptomycin $50 \mu \mathrm{g} / \mathrm{ml}$ ) (Invitrogen). Cells were incubated at $37{ }^{\circ} \mathrm{C}$ in a $5 \% \mathrm{CO}_{2}$ atmosphere for 48 hours. Extracts to be tested were serially diluted twofold in a $50 \mu$ volume in a 96 well tissue culture plates (BD biosciences). Cells were then seeded (50 $\mu$ l) 
in the 96 wps to produce a final cell concentration of $10^{4}$ cells/well. This was counted with a hemocytometer for both cell-lines. For J774 cells an additional step of trypan blue stain $(0.4 \% \mathrm{v} / \mathrm{v})$ (Sigma) was added before counting. A cytotoxic compound, Epothilone A (EpoA) (Merck), was included as a positive control with a starting concentration of $25 \mu \mathrm{g} / \mathrm{ml}$. A TB drug control RIF was also included with a starting concentration of 0.4 $\mathrm{mg} / \mathrm{ml}$. All extracts and controls were tested in triplicate. The plates were incubated for 48 hours followed by the addition of $10 \mu \mathrm{l}$ of Alamar Blue dye $(10 \% \mathrm{w} / \mathrm{v})$ (Invitrogen). Absorbance readings were then taken after 4 hours at $570 \mathrm{~nm}$ using a VersaMax ${ }^{T M}$ microplate reader (Molecular Devices, Inc) and SOFTmax Pro version 3.0 software (Informer Technologies, Inc.). 50\% inhibitory concentration $\left(\mathrm{IC}_{50}\right)$ values were calculated using SigmaPlot ${ }^{\circledR}$ (version 10.0) (Systat Software, Inc). 


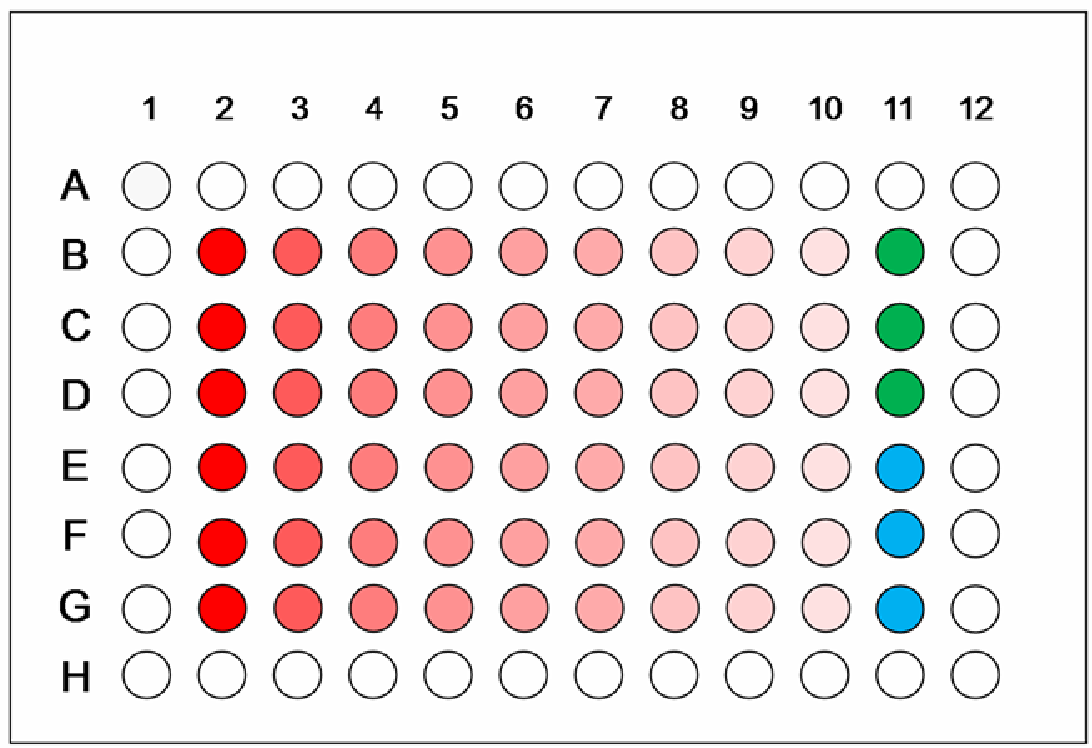

Figure 2.7.4. Outline of 96wp set-up for cytotoxity assay. The outer wells are blank as indicated by the white wells $(O)$. The green wells $(O)$ indicate cells + media in triplicate and the blue wells $(\odot)$ indicate media alone in triplicate. The red wells $(\bigcirc)$ indicate the 2:1 serial dilution of extract + cells + media in triplicate. In this layout rows B-D indicate one extract tested in triplicate and rows E-G indicate a second extract tested in triplicate. Drug controls were tested in the same format.

\subsection{Data collection and analysis}

An EnVision ${ }^{\circledR} 2102$ multilabel plate reader (Perkin Elmer, Inc) and the Wallace EnVision ${ }^{\circledR}$ Manager 1.12 software program (Perkin Elmer, Inc) were used to measure the fluorescent and absorbent GFP and OD signals of the microtitre plate cultures. GFP fluorescence was detected using a FITC bottom mirror, with excitation and emission wavelengths of $485 \mathrm{~nm}$ and $510 \mathrm{~nm}$, respectively. OD was measured with an excitation light of $590 \mathrm{~nm}$. 12-point scans were performed on each well to minimise intrawell variation, such as 'clumping' that can occur with mycobacteria. The intrinsic absorbance and fluorescence readings of extracts in media alone 
were also measured to account for any background signals that were later subtracted from the readings for the samples tested. Data was normalised by expressing the absorbance and fluorescence values as a percentage of a no-drug negative control. Sigmaplot ${ }^{\circledR} 10.0$ software (version 10.0 ) was used to calculate non-linear dose-response inhibitory curves. A simple scatter plot was created with the means of the triplicate data and error bars representing standard deviation. A log (common) scale was applied. A four parameter logistic curve was calculated to fit the plotted data and as a result $\mathrm{MIC}$ values and $\mathrm{IC}_{50}$ values with standard errors were generated.

\subsection{Disc Diffusion}

For M. smegmatis, $100 \mu \mathrm{l}$ of culture at an $\mathrm{OD}_{600}$ of 0.2 was spread on LA agar containing kanamycin $(50 \mu \mathrm{g} / \mathrm{ml})$ and allowed to dry. For $S$. aureus $100 \mu \mathrm{l}$ of culture at an $O D_{600}$ of 0.2 was spread on LA agar containing erythromycin $(30 \mu \mathrm{g} / \mathrm{ml})$ and allowed to dry. The extract to be tested was mixed with an aqueous cream solution (MedCo), to give a final extract concentration of $0.5 \%(\mathrm{w} / \mathrm{v})$. Sterile paper discs (Becton, Dickinson and Company) $6 \mathrm{~mm}$ in diameter were then dipped in the solution and gently placed onto the agar surface. A negative control of just aqueous cream alone and positive controls extract alone (i.e. no aqueous cream added) and RIF (1 $\mathrm{mg} / \mathrm{ml})$ were also tested. The plates were then sealed with parafilm and incubated at $37^{\circ} \mathrm{C}$ for 24 hours for $S$. aureus and 96 hours for M. smegmatis. Any zones of inhibition surrounding the discs were then circled and measured. 
CHAPTER THREE:

Development of the

Plant Extract Library 


\subsection{Introduction}

This research involved collecting native NZ plants and screening them for antimycobacterial activity. Hence, a suitable protocol was developed for the selection and processing of native plants in preparation for screening against $M$. smegmatis.

The selection of plant samples was based on native species and ethnomedicine [49]. Ethnobotany is the study of how a particular culture use and understand plants in terms of food, medicine and religion [111]. Ethnomedicine is the study of an indigenous culture and its use of native plants for medicinal practices [111]. This is a method of targeted collection, selecting plants based on their use in Rongoa Māori (traditional medicine). It would be difficult with the timeframe and financial circumstances to randomly test native NZ plants for antimycobacterial activity. Therefore ethnomedicine was chosen as the focus for selection of plants in this study.

Many bioactive compounds derived from plants are generally flavonoids, alkaloids, terpenoids or phenols [88]. Because of this, the polar solvents ethanol and methanol would be used for solvent extraction. An aqueous solvent was also chosen as many plants were heated in water for various treatments [97].

Plant extracts were initially screened against the surrogate species, $M$. smegmatis. M. smegmatis is an acid-fast, aerobic, saprophytic bacterium [112]. It has a genome 1.7 times larger than M. tuberculosis and is nonpathogenic, but $M$. smegmatis does share homology with some virulence genes of $M$. tuberculosis [113]. M. smegmatis also has a fast doubling 
time of 3-4 hours, therefore it can be a rapid and safe model for testing anti-TB compounds in physical containment level-2 laboratories [113].

M. smegmatis $\mathrm{mc}^{2} 155$ strain was used with a $\mathrm{pSHIGH}$ plasmid containing a GFP (green fluorescent protein) gene. This protein was isolated from Aequorea victoria [114], causing the bacteria to emit a green fluorescence which allows for easy detection of bacterial growth under inspection [114]. 


\subsection{Results}

\subsubsection{Medicinal information on native New Zealand plants collected for antimycobacterial screening}

A library was complied of native plants selected for sampling. Table 3.2.1 is a list of the NZ plants collected and any medicinal uses noted.

\begin{tabular}{|c|c|c|}
\hline Plant name (common) & Part & Medicinal Use \\
\hline $\begin{array}{l}\text { Adiantum raddianum (Delta } \\
\text { maidenhair fern) }\end{array}$ & Leaf & Genus Adiantum used medicinally ${ }^{[115]}$ \\
\hline Agathis australis (Kauri) & Leaf & Presence of antiviral agathisflavone $e^{[116]}$ \\
\hline $\begin{array}{l}\text { Arthropodium cirratum (New } \\
\text { Zealand rock lily) }\end{array}$ & Leaf & Used in Rongoa Māori to treat ulcers ${ }^{[117]}$ \\
\hline $\begin{array}{l}\text { Asplenium bulbiferum (Hen } \\
\text { and chicken fern) }\end{array}$ & Leaf & $\begin{array}{l}\text { Genus Asplenium known to have } \\
\text { antibacterial activity }{ }^{[118]}\end{array}$ \\
\hline $\begin{array}{l}\text { Asplenium flaccidum } \\
\text { (Drooping Spleenwort) }\end{array}$ & Leaf & $\begin{array}{l}\text { Genus Asplenium known to have } \\
\text { antibacterial activity }{ }^{[118]}\end{array}$ \\
\hline Beilschmiedia tawa (Tawa) & Leaf & $\begin{array}{l}\text { Used in Rongoa Māori to treat sore throat, } \\
\text { colds, cough }\end{array}$ \\
\hline Blechnum fluviatile (Kiwikiwi) & Leaf & $\begin{array}{l}\text { Used in Rongoa Māori to treat sore tongue } \\
\text { and mouth }{ }^{[98]}\end{array}$ \\
\hline $\begin{array}{l}\text { Brachyglottis repanda } \\
\text { (Rangiora) }\end{array}$ & Leaf & $\begin{array}{l}\text { Used in Rongoa Māori to treat wounds, } \\
\text { ulcers and boils }{ }^{[98]}\end{array}$ \\
\hline $\begin{array}{l}\text { Carpodetus serratus (Marble } \\
\text { leaf) }\end{array}$ & $\begin{array}{l}\text { Leaf } \\
\text { seed }\end{array}$ & ni \\
\hline $\begin{array}{l}\text { Clianthus puniceus } \\
\text { (Kakabeak) }\end{array}$ & $\begin{array}{l}\text { Leaf } \\
\text { Seed }\end{array}$ & $\begin{array}{l}\text { Family Fabaceae has recorded } \\
\text { antibacterial activity }{ }^{[119,120]}\end{array}$ \\
\hline $\begin{array}{l}\text { Cordyline australis (Cabbage } \\
\text { tree) }\end{array}$ & Leaf & $\begin{array}{l}\text { Used in Rongoa Māori to treat dysentery, } \\
\text { diarrhoea and sores }{ }^{[121]}\end{array}$ \\
\hline Cortaderia toetoe (Toetoe) & Shoot & $\begin{array}{l}\text { Used in Rongoa Māori to treat diarrhoea, } \\
\text { relief of kidney, bladder complaints }{ }^{[97,122]}\end{array}$ \\
\hline Cyathea dealbata (Ponga) & Fronds & Used in Rongoa Māori to treat boils ${ }^{[99]}$ \\
\hline $\begin{array}{l}\text { Dacrydium cupressinum } \\
\text { (Rimu) }\end{array}$ & Leaf & Used in Rongoa Māori to treat sores ${ }^{[121]}$ \\
\hline $\begin{array}{l}\text { Dracophyllum longifolium } \\
\text { (Inanga) }\end{array}$ & Leaf & $\begin{array}{l}\text { Genus Dracophyllum known to have } \\
\text { antibacterial activity }{ }^{[123]}\end{array}$ \\
\hline Dodonaea viscosa (Ake ake) & $\begin{array}{l}\text { Leaf } \\
\text { Seed }\end{array}$ & 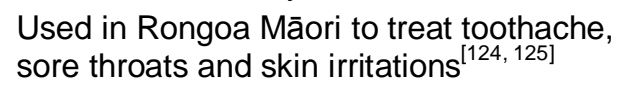 \\
\hline $\begin{array}{l}\text { Dysoxylum spectabile } \\
\text { (Kohekohe) }\end{array}$ & Leaf & $\begin{array}{l}\text { Used in Rongoa Māori to relieve coughing, } \\
\text { colds and fevers }{ }^{[96]}\end{array}$ \\
\hline Exocarpus bidwillii & $\begin{array}{l}\text { Leaf } \\
\text { Seed }\end{array}$ & Root parasite of other species ${ }^{[126]}$ \\
\hline Hebe stricta (Koromiko) & $\begin{array}{l}\text { Leaf } \\
\text { Flower }\end{array}$ & $\begin{array}{l}\text { Leaf was used in Rongoa Māori to treat } \\
\text { skin problems and ulcers }{ }^{[96,121]}\end{array}$ \\
\hline $\begin{array}{l}\text { Hymenophyton flabellatum } \\
\text { (Liverwort) }\end{array}$ & Leaf & Liverworts commonly used medicinally ${ }^{[127]}$ \\
\hline Knightia excelsa (Rewarewa) & Leaf & $\begin{array}{l}\text { Used in Rongoa Māori to relieve } \\
\text { coughing }^{[121]}\end{array}$ \\
\hline
\end{tabular}


Kunzea ericoides (Kanuka)

Laurelia novae-zelandiae

(Pukatea)

Leptospermum scoparium

(Manuka)

Lophomyrtus bullata

(Ramarama)

Macropiper excelsum

(Kawakawa)

Melicytus ramiflorus (Mahoe)

Meryta sinclairii (Puka)

Metrosideros excelsa

(Pohutukawa)

Metrosideros umbellata

(Southern Rata)

Microsorum pustulatum

(Hound's tongue)

Myoporum laetum (Ngaio)

Nothofagus fusca (Red beech)

Paesia scaberula (Lace fern)

Phormium tenax (New Zealand

flax)

Pittosporum tenuifolium

(Kohuhu)

Plagiochila stephensoniana

(Liverwort)

Pseudopanax arboreus (Five finger)

Pseudopanax crassifolius

(Lancewood)

Pseudowintera colorata

(Horopito)

Pteridium esculentum

(Bracken)

Rubus cissoides (Bush lawyer) Leaf

Schefflera digitata (Seven Leaf

finger)

Sophora microphylla (Kowhai) Leaf

Urtica ferox (Stinging nettle) Leaf

Vitex lucens (Puriri) Leaf

Weinmannia racemosa

(Kamahi)
Fruit

Seed

Leaf

Cambium

Bark

Leaf

Leaf

Flower

Leaf

Leaf

Leaf

Leaf

Leaf

Flower

Leaf

Leaf

Leaf

Leaf

Leaf

Leaf

Leaf

Leaf

Leaf

Leaf

Leaf

Leaf

Leaf
Used in Rongoa Māori to relieve pain, headaches and coughs

Used in Rongoa Māori to treat sores, ulcers and tuberculosis ${ }^{[97,99,121]}$

Used to treat skin conditions, venereal disease and used as a painkiller ${ }^{[117]}$ Treated toothache ${ }^{[121]}$

Leaf was used in Rongoa Māori to treat colds, pains, urinary troubles ${ }^{[121]}$

Used in Rongoa Māori to treat bruises ${ }^{[121]}$

Used in Rongoa Māori to treat arthritis, rheumatism and chest difficulties ${ }^{[99,128]}$

Used in Rongoa Māori to treat rheumatism and stomach wounds ${ }^{[121]}$

The family Araliaceae has plants used medicinally ${ }^{[129]}$

Flower was used in Rongoa Māori to treat sore throats ${ }^{[121]}$

Genus Metrosideros was used in traditional medicine ${ }^{[121]}$

Genus Microsorum was used in traditional medicine ${ }^{[130]}$

Used in Rongoa Māori to treat bruises and infected wounds ${ }^{[121]}$

Presence of polyphenolic antioxidant nothofagin $^{[131]}$

Family Dennstaedtiaceae has recorded antibacterial activity ${ }^{[132]}$

Used in Rongoa Māori to treat cuts and constipation ${ }^{[98]}$

Used in Rongoa Māori to treat eczema, other skin diseases and fever ${ }^{[121]}$

Genus Plagiochila known to have antibacterial activity ${ }^{[127]}$

The family Araliaceae contains plants used medicinally ${ }^{[129]}$

The family Araliaceae contains plants used medicinally ${ }^{[129]}$

Used in Rongoa Māori to treat toothache, skin irritations, and used as a painkiller ${ }^{[96]}$

Used as an antiseptic as well as treats sores $^{[125]}$

Used in Rongoa Māori to treat chest congestion, coughs and sore throat ${ }^{[121]}$

Contains anti-dermatophyte compound Falcarindiol ${ }^{[133]}$

Used in Rongoa Māori to treat wounds, back, abdominal and internal pains ${ }^{[99]}$ Genus Urtica has known anti-fungal and anti-viral activity ${ }^{[134]}$

Used in Rongoa Māori to treat backache, ulcers, and sore throats ${ }^{[121]}$

Parts of plant used medicinally to treat stomach aches and cuts ${ }^{[121]}$ 
Table 3.2.1. Medicinal information on native New Zealand plants selected for antimycobacterial screening. Information on the native NZ plants was either related to Māori medicinal use or any other known anti-infective properties. $n i=$ no information available.

\subsubsection{Location of collection sites}

The majority of samples were collected in the Wellington region, in Wellington central, Karori, Otari-Wilton, Ngaio and Kaitoke as shown below in Figure 3.2.2. From the Wellington region most of the plants collect were form Otari-Wilton bush, a reserve with a wide range of native plants with easy access to them for collection. Other reserves included Karori Wildlife Sanctuary (Zealandia) and Kaitoke Regional Park. Leaves were chosen from the same apical node from each branch with similar size and colouring to reduce the amount of variability of compounds present in each individual sample. 


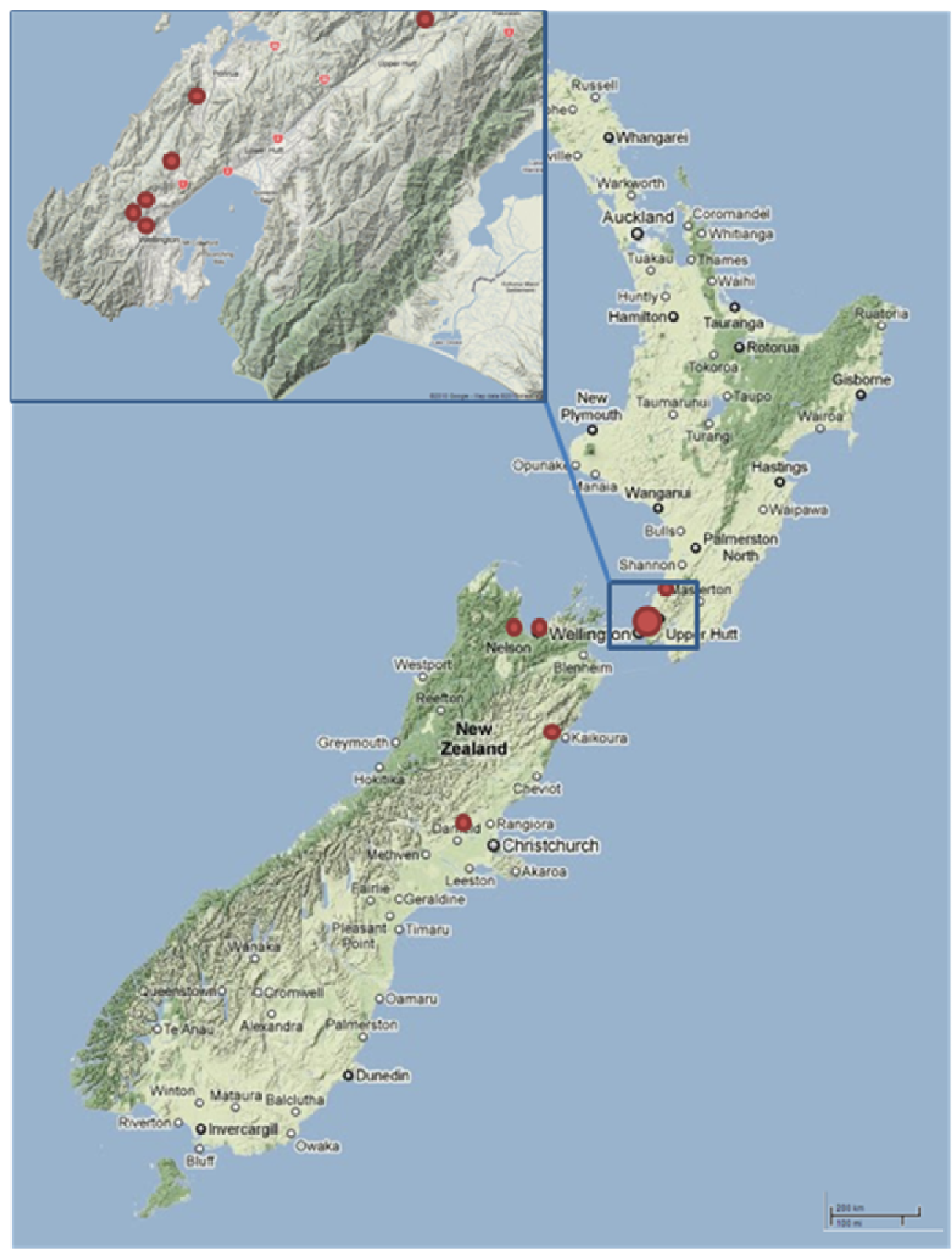

Figure 3.2.2. Plant sample collection sites in New Zealand. Collection sites are indicated by the red dots. Inset is an enlarged view of the Wellington region. Map reproduced and adapted from Google Maps, (C2010 Google - and (C) 2010 MapData Sciences Pty Ltd, PSMA. 


\subsubsection{Conditional information of the samples collected}

The location, season and local conditions were recorded for each sample and documented in Table 3.2.3. This information may provide some insight into the plants with activity, such as if there is a correlation between location, season or condition and the levels of inhibitory activity.

\begin{tabular}{|c|c|c|c|}
\hline Plant & Area & Season & Conditions \\
\hline Adiantum raddianum & Ngaio & Spring & Filtered light, moist, low \\
\hline Agathis australis & Otari-Wilton & Summer & Sunny, dry, slightly damp \\
\hline Arthropodium cirrhatum & Ngaio & Spring & Filtered light, moist \\
\hline Asplenium bulbiferum & Upper Hutt & Autumn & Filtered light, damp, low \\
\hline Asplenium flaccidum & Upper Hutt & Summer & ni \\
\hline Beilschmiedia tawa & Upper Hutt & Autumn & ni \\
\hline Blechnum fluviatile & Otari-Wilton & Summer & Shaded, damp \\
\hline Brachyglottis repanda & Karori & Summer & Filtered light, moist, low \\
\hline Carpodetus serratus & S. Island & Spring & Shaded, damp \\
\hline Clianthus puniceus & Tawa & Winter & Sunny, highland \\
\hline Cordyline australis & Ngaio & Winter & Shaded, damp \\
\hline Cortaderia toetoe & Karori & Summer & Sunny, dry \\
\hline Cyathea dealbata & Otari-Wilton & Spring & Shaded, damp \\
\hline Dacrydium cupressinum & Upper Hutt & Autumn & ni \\
\hline Dracophyllum longifolium & Kaikoura & Winter & Sunny, dry, highland \\
\hline Dodonaea viscosa & Otari-Wilton & Autumn & Sunny, damp \\
\hline Dysoxylum spectabile & Karori & Summer & Filtered light, damp \\
\hline Exocarpus bidwillii & Canterbury & Winter & Sunny, dry \\
\hline Hebe speciosa & Otari-Wilton & Summer & Sunny, dry \\
\hline Hymenophyton flabellatum & Otari-Wilton & Summer & Shaded, damp, lowland \\
\hline Knightia excelsa & Otari-Wilton & Summer & Filtered light, moist \\
\hline Kunzea ericoides & Upper Hutt & Autumn & ni \\
\hline Laurelia novae-zelandiae & Otari-Wilton & Summer & Shaded, wet, lowland \\
\hline Leptospermum scoparium & Kelburn & Winter & Sunny, dry, highland \\
\hline Lophomyrtus bullata & Otari-Wilton & Summer & Filtered light, moist \\
\hline Macropiper excelsum & Otari-Wilton & Autumn & Filtered light, damp \\
\hline Melicytus ramiflorus & Karori & Summer & Filtered light, moist \\
\hline Meryta sinclairii & Kelburn & Summer & Shaded, damp \\
\hline Metrosideros excelsa & Ngaio & Summer & Sunny, damp \\
\hline Metrosideros umbellata & Kaiteriteri & Spring & ni \\
\hline Microsorum pustulatum & Karori & Summer & ni \\
\hline Myoporum laetum & Ngaio & Winter & Sunny, damp \\
\hline Nothofagus fusca & Otari-Wilton & Summer & Sunny, moist \\
\hline Paesia scaberula & Otari-Wilton & Summer & Filtered light \\
\hline Pittosporum tenuifolium & Ngaio & Winter & Sunny, dry \\
\hline Plagiochila stephensoniana & Otari-Wilton & Summer & Shaded, damp \\
\hline Pseudopanax arboreus & Ngaio & Winter & Shaded, damp \\
\hline Pseudopanax crassifolius & Otari-Wilton & Spring & Filtered light, moist \\
\hline Pseudowintera colorata & Nelson & Spring & ni \\
\hline Pteridium esculentum & Karori & Summer & Filtered light, moist \\
\hline Rubus cissoides & Moutere Hill & Spring & ni \\
\hline Schefflera digitata & Ngaio & Winter & Shaded, damp \\
\hline Sophora microphylla & Ngaio & Winter & Shaded, damp \\
\hline Urtica ferox & Otari-Wilton & Summer & Shaded, moist \\
\hline Vitex lucens & Kaitoke & Spring & Filtered light, damp \\
\hline Weinmannia racemosa & Upper Hutt & Autumn & ni \\
\hline
\end{tabular}


Table 3.2.3. Information of the samples collected. The location, season and local conditions were recorded for each sample. $n i=$ no information recorded.

\subsubsection{Development of Solvent Extraction}

The leaf of $M$. excelsa was tested in various conditions to validate the protocol that was in development. It was questioned that, under solvent extraction, if dried plant material would have improved antimycobacterial activity compared to fresh. It also was hypothesized that heating the sample during the extraction process would have better activity than if tested fresh. In traditional medicine a lot of plants were boiled before treatment [97]. Thus, it was queried if a period of incubation would help increase the yield of bioactive compounds extracted and thus increase the potential activity of the sample. In the first condition the leaf extract was tested fresh as well as dried with a desiccate. There was no incubation involved at this stage. As shown in Table 3.2.4 it appears that there was a higher yield and lower MIC with the dried extract than when tested fresh. In the second condition a dried sample of leaf was added to $\mathrm{MeOH}$ and either incubated at $55^{\circ} \mathrm{C}$ or had no incubation involved. The solvent of the resulting extracts was then evaporated and the yield of the remaining extract was determined. The extracts were then resuspended in $\mathrm{MeOH}$ and analysed for antimycobacterial activity against $M$. smegmatis to give an MIC. The two conditions gave similar yields, but the extract that was incubated had an MIC of $0.75 \mathrm{mg} / \mathrm{ml}$, whereas the MIC was more than 2 $\mathrm{mg} / \mathrm{ml}$ for the extract with no incubation performed. 


\begin{tabular}{lcc}
\hline \multicolumn{1}{c}{ Condition } & Yield $(\mathbf{g})$ & MIC $(\mathbf{m g} / \mathbf{m l})$ \\
\hline Fresh & 0.0118 & $>2$ \\
Dried & 0.0184 & 0.9 \\
& & \\
No Incubation & 0.01 & $>2$ \\
Incubation & 0.0168 & 0.75 \\
\hline
\end{tabular}

Table 3.2.4. Yield and MIC of $M$. excelsa methanol leaf extract in various extraction conditions. The leaf $\mathrm{MeOH}$ extract of $M$. excelsa was tested in various conditions to validate the protocol that was in development. In the first condition, the leaf extract was tested 'fresh' as well as 'dried' with a desiccate. In the second condition a dried sample of leaf was either incubated at $55^{\circ} \mathrm{C}$ or had no incubation performed. The resulting yield was weighed and then resuspended in $\mathrm{MeOH}$ before screening against $M$. smegmatis to determine the MIC.

\subsubsection{Initial Screening of Native Plants against $M$. smegmatis}

The library of extracts was screened against $M$. smegmatis for initial antimycobacterial activity. The $\mathrm{EtOH}$ and $\mathrm{MeOH}$ solvents were tested at a starting solvent concentration of $2 \%$ which did not affect normal growth of the bacteria. A minimum of $90 \%$ inhibition was considered to be an active extract. As shown below in Table 3.2.5 the nine extracts from seven species (L. novae-zelandiae, L. bullata, M. excelsa, M. laetum, $P$. tenuifolium, $P$. crassifolius, $P$. colorata) were found to cause $\geq 90 \%$ inhibition. 


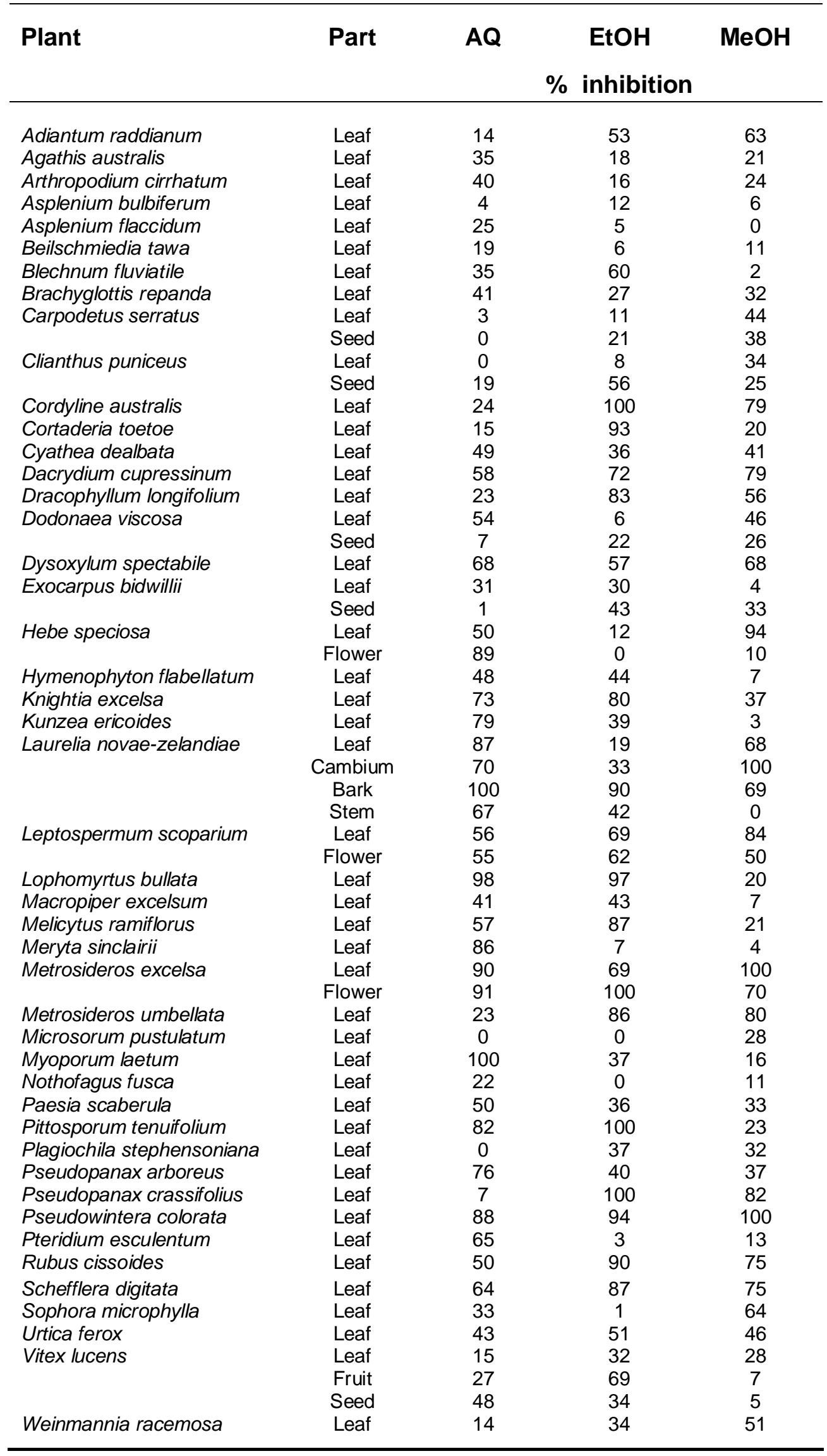


Table 3.2.5. Inhibition levels of native New Zealand plants with respect to $M$. smegmatis. Plants were extracted in an $\mathrm{AQ}, \mathrm{EtOH}$ or $\mathrm{MeOH}$ solvent and screened against $M$. smegmatis. Levels of inhibition were calculated by expressing the GFP fluorescence values as a percentage compared to a no-drug negative control. $100 \%$ represents complete inhibition of $M$. smegmatis growth. All extracts were tested at a starting concentration of $2 \mathrm{mg} / \mathrm{ml}$. 


\subsubsection{Summary of Native Plant Extracts active against $M$. smegmatis}

Of the 46 native NZ plants initially tested, 7 plant species displayed antimycobacterial activity against $M$. smegmatis. Laurelia novaezelandiae, Lophomyrtus bullata, Metrosideros excelsa, Myoporum laetum, Pittosporum tenuifolium, Pseudopanax crassifolius and Pseudowintera colorata had extracts that showed inhibition towards $M$. smegmatis, with activity specific to one solvent; water, $\mathrm{EtOH}$ or $\mathrm{MeOH}$.

\begin{tabular}{|c|c|c|c|c|c|c|}
\hline Plant species & $\begin{array}{l}\text { Common } \\
\text { Name }\end{array}$ & Part & Location & $\mathbf{A Q}$ & EtOH & $\mathrm{MeOH}$ \\
\hline \multirow[t]{2}{*}{$\begin{array}{l}\text { Laurelia novae- } \\
\text { zelandiae }\end{array}$} & Pukatea & Bark & $\begin{array}{l}\text { Otari- } \\
\text { Wilton }\end{array}$ & + & - & - \\
\hline & & Cambium & $\begin{array}{l}\text { Otari- } \\
\text { Wilton }\end{array}$ & - & - & + \\
\hline $\begin{array}{l}\text { Lophomyrtus } \\
\text { bullata }\end{array}$ & Ramarama & Leaf & $\begin{array}{l}\text { Otari- } \\
\text { Wilton }\end{array}$ & - & - & + \\
\hline \multirow[t]{2}{*}{$\begin{array}{l}\text { Metrosideros } \\
\text { excelsa }\end{array}$} & Pohutukawa & Leaf & Ngaio & - & - & + \\
\hline & & Flower & Ngaio & - & + & - \\
\hline $\begin{array}{l}\text { Myoporum } \\
\text { laetum }\end{array}$ & Ngaio & Leaf & Ngaio & + & - & - \\
\hline $\begin{array}{l}\text { Pittosporum } \\
\text { tenuifolium }\end{array}$ & Kohuhu & Leaf & Ngaio & - & + & - \\
\hline $\begin{array}{l}\text { Pseudopanax } \\
\text { crassifolius }\end{array}$ & Lancewood & Leaf & $\begin{array}{l}\text { Otari- } \\
\text { Wilton }\end{array}$ & - & + & - \\
\hline $\begin{array}{l}\text { Pseudowintera } \\
\text { colorata }\end{array}$ & Horopito & Leaf & Nelson & - & - & + \\
\hline
\end{tabular}

Table 3.2.6. Antimycobacterial activity of plant extracts against $M$. smegmatis. ' + ' indicates $\geq 90 \%$ inhibition of $M$. smegmatis growth at a concentration of $2 \mathrm{mg} / \mathrm{ml}$ or lower. 


\subsubsection{Comparison of GFP and OD results of active extracts against $M$.}

\section{smegmatis}

The most active extract was derived from L. novae-zelandiae (Pukatea). The bark of $L$. novae-zelandiae generated an $\mathrm{IC}_{50}$ value of $0.02 \mathrm{mg} / \mathrm{ml}$ and the cambium had an $\mathrm{IC}_{50}$ of $0.25 \mathrm{mg} / \mathrm{ml}$ (Table 3.2.7). Significant activity was also observed with respect to the leaf, $\mathrm{IC}_{50}$ of $0.11 \mathrm{mg} / \mathrm{ml}$, and flower, $\mathrm{IC}_{50}$ of $0.41 \mathrm{mg} / \mathrm{ml}$, of $M$. excelsa. $P$. tenuifolium and $P$. colorata leaves were less active with $I_{50}$ values of $0.78 \mathrm{mg} / \mathrm{ml}$ and $0.74 \mathrm{mg} / \mathrm{ml}$, respectively (Table 3.2 .7 ). The $\mathrm{MIC}$ and $\mathrm{IC}_{50}$ values determined by $\mathrm{OD}$ were higher than those determined by GFP.

\begin{tabular}{|c|c|c|c|c|c|}
\hline \multirow[t]{2}{*}{ Plant } & \multirow[t]{2}{*}{ Part } & \multicolumn{2}{|r|}{ GFP } & \multicolumn{2}{|r|}{ OD } \\
\hline & & MIC & $I_{50}$ & $\mathrm{MIC}$ & $\mathrm{IC}_{50}$ \\
\hline L. novae-zelandiae & $\begin{array}{c}\text { Bark } \\
\text { Cambium }\end{array}$ & $\begin{array}{l}0.04 \\
0.50\end{array}$ & $\begin{array}{c}0.02 \pm 0.004 \\
0.25 \pm 0.01\end{array}$ & $\begin{array}{l}0.32 \\
0.50\end{array}$ & $\begin{array}{l}0.29 \pm 0.13 \\
0.25 \pm 0.02\end{array}$ \\
\hline L. bullata & Leaf & 1.00 & $0.31 \pm 0.15$ & 2.00 & $0.024 \pm 0.04$ \\
\hline M. excelsa & $\begin{array}{l}\text { Leaf } \\
\text { Flower }\end{array}$ & $\begin{array}{l}0.63 \\
0.63\end{array}$ & $\begin{array}{l}0.11 \pm 0.06 \\
0.41 \pm 0.06\end{array}$ & $\begin{array}{l}1.25 \\
2.0\end{array}$ & $\begin{array}{c}0.078 \pm 0.02 \\
1.36 \pm 1.53\end{array}$ \\
\hline M. laetum & Leaf & 0.63 & $0.34 \pm 0.02$ & 2.0 & $0.46 \pm 0.11$ \\
\hline P. tenuifolium & Leaf & 2.00 & $0.78 \pm 0.34$ & 2.0 & $1.49 \pm 0.41$ \\
\hline P. crassifolius & Leaf & 0.63 & $0.31 \pm 0.01$ & 1.25 & $0.74 \pm 0.72$ \\
\hline P. colorata & Leaf & 1.25 & $0.74 \pm 0.40$ & 2.0 & $1.25 \pm 0.17$ \\
\hline RIF & - & 0.013 & $\begin{array}{c}0.003 \pm \\
0.001\end{array}$ & 0.013 & $\begin{array}{c}0.004 \pm \\
0.001\end{array}$ \\
\hline
\end{tabular}

Table 3.2.7. MIC and $I_{50}$ values for GFP and OD of active crude plant extracts with respect to $M$. smegmatis. Extract and drug control values are in $\mathrm{mg} / \mathrm{ml}$. ' \pm ' denotes standard error between triplicate results. 


\subsubsection{Bacteriostatic inhibition curves of extracts with activity} against $M$. smegmatis

Dose-response experiments were performed on the active extracts that were found to have $\geq 90 \%$ inhibition in the initial screen against $M$. smegmatis. Figure 3.2.7.1 depicts the bacteriostatic curves for the two most active extracts, the bark and cambium of $L$. novae-zelandiae. See Appendix 2 for the bacteriostatic curves of the remaining active extracts.
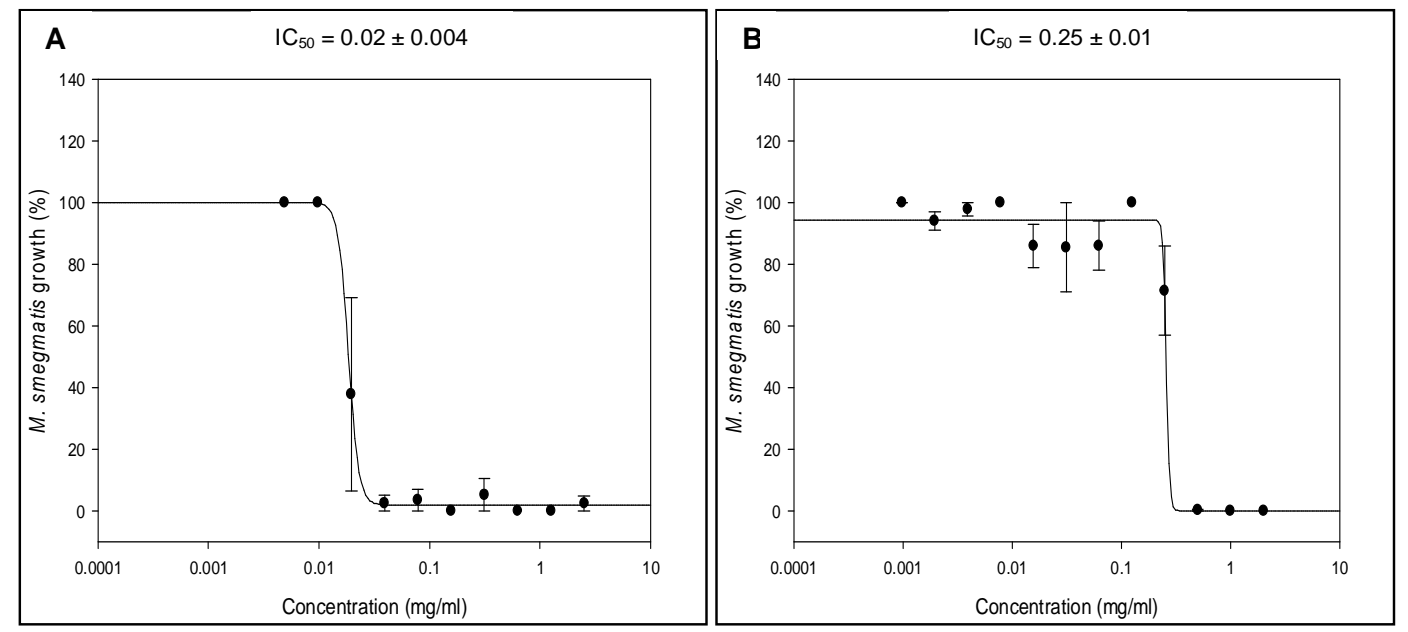

Figure 3.2.7.1. Bacteriostatic inhibition curves for bark and cambium extracts of $L$. novae-zelandiae against $\boldsymbol{M}$. smegmatis. A) AQ bark extract. B) $\mathrm{MeOH}$ cambium extract. Values are based on GFP results. 100\% represents complete growth of $M$. smegmatis cells compared to the untreated control. Error bars denote standard deviation between triplicate values. 


\subsection{Discussion}

\subsubsection{Construction of Plant Extract Library}

Ethnobotany was chosen as the method for selection of plants in order to increase the chances of finding a positive hit. The reasoning behind this was that if the plants were used medicinally then there was a high chance of the plants having antibacterial activity as well as low toxicity $[49,135]$. Rongoa Māori can also provide other information such as which parts of the plant were likely to have activity and which season was best for collection. This can make the selection of plants easier to compile in order to increase the chance of attaining a positive hit, considering the thousands of species of NZ flora. Other plants with no traditional use were also selected, based on their physical properties (e.g. E. bidwilli is a parasitic plant) or their homology to other plants that were used medicinally (for example, M. umbellata compared to M. excelsa). Overall, this method of selection appeared to be advantageous as a $15 \%$ hit rate of active extracts was obtained from a small selection of extracts collected and tested.

\subsubsection{Method Validation}

Leaves were mainly chosen for sampling rather than bark, roots or flowers. This was because it was assumed that if secondary metabolites were the compounds present with antibacterial activity then they would logically be in the highest concentrations in the epidermal tissue in order to deter predators or pathogens [85]. Bark or flowers were generally only chosen if traditional medicine used those particular parts. However, the season at 
time of collection could have affected the levels of compound present in the plant tissue. In order to conserve energy in the colder seasons the plant could have decreased the levels of metabolites present in the external tissue. An interesting result though was the leaf sample from $M$. laetum, which was taken in the winter and yet it was picked up in the screen as an active hit.

A desiccate was used as many plants were dried first when traditionally used [97]. It was also used to prevent water retention; otherwise the results would be affected by the presence of water remaining in the tissue. Other non-polar solvents were also attempted for solvent extraction. Toluene, xylene and chloroform $\left(\mathrm{CHCl}_{3}\right)$ were used for solvent extraction for some plant samples collected (results not shown). However, these solvents did not yield any positive results, including for those plants which had activity when extracted with polar solvents. Thus, only polar solvents were used for extraction as they were inexpensive and generated extracts with good antimycobacterial activity. $\mathrm{EtOH}$ and $\mathrm{MeOH}$ solvents were chosen as they have been considered effective solvents for liquidextraction of plant samples without degrading the tissue $[136,137]$. SDW was also chosen as a solvent for extraction even though it does not extract compounds easily through the plants tough cellulose wall due to its high polarity [138]. Water was used for solvent extraction as many of the traditional preparations used in Rongoa Māori involved boiling the plant in water and then using the resulting liquid for treatment [97]. This was also the rationale for the incubation process, as it imitated the preparations 
used in traditional Māori medicine with the intention of increasing the potency of the plants activity.

The maceration procedure was performed in order to help increase solvent extraction by increasing surface area of the plant tissue. The heat was also thought to help increase the concentration of compounds extracted from the tissue. This was also facilitated by refrigeration after the incubation process. The extracts activity remained stable when stored at $8^{\circ} \mathrm{C}$, that is, they still retained antimycobacteria I activity when retested months later.

There were major differences noted in the activity of extracts between solvents used on the same sample. A possible explanation could be that one solvent was able to 'extract more' of the active component present in the sample, thus increasing the antimycobacterial activity. For example, if the active compound was an alkaloid there would be lower concentrations in an aqueous solution than in an alcohol solution. What was especially noted was that many of the aqueous extracts had better activity than the $\mathrm{EtOH}$ or $\mathrm{MeOH}$ extracts. This could be due to the possibility that the compounds were more stable in a 'natural' state than when in $\mathrm{EtOH}$ or $\mathrm{MeOH}$, even though the aqueous solution is more polar and therefore unlikely to extract compounds through the plants cellulose membrane [138]. Overall, the variability between solvents justified the use of more than one solvent in order to maximise the hit rate of active extracts. 


\subsubsection{Initial screening of extracts against $M$. smegmatis}

Extracts from 7 plants species, Laurelia novae-zelandiae, Lophomyrtus bullata, Metrosideros excelsa, Myoporum laetum, Pittosporum tenuifolium, Pseudopanax crassifolius and Pseudowintera colorata showed inhibition towards M. smegmatis. In Rongoa Māori the flower of M. excelsa was used to treat sore throats $[97,121]$. Lophomyrtus bullata, Myoporum laetum, Pittosporum tenuifolium and Pseudowintera colorata were either used for wounds, bruises or skin conditions $[96,121]$. This lends to the idea that they potentially have antibacterial compounds. Pseudopanax crassifolius was the only extract with activity that was not traditionally used in Rongoa Māori medicine. The bark of Laurelia novae-zelandiae (Pukatea) was used by Māori in a number of medicinal remedies [121]. The bark had the best antimycobacterial activity against $M$. smegmatis with an MIC and $\mathrm{IC}_{50}$ of $0.04 \mathrm{mg} / \mathrm{ml}$ and $0.02 \pm 0.004 \mathrm{mg} / \mathrm{ml}$, respectively (Figure 3.2.7.1 A), indicating that the bark contained antibacterial compounds. It is possible that during development $L$. novae-zelandiae produced bioactive agents to act as protective measures against predators as well as for maintenance [85], thus signifying it as a good source for novel antitubercular compounds. This would need to be confirmed by validating the activity of the extract against $M$. tuberculosis, as well as establishing its type of activity. 


\section{CHAPTER FOUR: Validation of Active Plant Extracts}

(Results in this Chapter were peer-reviewed and published in BMC Complementary and Alternative Medicine, 2010, 10(1):25) 


\subsection{Introduction}

In the previous chapter native plant samples were screened against $M$. smegmatis and seven plant species had extracts with antimycobacterial activity. The aim of this chapter was to then validate the bacteriostatic activity of these extracts against the slow-growing species $M$. bovis BCG and M. tuberculosis H37Ra. The extracts were then investigated for bactericidal activity against $M$. smegmatis. The extracts were also tested against $E$. coli and $S$. aureus for antibacterial activity. The active extracts potential cytotoxicity was also assessed. In addition, the potential compounds present in the active extracts are discussed.

M. tuberculosis H37Rv is a commonly used strain for the screening of antitubercular compounds in laboratories. However, it is restricted to physical containment level-3 facilities due to its virulent nature. Therefore other species of the mycobacterium genus have been utilized as a surrogate species for $M$. tuberculosis H37Rv. M. smegmatis and M. bovis BCG are therefore generally used for screening of compounds with potential antimycobacterial activity [139].

Mycobacterium bovis is an aerobic, slow-growing organism that is the causative agent of bovine TB in cattle. M. bovis is pathogenic and can cause TB in humans. M. bovis has a similar genome to $M$. tuberculosis with more than $99.9 \%$ homology in sequence [140] and so it is a suitable model when screening for antitubercular compounds. However, $M$. tuberculosis H37Ra was also used as it has the closest homology to the virulent strain M. tuberculosis H37Rv. By examining all three species it is possible to get an indication as to what type of inhibition is occurring, e.g. 
which of the three mycobacteria species are more susceptible to the active plant extracts. A blue dye, resazurin, that is oxidized to pink (resorufin) in the presence of live cells, was also used to test for the plant extracts bactericidal effect on cell viability [141, 142].

Escherichia coli and Staphylococcus aureus are part of our natural bacterial flora; however, these species are also the cause of many widespread diseases. E. coli is an opportunistic pathogen, usually the common source of food poisoning, but can also be the causal agent for neonatal meningitis [143]. $S$. aureus is one of the most widespread nosocomial infections and can cause the onset of serious diseases such as endocarditis, toxic shock syndrome (TSS) and even sepsis [144-146]. However, there is now the issue of drug-resistant strains of $S$. aureus, one of the major concerns in nosocomial infections [147]. In NZ it appears there is a progressive increase in the number of methicillin-resistant Staphylococcus aureus (MRSA) infections [148] and so there is also a need to search a variety of sources for novel antibacterial compounds.

Although plant extracts have been shown to be active against Mycobacteria they must also be non-toxic to humans. As M. tuberculosis infects macrophages in the lung, testing against a macrophage cell line presents a more comprehensible indication as to the extracts toxicity. In this research the murine macrophage cell-line $\mathrm{J} 774$ was used. A human cell-line HL-60 was also used for examination of the extracts cytotoxicity. HL-60 cells are also commonly used to study the cytotoxicity of anti-cancer drugs; however, they can also be applied for investigating the cytotoxicity of antimycobacterial extracts. 


\subsection{Results}

The seven species of active native plants were tested for antimycobacterial activity against $M$. bovis BCG, M. tuberculosis H37Ra and for their antibacterial activity against the clinically-important species $E$. coli and S. aureus.

\subsubsection{Summary of initial screening of active extracts against clinically-relevant species}

The extracts of $L$. novae-zelandiae, L. bullata, M. excelsa, M. laetum, $P$. tenuifolium, $P$. crassifolius and $P$. colorata were tested against $M$. bovis BCG and M. tuberculosis H37Ra. The use of GFP and OD were used to measure growth levels in $M$. smegmatis and $M$. bovis BCG whereas only OD was used for M. tuberculosis H37Ra, as it does not contain a plasmid with the GFP gene. However, GFP and OD are considered to have a correlation in measurement of growth levels.

The leaf of $P$. tenuifolium was the most active extract with respect to $M$. tuberculosis with an $\mathrm{IC}_{50}$ of $0.51 \mathrm{mg} / \mathrm{ml}$ (Table 4.2.1). The bark extract of L. novae-zelandiae had an $\mathrm{IC}_{50}$ of $0.54 \mathrm{mg} / \mathrm{ml}$ against $M$. bovis and an $\mathrm{IC}_{50}$ of $2.39 \mathrm{mg} / \mathrm{ml}$ against $M$. tuberculosis (Table 4.2.1, Figure 4.2.1). The cambium of $L$. novae-zelandiae was similarly active against both $M$. bovis and M. tuberculosis (Table 4.2.1, Figure 4.2.1) with an $\mathrm{IC}_{50}$ of $1.63 \pm 0.21$ $\mathrm{mg} / \mathrm{ml}$ and $1.86 \pm 0.22 \mathrm{mg} / \mathrm{ml}$, respectively. The leaf extract from $M$. laetum was not active against $M$. bovis or $M$. tuberculosis. To examine the specificity of the anti-bacterial activity of the plant extracts, the extracts were also tested against $S$. aureus and $E$. coli. The leaf of $M$. excelsa 
which was active against $M$. smegmatis and to a lesser extent, $M$. tuberculosis, also displayed antibacterial activity towards $S$. aureus. The leaf of $P$. colorata was the most active of the extracts tested towards $S$. aureus with an $\mathrm{IC}_{50}$ of $0.43 \mathrm{mg} / \mathrm{ml}$. None of the extracts tested exhibited anti-bacterial activity towards $E$. coli up to $10 \mathrm{mg} / \mathrm{ml}$ concentration. 


\begin{tabular}{|c|c|c|c|c|c|c|c|c|c|c|c|}
\hline \multirow[t]{2}{*}{ Plant } & \multirow[t]{2}{*}{ Part } & \multicolumn{2}{|c|}{ M. smegmatis } & \multicolumn{2}{|c|}{ M. bovis } & \multicolumn{2}{|c|}{ M. tuberculosis } & \multicolumn{2}{|c|}{ S. aureus } & \multicolumn{2}{|c|}{ E. colit } \\
\hline & & MIC & $I C_{50}$ & MIC & $I \mathrm{C}_{50}$ & MIC & $1 \mathrm{C}_{50}$ & MIC & $1 \mathrm{C}_{50}$ & MIIC & $I C_{50}$ \\
\hline \multirow[t]{2}{*}{ L. novae-zelandiae } & Bark & 0.04 & $0.02 \pm 0.004$ & 1.50 & $0.54 \pm 0.03$ & 4.16 & $2.39 \pm 0.33$ & $>10$ & $>10$ & $>10$ & $>10$ \\
\hline & Cambium & 0.50 & $0.25 \pm 0.01$ & 2.50 & $1.63 \pm 0.21$ & 3.75 & $1.86 \pm 0.22$ & $>10$ & $>10$ & $>10$ & $>10$ \\
\hline L. bullata & Leaf & 1.00 & $0.31 \pm 0.15$ & 3.12 & $2.59 \pm 0.43$ & 6.51 & $5.59 \pm 0.32$ & $>10$ & $>10$ & $>10$ & $>10$ \\
\hline \multirow[t]{2}{*}{ M. excelsa } & Leaf & 0.63 & $0.11 \pm 0.06$ & 8.35 & $6.95 \pm 3.07$ & $>10$ & $4.83 \pm 0.43$ & 2.20 & $1.17 \pm 0.39$ & $>10$ & $>10$ \\
\hline & Flower & 0.63 & $0.41 \pm 0.06$ & 3.13 & $1.12 \pm 0.12$ & 4.18 & $2.19 \pm 0.76$ & $>10$ & $>10$ & $>10$ & $>10$ \\
\hline M. laetum & Leaf & 0.63 & $0.34 \pm 0.02$ & $>10$ & $>10$ & $>10$ & $>10$ & $>10$ & $>10$ & $>10$ & $>10$ \\
\hline P. tenuifolium & Leaf & 2.00 & $0.78 \pm 0.34$ & 10 & $5.37 \pm 1.35$ & 1.25 & $0.51 \pm 0.11$ & $>10$ & $>10$ & $>10$ & $>10$ \\
\hline P. crassifolius & Leaf & 0.63 & $0.31 \pm 0.01$ & 6.25 & $4.08 \pm 1.76$ & 3.58 & $1.74 \pm 0.18$ & $>10$ & $>10$ & $>10$ & $>10$ \\
\hline P. colorata & Leaf & 1.25 & $0.74 \pm 0.40$ & 7.15 & $5.95+1.28$ & 7.15 & $3.66 \pm 0.39$ & 0.75 & $0.43 \pm 0.2$ & $>10$ & $>10$ \\
\hline RIF & - & 0.013 & $\begin{array}{c}0.003 \pm \\
0.001\end{array}$ & $\begin{array}{c}0.12 \\
\times 10^{-1}\end{array}$ & $\begin{array}{c}4.94 \times 10^{-4} \pm \\
5.02 \times 10^{-6 i}\end{array}$ & $\begin{array}{l}2.06 \\
\times 10^{-4}\end{array}$ & $\begin{array}{c}4.84 \times 10^{-5} \pm \\
4.03 \times 10^{-5}\end{array}$ & 0.02 & $\begin{array}{c}0.006 \pm \\
0.001\end{array}$ & 0.04 & $0.03 \pm 0.02$ \\
\hline
\end{tabular}

Table 4.2.1. Comparison of MIC and IC $\mathrm{I}_{50}$ values of active plant extracts with respect to $M$. smegmatis, M. bovis, M. tuberculosis, S. aureus and E. coli. M. smegmatis, M. bovis, S. aureus and E. coli values are based on GFP results and $M$. tuberculosis values are based on $\mathrm{OD}$ results. Extract and drug control values are in $\mathrm{mg} / \mathrm{ml}$. ' \pm ' denotes standard error between triplicate results. MIC, Minimum Inhibitory Concentration. $\mathrm{IC}_{50}, 50 \%$ inhibitory concentration. 

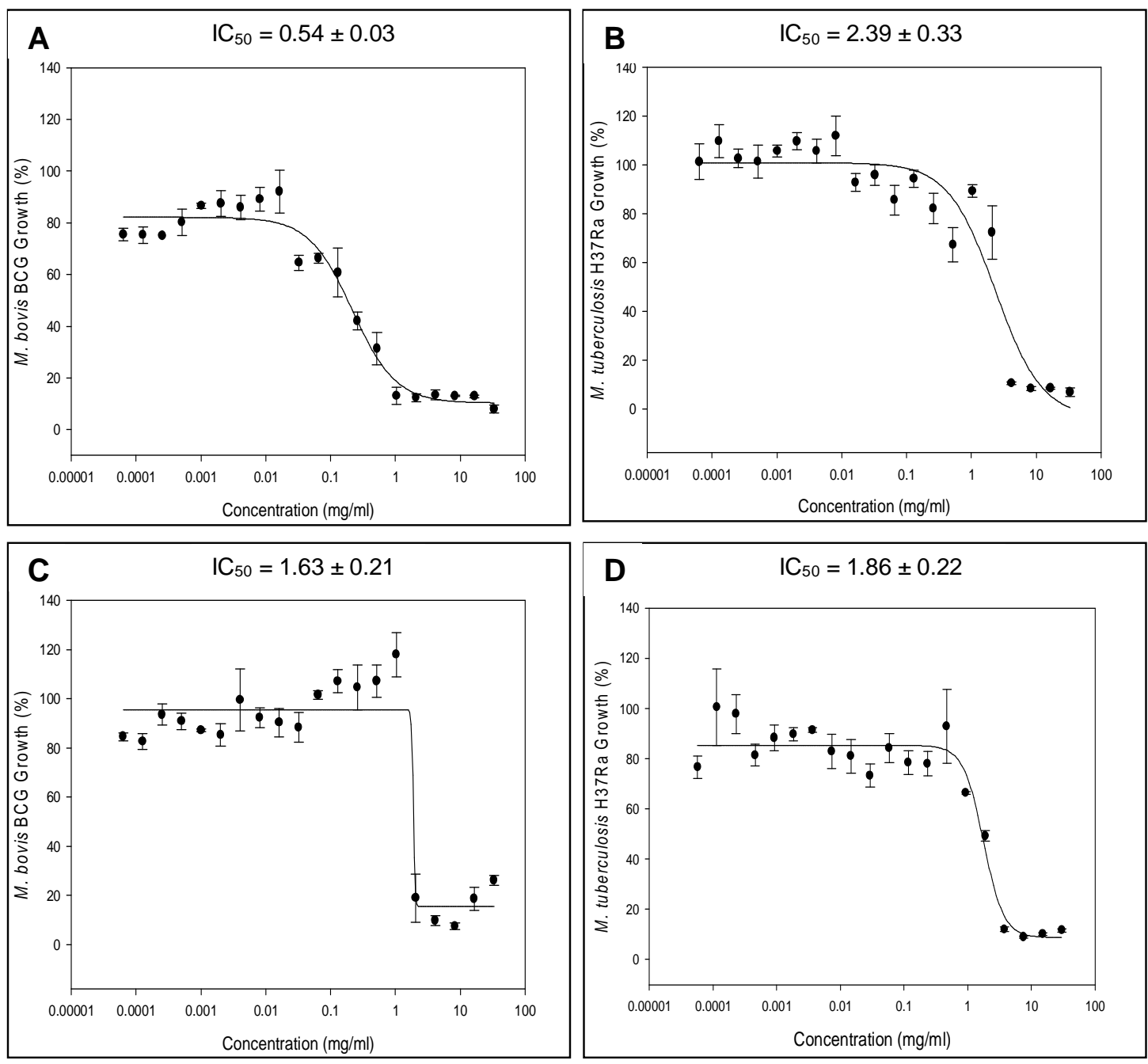

Figure 4.2.1. Bacteriostatic inhibition curves for bark and cambium extracts of $L$. novae-zelandiae against $M$. bovis and $M$. tuberculosis. A) Inhibitory activity of $A Q$ bark extract against $M$. bovis BCG and B) M. tuberculosis H37Ra. C) Inhibitory activity of $\mathrm{MeOH}$ cambium extract against $M$. bovis BCG and D) $M$. tuberculosis $\mathrm{H} 37 \mathrm{Ra}$. $100 \%$ represents complete growth of $M$. smegmatis cells compared to the untreated control. All values are in $\mathrm{mg} / \mathrm{ml}$. Error bars denote standard deviation between triplicate values. 


\subsubsection{Bactericidal screening of active extracts}

To elucidate the type of inhibitory activity, the active extracts were also tested for bactericidal activity. The results shown below in Figure 4.2.2 show the bactericidal activity of each extract compared to its bacteriostatic activity. As bactericidal activity was measured using resazurin reduction the bacteriostatic results were also based on resazurin values. The leaf of M. laetum, $P$. tenuifolium and $P$. crassifolius appeared to have lost some bacteriostatic activity with the resazurin reduction, although this was likely due to auto-reduction by the extracts. The bark and cambium extracts of $L$. novae-zelandiae displayed considerable bactericidal activity at concentration of $2 \mathrm{mg} / \mathrm{ml}$. The flower of $M$. excelsa and leaf of $P$. tenuifolium also had some bactericidal activity towards $M$. smegmatis.

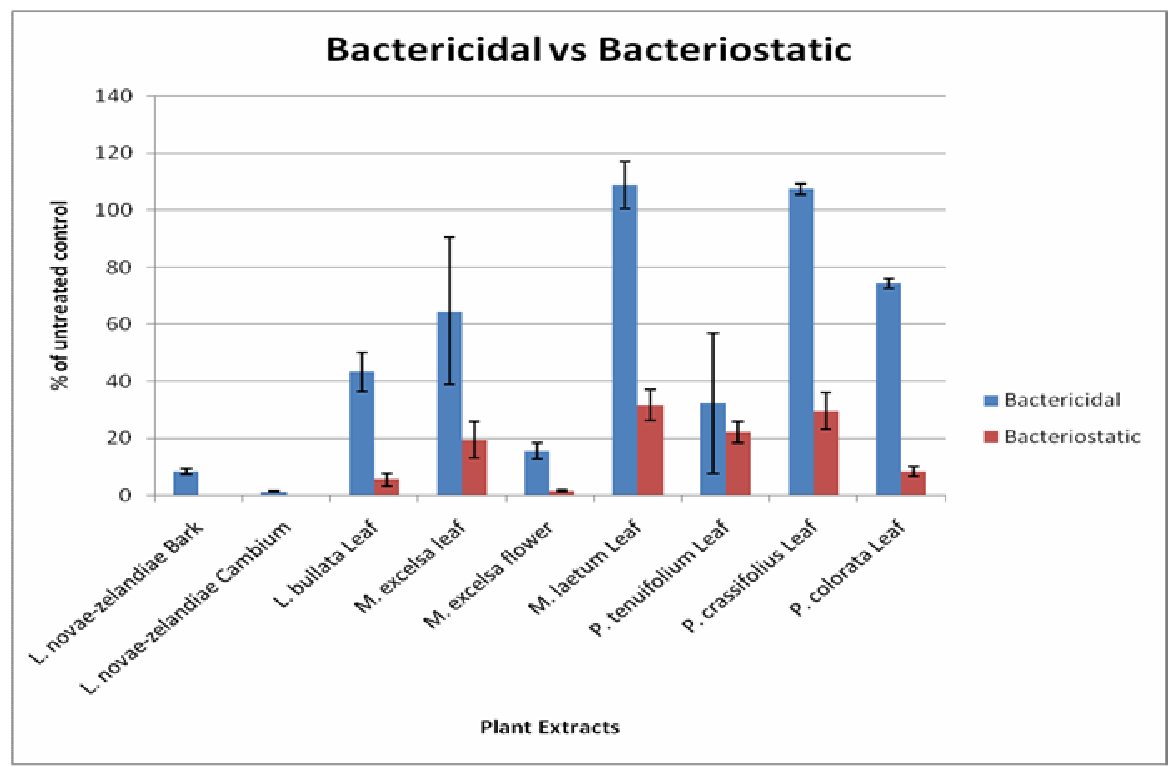

Figure 4.2.2. Bactericidal activity of crude plant extracts with respect to $\boldsymbol{M}$. smegmatis. All extracts had a starting concentration of $2 \mathrm{mg} / \mathrm{ml}$. Values are based on Resazurin results. $100 \%$ represents no inhibition of $M$. smegmatis growth compared to the untreated control. Error bars denote standard deviation between triplicate values. 


\subsubsection{Cytotoxicity of active plant extracts}

Active extracts were tested against murine macrophage cell line J774 and human cell line HL-60 to give an indication of cytotoxicity. A cytotoxic compound, EpoA, was included as a positive control. As shown in Table 4.2.3, EpoA had an $\mathrm{IC}_{50}$ of $5.32 \times 10^{-6} \pm 8.13 \times 10^{-7} \mathrm{mg} / \mathrm{ml}$ and $2.91 \times 10^{-6}$ $\pm 1.11 \times 10^{-6} \mathrm{mg} / \mathrm{ml}$ against $\mathrm{J} 774$ and $\mathrm{HL}-60$ cell lines, respectively. Using this value as the criteria for toxicity, all active extracts could be considered non-toxic. The flower extract of $M$. excelsa had the lowest $I_{50}$ value of $2.34 \pm \leq 0.001 \mathrm{mg} / \mathrm{ml}$ towards the macrophages, whereas the bark of $L$. novae-zelandiae had the lowest value towards the HL-60 cells with an $\mathrm{IC}_{50}$ of $13.64 \pm 0.01 \mathrm{mg} / \mathrm{ml}$. All of the extracts had lower $I_{50}$ values than the TB drug control RIF, which had an $\mathrm{IC}_{50}$ of $1.27 \pm 2.25 \mathrm{mg} / \mathrm{ml}$ against $\mathrm{J} 774$ cells and $0.12 \pm 0.03 \mathrm{mg} / \mathrm{ml}$ against $\mathrm{HL}-60$ cells. The results imply that the extracts were less toxic than the TB drug.

\begin{tabular}{lccc}
\hline \multirow{2}{*}{ Plant } & Part Used & \multicolumn{2}{c}{ Cytotoxicity $\left(\mathbf{I C}_{50}\right)$} \\
\hline & & $\mathbf{J 7 7 4}$ & HL-60 \\
\cline { 3 - 4 } & & $0.14 \pm 0.02$ & $13.64 \pm 0.01$ \\
L. novae-zelandiae & Bark & $0.78 \pm 0.05$ & $0.63 \pm 0.13$ \\
& Cambium & $0.24 \pm 0.02$ & $0.09 \pm 0.01$ \\
L. bullata & Leaf & $0.03 \pm 0.05$ & $0.15 \pm 0.001$ \\
M. excelsa & Leaf & $2.34 \pm \leq 0.001$ & $0.08 \pm 0.005$ \\
M. laetum & Flower & $0.42 \pm 0.07$ & $0.94 \pm 0.08$ \\
$P$. tenuifolium & Leaf & $0.02 \pm 0.003$ & $0.04 \pm 0.01$ \\
$P$. crassifolius & Leaf & $0.17 \pm 0.008$ & $0.14 \pm 0.007$ \\
$P$. colorata & Leaf & $0.22 \pm 0.02$ & $0.15 \pm 0.03$ \\
RIF & Leaf & $1.27 \pm 2.25$ & $0.12 \pm 0.03$ \\
EpoA & - & $10^{-7}$ & $2.91 \times 10^{-6} \pm 1.11 \times$ \\
& - & $5.32 \times 10^{-6} \pm 8.13 \times$ & $10^{-6}$ \\
\hline
\end{tabular}

Table 4.2.3. Cytotoxicity of active extracts against $\mathbf{J 7 7 4}$ and HL-60 cell-lines.

The extracts were evaporated and resuspended in SDW to eliminate any bias 
effect due to the $\mathrm{EtOH}$ or $\mathrm{MeOH}$ solvents. All values are in $\mathrm{mg} / \mathrm{ml}$. ' \pm ' denotes standard error between triplicate results.

\subsection{Discussion}

\subsubsection{Screening of active samples against clinically-relevant species}

Of the seven plant species found to be active against $M$. smegmatis, only six had antimycobacterial activity against the slow-growing species $M$. bovis and $M$. tuberculosis. The bark and cambium of $L$. novae-zelandiae were particularly active against the mycobacterium species and are discussed further in Sub-section 4.3.1.1. The flower of M. excelsa and leaf of $P$. tenuifolium had considerable activity against $M$. bovis and $M$. tuberculosis. In Rongoa Māori, M. excelsa was used for the treatment of sore throats and the leaf of $P$. tenuifolium was used to treat skin infections $[97,121]$. Therefore, the antimycobacterial activities that were detected for M. excelsa and $P$. tenuifolium extracts of $M$. excelsa could relate to their traditional use. The flower of $M$. excelsa and leaf of $P$. tenuifolium also exhibited some substantial bactericidal activity and low cytotoxicity, lending further emphasis that these are extracts to focus on as sources of novel antitubercular compounds. The leaf of $M$. excelsa appeared to have lost activity when tested against $M$. bovis and $M$. tuberculosis, or in the case of the $M$. laetum extract had no activity at all. It could be that the extracts had activity specific to $M$. smegmatis. However, as the extracts did not have activity towards the slow-growing species they may not be considered worthy samples for further analysis for potential lead compounds.

Only the leaf of $P$. colorata and $M$. excelsa displayed activity against $S$. aureus. Interestingly, none of the plant species tested exhibited 
antibacterial activity towards $E$. coli. This suggested that the activity of the seven plant species might be specific to mycobacteria. Based on phylogeny with $16 \mathrm{~S}$ ribosomal RNA, M. tuberculosis has similarities with gram-positive bacteria. This would correlate with the antibacterial activity against $S$. aureus that was observed with some of the extracts. However, Fu et al (2002) demonstrated that M. tuberculosis also has similarities with gram-negative bacteria like E. coli [149]. The extracts antimycobacterial activity could therefore be due to other features such as specific virulence factors or pathways.

It should be mentioned that the $\mathrm{MIC}$ and $\mathrm{IC}_{50}$ values of the extracts against the different mycobacteria species (Table 4.2.1) were subject to variation due to differences in growth media used as well as assay incubation time. The activity of the extracts could also vary between mycobacterial species, with higher $\mathrm{MIC}$ and $\mathrm{IC}_{50}$ values towards $M$. bovis and $M$. tuberculosis due to slower metabolism. The compounds in the extract could have degraded over time before being able to fully act upon the mycobacterium's growth. If this was the case then the extracts with higher MICs may not be suitable sources for new anti-TB compounds.

It should also be noted that the MIC and $\mathrm{IC}_{50}$ of a crude extract is not a reliable indicator of activity. Aliquots of the same extract may have different concentrations of the antimycobacterial compound, or the extract may not have a highly active compound. For example, activity could be due to high concentrations of several moderately active antimycobacterial components rather than an individual component [150]. Further purification 
techniques would have to be performed in order to clarify if the activity is due to a single agent or multiple compounds working in synergy.

\subsubsection{Antimycobacterial activity of Laurelia novae-zelandiae}

Bark and cambium extracts from Laurelia novae-zelandiae (Pukatea)

(Figure 4.3.1.1) were the most active against $M$. smegmatis (Table 4.2.1). Furthermore, the bark and cambium extracts also displayed antimycobacterial activity against $M$. bovis and $M$. tuberculosis, exhibiting dose-response inhibition (Figure 4.2.1). The bark of $L$. novae-zelandiae was also the least toxic to HL-60 cells and non-toxic as well towards J774 cells. The activity of Pukatea was of particular interest as the bark was medicinally used in Rongoa Māori to treat tubercular lesions [121]. The pulp of the cambium was boiled in water and the resulting liquid used for treating tubercular ulcers [97]. The antimycobacterial activity of the extract therefore correlated with the use of Pukatea to treat tubercular lesions in Rongoa Māori. The L. novae-zelandiae extract also displayed significant bactericidal activity against $M$. smegmatis, reinforcing the possibility that the bark of Pukatea contains previously unknown anti-tubercular compounds.

Figure 4.3.1.1. Laurelia novae-zelandiae (Pukatea) from Otari-Wilton Bush Reserve. Pukatea is generally found in lowland forests areas [151]. It can grow up to 35 metres and possesses plank buttresses to support the tree's growth in swamp areas [151]. A) Image of Pukatea with two main branches separating from the base of the tree. B) Plank buttress, a typical feature of Pukatea.

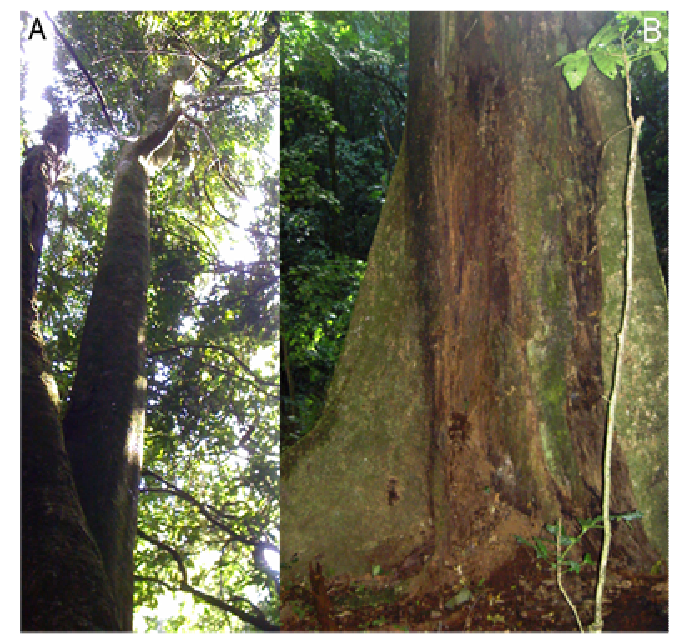




\subsubsection{Potential bioactive compounds present}

Although the chemical basis for the anti-tubercular activity of the active extracts needs to be elucidated, earlier chemical studies have identified some compounds, as shown in Figure 4.3.2.

1.<smiles>CN1CCc2cc3c(c4c2[C@@H]1Cc1cccc(O)c1-4)OCO3</smiles>

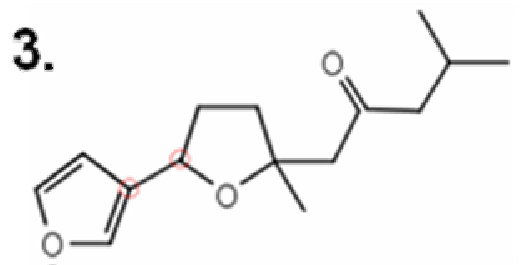

2.<smiles>CC1(C)OC(c2ccccc2)=CC1=O</smiles><smiles>CC1(C)CCCC2(C)C(C=O)C(C=O)=CCC12</smiles>

Figure 4.3.2. Identified compounds in some native plants. Some compounds have already been identified in four of the plants that have exhibited antimycobacterial activity. 1. = Pukateine, 2. = Bullatenone, 3. = Ngaione, 4. = Polygodial. Pukateine reproduced from Dajas-Bailador F.A. et al (1999). Bullatenone, Ngaione and Polygodial adapted and reproduced from Woollard, J.M.R et al (2008), Sugimura T. et al (1993) and Taniguchi M et al (1988). Images created using SktechEl open source software downloable at [http://sourceforge.net/projects/sketchel].

The compounds pukateine, bullatenone and ngaione have so far been isolated from NZ plants. Pukateine is a novel alkaloid isolated from the bark of Pukatea [152]. Pukateine is an analgesic similar to morphine, 
which binds to the $D_{2}$ dopamine receptor and acts as a dopaminergic agonist [153]. It also acts as an antagonist to the a1 adrenergic receptor $[153,154]$. Bullatenone was isolated from L. bullata (Ramarama) [155] and is an antiseptic [98]. Chemical derivatives of bullatenone have been determined to have antibacterial properties against Bacillus subtilis [156]. The hepatotoxic sesquiterpene ngaione was found in the leaves of $M$. laetum (Ngaio) [157] and has been used in the treatment of athletes foot [98]. The leaves of $P$. colorata (Horopito) contain the compound polygodial [158], a drimane sesquiterpene that has been shown to be active against Candida albicans [103]. An interesting note is the fern $B$. fluviatile is also known to contain the compound polygodial [127] and yet it did not display any activity. The difference in activity between samples could be due to varying levels of polygodial present in each tissue. Finally, the flower of $M$. excelsa was determined to contain ellagic acid, which is a polyphenol antioxidant [98]. It is possible that compounds such as pukateine, bullatenone, ngaione, polygodial or ellagic acid may contribute to the antibacterial activity of their plant extracts. These compounds offer a starting point for future studies to characterise the chemical basis of the antimycobacterial activity of $L$. novae-zelandiae, M. excelsa, L. bullata and P. colorata. 


\section{CHAPTER FIVE: \\ Efficiency and delivery \\ of Plant Extract activity}




\subsection{Introduction}

In the previous chapter, eight extracts were validated with antimycobacterial activity against $M$. tuberculosis. In this chapter the efficiency of extraction was investigated to determine if the activity of the extracts could be improved through various purification methods. Possible practical applications of some of the active extracts were also explored.

Size exclusion fractionation is the separation of compounds based on size. This is generally done by chromatography $[159,160]$ but the protocol has been modified for this research. The fractionation in this research involved centrifuging the extracts through filters of varying sizes. It was hypothesized that the activity of extracts could be improved by removing unwanted compounds. It could also provide information as to the general size of the compound(s) exhibiting antibacterial activity in the extracts.

Solvent Phase Separation (SPS) is a form of liquid-liquid partitioning. This was a procedure used to separate two immiscible liquids in order to extract a substance or compound from one phase to another [161]. Therefore, SPS can be used to 'purify' a sample by removing unwanted compounds [161]. This type of extraction generally involved water and an organic solvent, in this case, Ethyl Acetate (EtOAc). EtOAc was chosen as a solvent for SPS as it is cheap, available and is commonly used in extractions [162]. Chloroform $\left(\mathrm{CHCl}_{3}\right)$ was also used as a phase for SPS as it has also been previously used for liquid-liquid extraction with plant samples [163]. Combinations of different fractionation techniques were also applied. 
This chapter also involved an initial study involving the utilization of the active extracts in a practical application. The active extracts from L. novaezelandiae, M. excelsa and $P$. colorata were added to an aqueous cream and tested against M. smegmatis and S. aureus. Based on these initial results the active extracts could potentially be used, for example, for the treatment of skin infections in the form of a cream-based solution. 


\subsection{Results}

The nine active extracts were subjected to numerous purification techniques. This included techniques such as size exclusion fractionation and solvent phase separation. The leaf of $L$. bullata, $M$. laetum, $P$. tenuifolium and $P$. crassifolius lost antimycobacterial activity upon application of these purification techniques and so were not included in the results. Thus, the following section will focus on the bark and cambium extracts of $L$. novae-zelandiae, the leaf and flower of $M$. excelsa and the leaf of $P$. colorata.

\subsubsection{Activity of aqueous extracts tested against $M$. smegmatis}

Due to the slight toxicity of some solvents used for extraction, it was investigated if the crude extracts could retain activity when the solvent was evaporated and the sample resuspended in SDW. The rationale was that water extracts were easier to purify, as the filters used would be destroyed by the $\mathrm{EtOH}$ or $\mathrm{MeOH}$. Table 5.2.1 gives the activity of the extracts when resuspended in SDW. The bark of $L$. novae-zelandiae was already an AQ extract and so retained antimycobacterial activity. The remaining extracts appeared to have lost activity, with a high $\mathrm{MIC}$ and $\mathrm{IC}_{50}$ when tested against $M$. smegmatis. However, it must be taken into consideration that these values are a measure of potency rather than actual concentration of an active compound, which most likely varies between extracts. 


\begin{tabular}{|c|c|c|c|c|c|}
\hline \multirow[t]{2}{*}{ Plant } & \multirow[t]{2}{*}{ Part } & \multicolumn{2}{|r|}{ Crude } & \multicolumn{2}{|c|}{ In $A Q$} \\
\hline & & MIC & $\mathrm{IC}_{50}$ & MIC & $\mathrm{IC}_{50}$ \\
\hline \multirow[t]{2}{*}{$\begin{array}{l}\text { L. novae- } \\
\text { zelandiae }\end{array}$} & Bark & 0.04 & $0.02 \pm 0.004$ & 0.04 & $\begin{array}{c}0.0006 \pm \\
0.004\end{array}$ \\
\hline & Cambium & 0.50 & $0.25 \pm 0.01$ & 2.5 & $1.52 \pm 0.18$ \\
\hline \multirow[t]{2}{*}{ M. excelsa } & Leaf & 0.63 & $0.11 \pm 0.06$ & 10 & $0.33 \pm 0.07$ \\
\hline & Flower & 0.63 & $0.41 \pm 0.06$ & 5 & $0.06 \pm 0.02$ \\
\hline P. colorata & Leaf & 1.25 & $0.74 \pm 0.40$ & 10 & $2.14 \pm 1.49$ \\
\hline
\end{tabular}

Table 5.2.1. Comparison of MIC and IC $\mathrm{C}_{50}$ values of crude and aqueous plant extracts with respect to $\boldsymbol{M}$. smegmatis. Extracts were evaporated and resuspended in SDW and examined to determine if activity was retained in an aqueous solution. All values are in $\mathrm{mg} / \mathrm{ml}$ and based on GFP results. ' \pm ' denotes standard error between triplicate results. 


\subsubsection{Size exclusion fractionation of active extracts}

Fractionation of active samples was performed via size exclusion. The extracts were evaporated and resuspended in SDW before passed through a $30 \mathrm{kDa}$ filter followed by a $3 \mathrm{kDa}$ filter. The filtrate and retentate for each size were retained. The resulting samples were then evaporated and resuspended in SDW before analysis of antimycobacterial activity against $M$. smegmatis in a bacteriostatic assay. The levels of antimycobacterial activity shown in Figure 5.2.2 indicates that the bark from L. novae-zelandiae, flower from M. excelsa and leaf from $P$. colorata most likely have bioactive components that are smaller than $3 \mathrm{kDa}$. The cambium of $L$. novae-zelandiae and leaf of $M$. excelsa appear to have compounds exhibiting antimycobacterial activity that is smaller than 30 $\mathrm{kDa}$ but larger than $3 \mathrm{kDa}$. An interesting note is that the bark of $L$. novaezelandiae had constant antimycobacterial activity across all fraction sizes. However, size exclusion work is subject to significant variation, especially when working with crude samples where the concentration of the active component(s) is unknown. 


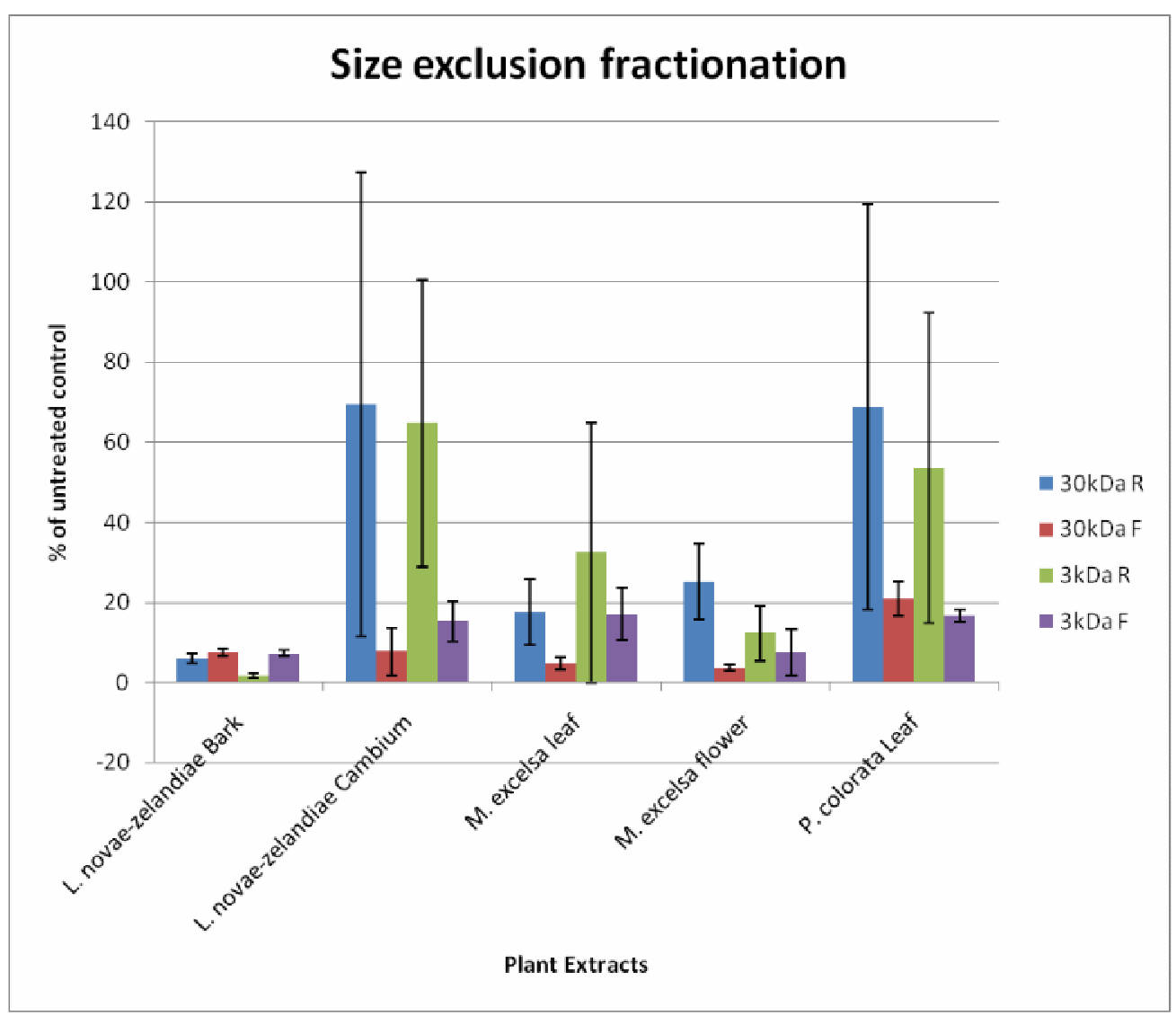

Figure 5.2.2. Comparison of different size fractions of active plant extracts.

Extracts were resuspended in SDW before fractionation by size exclusion and tested against $M$. smegmatis in a bacteriostatic assay. All extracts were tested at a concentration of $1 \mathrm{mg} / \mathrm{ml}$. These values are based on the GFP results. $100 \%$ represents no inhibition of $M$. smegmatis growth compared to the untreated control. Error bars denote standard deviation between triplicate values. 


\subsubsection{Solvent Phase Separation of active extracts}

Two different liquids, EtOAc and $\mathrm{CHCl}_{3}$, were used for SPS for the active extracts in order to purify the samples by liquid extraction of unwanted compounds.

\subsubsection{SPS of active extracts with Ethyl Acetate}

Liquid-liquid partitioning with the active samples was performed via SPS with EtOAc. The extracts were evaporated and resuspended in SDW before being purified via liquid partitioning with EtOAc. After solvent phase separation (SPS) the AQ (extract) layer was removed, evaporated and resuspended in SDW again before examination against $M$. smegmatis in a bacteriostatic assay. The crude extracts were also subjected to SPS with EtOAc (i.e. no resuspension in SDW) as a comparison to the original activity of the extracts in its crude form. There was significant bacteriostatic inhibition of mycobacteria growth for the L. novae-zelandiae extracts; however, the bark of $L$. novae-zelandiae had better antimycobacterial activity as a crude sample. It should be noted that the EtOAc layer was also tested when solvent phase separated with the $A Q$ and crude layer and was found to have no antimycobacterial activity for either condition (results not shown). 


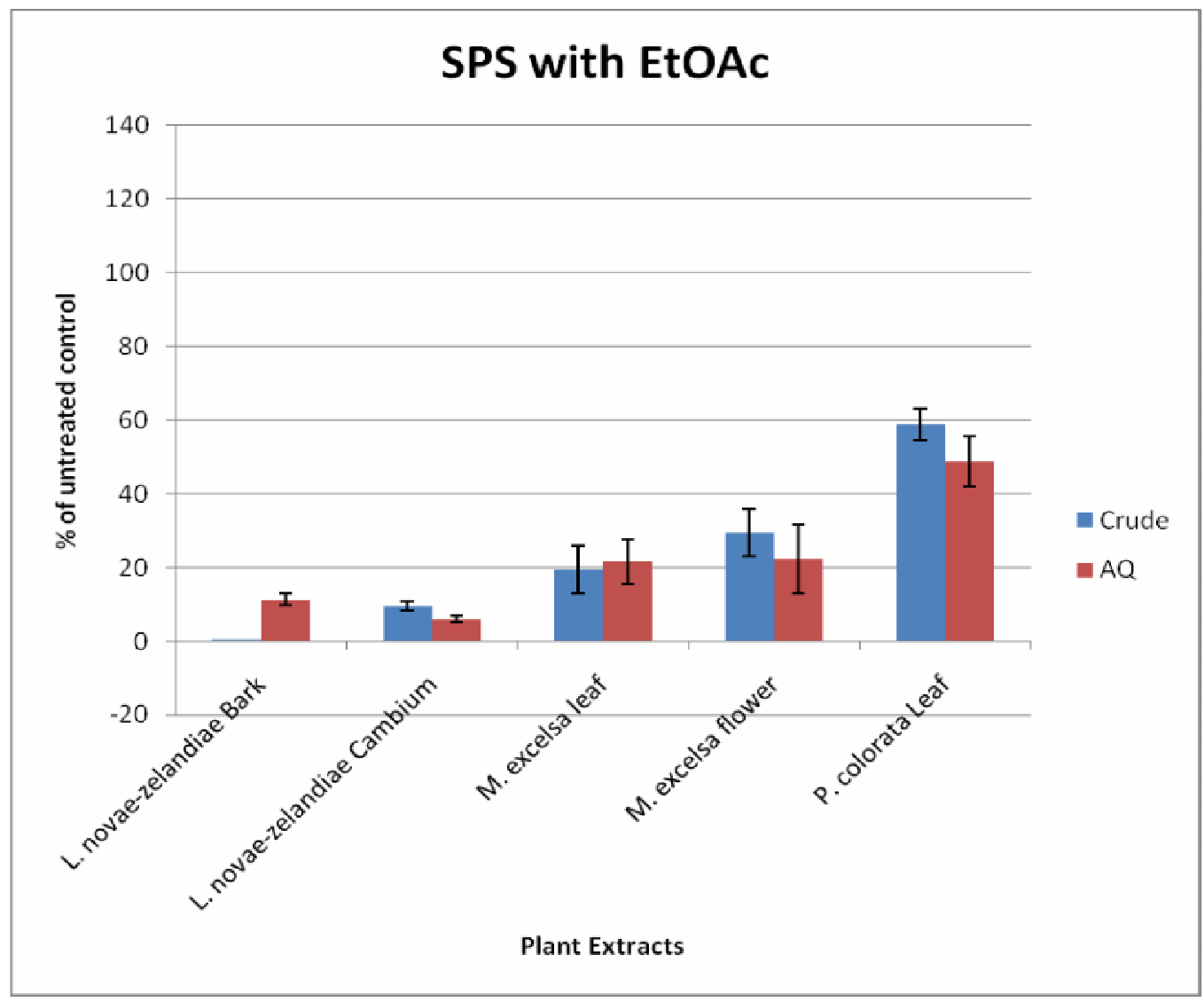

Figure 5.2.3.1. Comparison of crude and $A Q$ extracts activity when purified with EtOAc through SPS. Extracts were solvent phase separated from EtOAc and then tested against $M$. smegmatis. All extracts were tested at a concentration of 1 $\mathrm{mg} / \mathrm{ml}$. These values are based on the GFP results. $100 \%$ represents no inhibition of $M$. smegmatis growth compared to the untreated control. Error bars denote standard deviation between triplicate values. 


\subsubsection{SPS of active extracts with Chloroform}

The crude extracts were purified via SPS with $\mathrm{CHCl}_{3}$ to determine if activity of the extracts could be improved. After SPS, the extract layer was removed and evaporated before resuspension in SDW. The $\mathrm{CHCl}_{3}$ layer was also removed and evaporated before resuspension in DMSO, so as to dissolve any residual plant tissue in the $\mathrm{CHCl}_{3}$ layer. The results as displayed in Figure 5.2.3.2 indicate that the extracts from L. novae-zelandiae, M. excelsa and $P$. colorata had significant inhibitory activity. The $\mathrm{CHCl}_{3}$ layer also appeared to have antimycobacterial activity exhibited from some of the extracts. In fact, for the cambium extract from L. novae-zelandiae and leaf extract from $P$. colorata, the $\mathrm{CHCl}_{3}$ layer exhibited similar or better inhibition levels against $M$. smegmatis than the extract layer. 


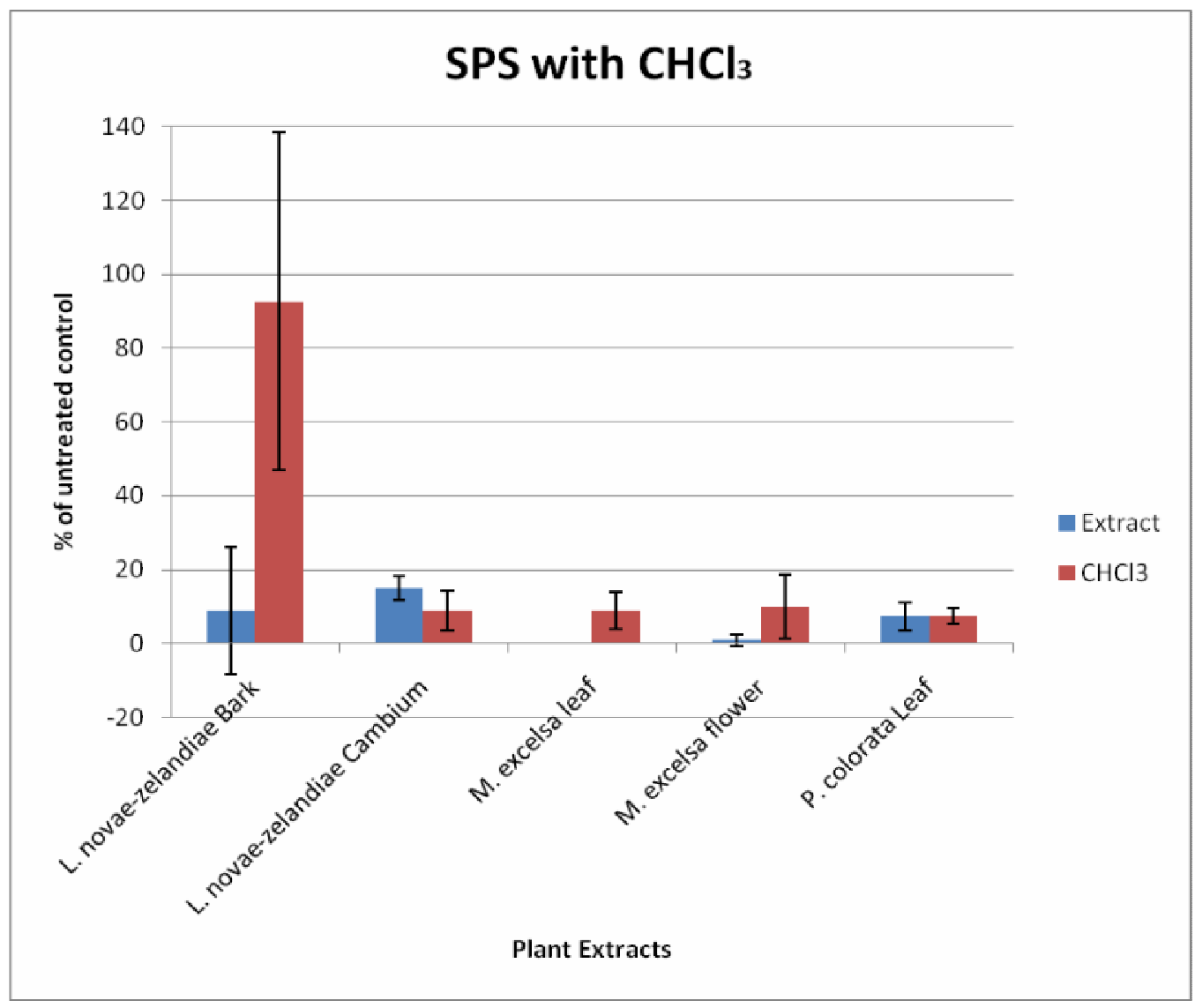

Figure 5.2.3.2. Comparison of SPS with Chloroform $\left(\mathrm{CHCl}_{3}\right)$ purified plant extracts. The extract layer and Chloroform layer were examined against $M$. smegmatis in a bacteriostatic assay. All extracts were tested at a concentration of 1 $\mathrm{mg} / \mathrm{ml}$. These values are based on the GFP results. $100 \%$ represents no inhibition of $M$. smegmatis growth compared to the untreated control. Error bars denote standard deviation between triplicate values. 


\subsubsection{Combination of Purification techniques}

A combination of previous techniques was applied in order to observe an improvement in activity. The extracts were evaporated and resuspended in SDW before purification via size exclusion with a $30 \mathrm{kDa}$ filter. The filtrate was then solvent phase separated with EtOAc. The aqueous layer was removed, evaporated and resuspended again in SDW before being screened against $M$. smegmatis in a bacteriostatic assay. In Figure 5.2.3.3 it can be observed that there was still significant activity exhibited in the bark extract from $L$. novae-zelandiae and the M. excelsa extracts. In comparison to the SPS with EtOAc, only the bark extract of $L$. novae-zelandiae and $M$. excelsa extracts had improved activity with the addition of $30 \mathrm{kDa}$ fractionation. It is important to note that this is only an indication of improved efficiency of extraction as there is bound to be variability among results with crude extracts. 


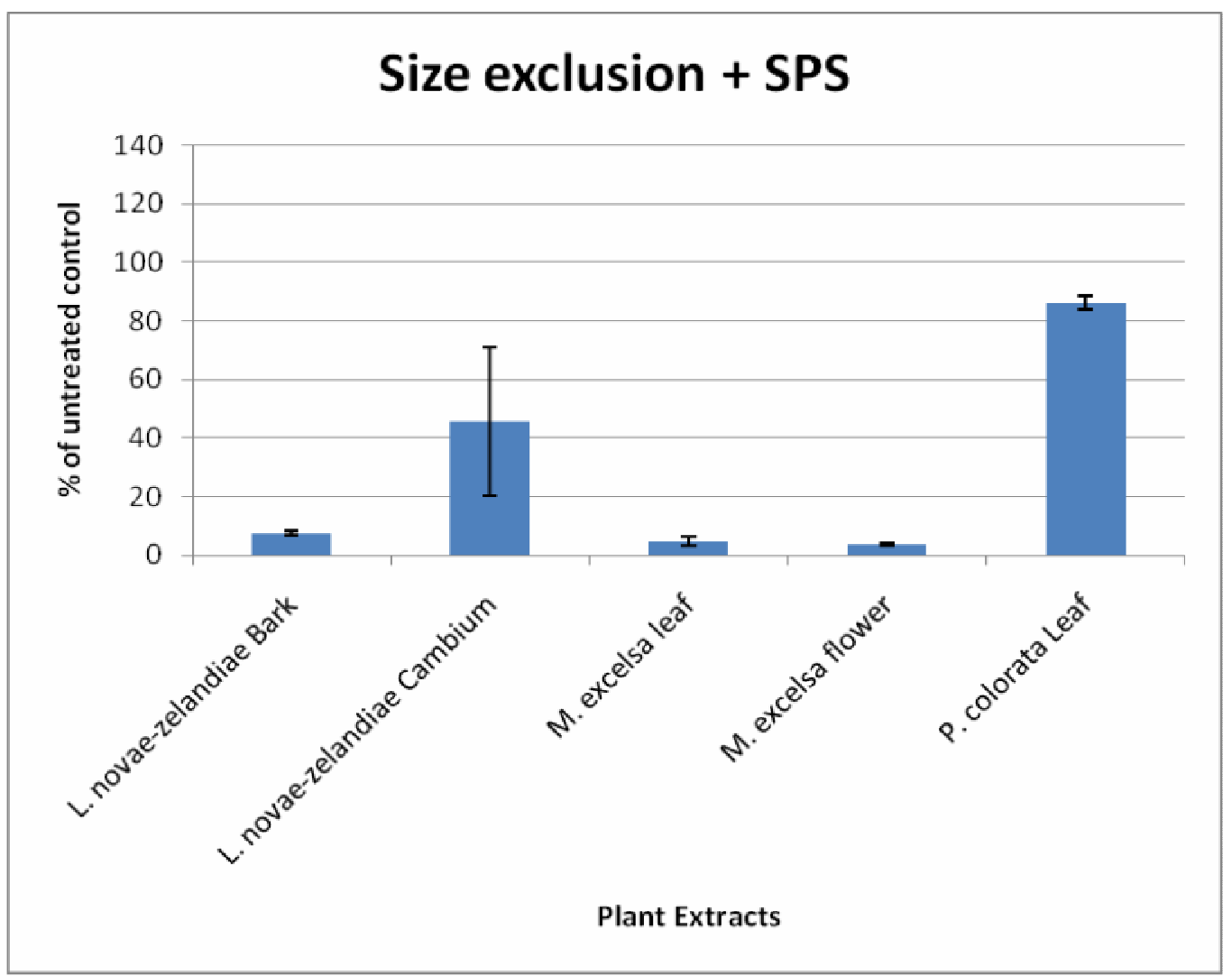

Figure 5.2.3.3. Bacteriostatic activity of purified plant extracts with respect to M. smegmatis. Extracts were subjected to $30 \mathrm{kDa}$ size exclusion fractionation and SPS with EtOAc. All extracts were tested at a concentration of $1 \mathrm{mg} / \mathrm{ml}$. Values are based on GFP results. $100 \%$ represents no inhibition of $M$. smegmatis growth compared to the untreated control. Error bars denote standard deviation between triplicate values. 


\subsubsection{Practical application of $L$. novae-zelandiae and other extracts}

Seven plants have been identified with antimycobacterial activity and part of this research has involved improving the efficiency of extraction in order to improve activity. Another aspect to consider is the use of this research. One notion was whether the active hits could be used in a practical application. For example, a moisturizing cream containing natural extracts that could have potential inhibitory effects against skin infections. In this study four of the active extracts were tested in an aqueous cream form against $M$. smegmatis and S. aureus. S. aureus is known to cause skin infections [144], which is why it was also included in the practical application. The bark and cambium of $L$. novae-zelandiae were tested as they were traditionally used for the treatment of tubercular ulcers on the skin. The leaf of $M$. excelsa and $P$. colorata were also tested as they were the only extracts tested to have activity against $S$. aureus. As shown below in Figure 5.2.4 and Table 5.2.4 it appears that the extracts (with the exception of the leaf extract of $M$. excelsa) lose activity in the aqeous cream form. 


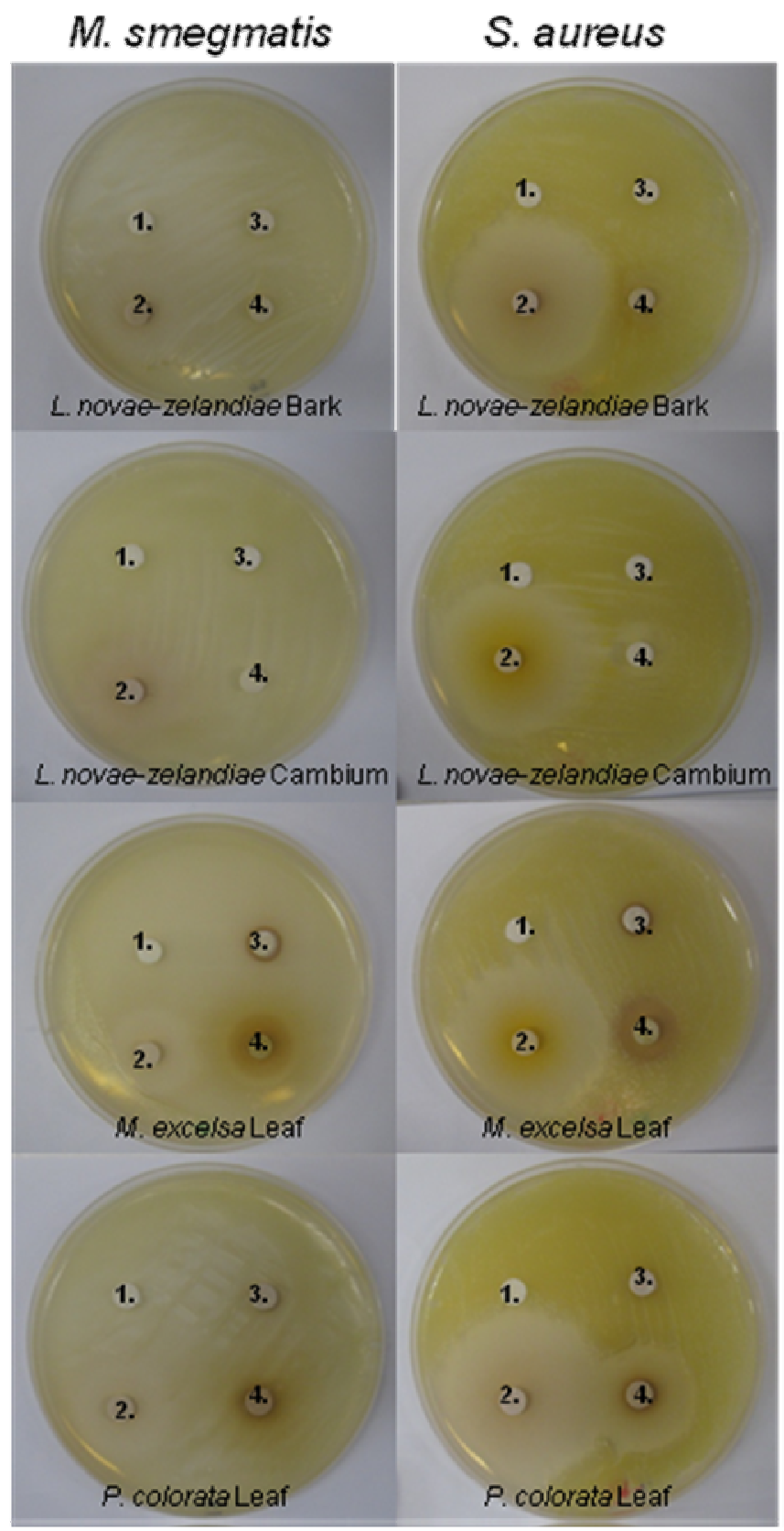

Figure 5.2.4. Disc Diffusion of active extracts in an aqueous cream against $M$. smegmatis and S. aureus. Extracts from L. novae-zelandiae, M. excelsa and $P$. colorata were tested in an aqueous cream form against $M$. smegmatis (Left column) and $S$. aureus (Right column). Layout is as follows; 1. = Negative control aqueous cream with no extract added, 2. = Positive control Rifampin $(1 \mathrm{mg} / \mathrm{ml}), 3$. = Extract added to an aqueous cream $(0.5 \% \mathrm{w} / \mathrm{v}), 4 .=$ Extract alone $(1 \mathrm{mg} / \mathrm{ml})$. 
Table 5.2.4 gives the zones of inhibition that were measured around the discs. The leaf of $M$. excelsa was the only extract to have activity against $M$. smegmatis in the aqueous cream form. None of the extracts had activity against $S$. aureus when added to the aqueous cream solution. All extracts displayed activity against $M$. smegmatis when the extract alone was tested, confirming their activity in liquid and solid conditions. However, all extracts also displayed activity against $S$. aureus, when only the $M$. excelsa and $P$. colorata extracts displayed antibacterial activity against $S$. aureus in the liquid assay.

\begin{tabular}{lccc} 
Plant Extract & Condition & \multicolumn{2}{c}{ Zone of inhibition (mm) } \\
& & M. smegmatis & S. aureus \\
\cline { 3 - 4 } & & & \\
L. novae-zelandiae & Bark + Cream & 0 & 0 \\
& Bark & 1 & 2 \\
& Cambium + Cream & 0 & 0 \\
M. excelsa & Cambium & 1 & 4 \\
& Leaf + Cream & 2 & 0 \\
$P$. colorata & Leaf & 5 & 4 \\
Aqueous Cream & Leaf + Cream & 0 & 0 \\
Rifampin & Leaf & 0 & 10 \\
& - & 0 & 0 \\
& - & 10 & 18
\end{tabular}

Table 5.2.4. Inhibitory activity of extracts in a cream-based solution. Active extracts from the plants $L$. novae-zelandiae, $M$. excelsa and $P$. colorata were applied to an aqueous cream and tested against $M$. smegmatis and $S$. aureus for any inhibitory activity in a cream-based solution. Listed are the zones of inhibition $(\mathrm{mm})$ surrounding the discs. 


\subsection{Discussion}

\subsubsection{Purification techniques}

The proposition was that the purification techniques used would improve the activity of the bioactive extracts. Due to the harsh properties of the polar solvents used for extraction, the crude extracts had to be resuspended in SDW before the purification techniques were performed. Size exclusion fractionation was employed so that the large compounds with no activity in an extract were removed, thus purifying and increasing the potency of the active compounds. This could be due to an increase in relative concentration of the active compound, or perhaps the reduction of unwanted molecules, allowing 'easier' access to the active compounds target. However, the $L$. novaezelandiae bark extract displayed similar activity across all fractions. A possible explanation was that the active constituent in the sample was a small compound (less than $3 \mathrm{kDa}$ ) that got 'trapped' with the larger, bulkier compounds in the filters. There was also the possibility of synergistic activity occurring, when more than one compound was working concurrently in the extract. If said compounds were of different size range then levels of activity would decrease. Overall, the use of size exclusion fractionation did not show a marked increase in antimycobacterial activity, but it did give an indication as to the general size of the bioactive compounds.

The purification techniques did improve the activity of the crude extracts when they were resuspended in SDW. The bark of L. novae-zelandiae was the only extract to display bactericidal activity with any of the purification techniques, notably size exclusion filtration combined with SPS of EtOAc. 
However, there was no significant improvement in activity compared to the crude extract (See Table 4.2.1).

Speculation suggests that the loss in antimycobacterial activity was due to the resuspension in SDW. Thus, the chemical environment was changed and therefore disrupted the nature of the bioactive components present in the extract, similar to that of Le Chatelier's Principle [164]. It proposes that if something is altered in the environment, there will be a reaction to make up for that change. $P$. colorata (Horopito) is already marketed for antibacterial purposes as a crude extract, demonstrating that perhaps in order to retain activity the plant extracts are best kept as close to the original state as possible.

The $\mathrm{CHCl}_{3}$ layer displayed antimycobacterial activity for seven of the active extracts. The $\mathrm{CHCl}_{3}$ layer could consequently provide some novel compounds that could be isolated for further chemical analysis, provided the compounds remain stable in a purified state.

Overall, it appears the purification techniques did not improve the extracts activity in its original solvent. The bark of $L$. novae-zelandiae and leaf of $M$. laetum were $A Q$ extracts that did not have improved activity, instead they had decreased activity upon purification. This suggests that the purification techniques were not suitable for $A Q$ extracts, possibly due to their inorganic nature. Future purification work would involve chemical analysis with more organic solvents. 


\subsubsection{Practical Application}

It was investigated as to whether the extracts from $L$. novae-zelandiae, $M$. excelsa, and $P$. colorata could be delivered in a feasible way. The advantage of this application was that the extracts could be used in a crude state, rather than having to work with an individual compound, as many skin cream products use natural extracts. It appeared that when the extracts were added to the aqueous cream, the extracts lost activity against both species tested, with the exception of the leaf of M. excelsa. This could possibly be due to the cream interfering with the plant extracts activity. However, it could also have been due to the low concentrations of extract in the aqueous cream, due to limitation of sample quantity available. What was interesting, however, was the inhibition exhibited by both $L$. novae-zelandiae against $S$. aureus, when none was previously exhibited in the liquid bacteriostatic assay. It could be speculated that the $L$. novae-zelandiae extracts had activity against $S$. aureus when the bacteria were grown on solid media than when in culture, suggesting a possible different mode of inhibition occurring of the extracts activity against $S$. aureus.

M. excelsa leaf extract displayed activity against $M$. smegmatis in an aqueous cream based solution as well as when tested with extract alone. This was interesting as the extract was resuspended in SDW and has been previously shown to have a drastic reduction in activity when in the extract is in an $A Q$ solution. It could be speculated that the activity of the $M$. excelsa leaf was better in a more solid-based condition. In addition, the bark of $L$. novae-zelandiae was considered a more likely candidate for activity against M. smegmatis in the cream form, yet it did not display antimycobacterial 
activity when added to the aqueous cream. However, its activity may be dependent on a liquid-based solution. Overall, other factors have to be included in order to create a cream-based product with marketable activity. There is the possibility of combinating the active extracts, ( $L$. novaezelandiae, $M$. excelsa and $P$. colorata) together in an aqueous cream. It could be feasible to apply these active extracts in a practical delivery system for antibacterial treatment. 


\section{CHAPTER SIX: \\ Summary and Future Directions}




\subsection{Summary of Research}

There is now more emphasis on analysing natural products as sources of novel drugs. The objective of this research was to test native NZ plants for antimycobacterial activity. This involved building a library of native NZ plants, developing a protocol for extracting the potential antitubercular compounds and then testing them against mycobacterial species. A library of 58 native NZ samples from 46 plant species was compiled from various locations and solvent extraction performed to give a total of 174 extracts. Drawing on knowledge from Rongoa Māori, nine extracts from seven native plant species demonstrated activity against $M$. smegmatis in the initial screen. Further validation led to the identification of eight extracts from $L$. novae-zelandiae, $L$. bullata, $M$. excelsa, $P$. tenuifolium, $P$. crassifolius and $P$. colorata that had activity against the clinically relevant slow-growing species $M$. bovis and M. tuberculosis H37Ra, suggesting the presence of potential antitubercular compounds. Extracts were also tested against S. aureus and E. coli for potential antibacterial activity and it was found that the activity suggested specificity to the mycobacteria. In addition, the extracts were non-toxic to murine macrophages and human cell-lines compared to the current TB drug RIF, thus indicating these extracts are worthy candidates for further research.

This study also involved improving the efficiency of extraction as well as investigating a potential delivery system of the active extracts. The efficiency of compound extraction from the plant's tissue was somewhat improved with the various purification techniques used. It was intended that the bioactive compounds have improved antimycobacterial activity 
upon purification, but it was found that this was generally not the case. In terms of a practical application such as a skin cream, this was a feasible proposal, as many natural remedies include natural products that are effective in their delivery and efficacy. The results showed that the extract lost activity instead when applied in an aqueous cream; however, other delivery systems of the bioactive extracts could still be explored. For example, the extracts could be taken as an herbal supplement in pill form.

There is an increased interest in identifying the compounds responsible for the anti-mycobacterial activity of plants and developing them as potential new TB drugs. With a high endemic rate of diverse NZ flora this research provides a starting point for discovering unique bioactive extracts that could lead to novel antitubercular drugs, using traditional Māori medicine as a basis for selection.

The flower of $M$. excelsa and leaf of $P$. tenuifolium exhibited substantial bacteriostatic and bactericidal activity against mycobacteria, which could relate to their traditional use in Rongoa Māori. The bark of $L$. novaezelandiae (Pukatea) was used in traditional medicine for the treatment of TB, correlating with the extracts antimycobacterial activity. For that reason the use of ethnomedicine (Rongoa Māori) was an effective method of sample selection. Furthermore, both the bark and cambium extracts of Pukatea had significant bactericidal activity against mycobacteria, signifying that Pukatea contains potential novel antitubercular compounds. Compounds such as pukateine from L. novae-zelandiae, ellagic acid from M. excelsa and bullatenone from $L$. bullata could provide insight into the type of activity in their plant extracts. Therefore, the bark of $L$. novae- 
zelandiae, leaf and flower of $M$. excelsa and leaf of $L$. bullata are excellent candidates for future chemical analysis for the development of novel drugs to help combat TB.

\subsection{Critique of the Research}

Although many drugs today are derived from plants there are limitations to researching natural extracts as a source of lead compounds. It is expensive in time and funding to extract, screen and separate compounds with potent antimycobacterial activity that merit further analysis. Often there is low yield of the desired compound from the extract, or it is not stable in a purified state. The fractionation process was based on the notion that the active compound in the purified extract was simple and stable, retained activity and did not have synergistic activity with other compounds in the extract $[49,150]$. There was also the possibility that the compound was not as active in vivo compared to activity in vitro. With these potential setbacks the potential lead compounds are then less likely to make it to clinical drug trials. For this reason there are still many plants with potential activity that have yet to be properly assessed as sources of lead compounds.

However, it can be speculated that plants that have been used in traditional medicine are more likely to contain potential lead compounds as they have medicinal properties and are likely to be non-toxic to the patient. Furthermore, in traditional medicine crude extracts are used and therefore the bioactive compound must be reasonably effective if the patient receives a low dosage. 
Another issue is that even if the bioactive compound is simple and retains activity in an isolated form, it may not be novel and could already have been marketed [49]. Although some compounds have already been identified to be present in other plants (e.g. polygodial in Horopito), it is thought that NZ plants are still likely to contain novel compounds due to the diverse flora and its isolation from other countries. Some compounds already identified have been found to be unique to NZ plants, e.g. Pukateine in Pukatea, Bullatenone in Ramarama and Ngaione in Ngaio. So there is a significant possibility that compounds pertaining to the NZ bioactive extracts activity are not novel.

\subsection{Future Directions}

There is a growing interest in identifying the compounds responsible for the antimycobacterial activity of extracts used in traditional medicines and developing them as potential new TB drugs. Future studies should therefore focus on isolating the bioactive compounds in extracts with validated antimycobacterial activity, such as Pukatea. This can be done by means of Mass Spectrometry (MS), High-Pressure-LiquidChromatography (HPLC) and Nuclear Magnetic Resonance (NMR). HPLC is a rapid and concise technique, providing accurate results with high specificity and good resolution [165, 166]. Bioassay-guided fractionation could be applied in order to ascertain the active constituents in a crude extract [150]. Mass spectrometry would be applied for broad identification of chemical composition of compounds present, whereas NMR would be employed in order to elucidate the structure of novel compounds with 
activity. NMR is an effective method as it can quickly identify unique structures with few resources needed for analysis [49]. These active compounds would then be tested against $M$. tuberculosis H37Ra in vitro to ensure bacteriostatic and bactericidal activity is retained. The compounds would also be analysed in vivo against the virulent strain such as $M$. tuberculosis $\mathrm{H} 37 \mathrm{Rv}$ to confirm antimycobacterial activity in an infected host.

Once the compounds of interest have been determined future studies would involve synthesizing derivatives of the compound with the purpose of improving efficacy or decreasing cytotoxicity. It would be desirable to isolate an active compound that has a simple structure, thus allowing basic derivatives to be manufactured. It would also be beneficial to have a novel mechanism of action (MOA) so as to decrease the possibility of cross-resistance with current TB drugs [167].

As the activity of the extracts in the application of a skin cream was ineffective, other delivery systems could still be investigated. The bioactive extracts could be applied in the form of an aerosol spray, or the extracts could be ingested as an herbal supplement. This is a successful application for Kolorex ${ }^{\circledR}$ (New Zealand), which markets kolorXtract ${ }^{\mathrm{TM}}$, herbal capsules and teas containing extracts of $P$. colorata which are used to help maintain intestinal microflora [168]. Nutraceuticals are becoming a promising area of research, introducing herbal supplements to the drug market rather than individual compounds [169]. Therefore, NZ plant extracts could be investigated as a source of adjuvants for TB drugs. A medical dictionary describes an adjuvant as an agent that increases the 
efficacy of an already existing drug without increasing its cytotoxicity. The drug Dzherelo ${ }^{\mathrm{TM}}$ (Immunoxel) is an herbal adjuvant for TB and is derived from a combination of aqueous-alcohol plant extracts including Aloe, Yarrow, Nettle, Dandelion, Marigold, Wormwood, and Juniper fruit [170, 171]. Dzherelo ${ }^{\mathrm{TM}}$ is a phytoconcentrate of plant extracts and has shown to increase the efficacy of TB drugs in recent clinical trials [170]. The trials also indicated that the herbal adjuvant decreased cytotoxic damage caused by current TB drugs as well as decreased treatment time. This clinical drug trial also included individuals infected with MDR-TB as well as individuals co-infected with HIV [170-173]. Thus, the addition of Dzherelo $^{\mathrm{TM}}$ produced an overall enhanced $\mathrm{TB}$ therapy by reducing treatment time and treating drug-resistant cases. Therefore, the bioactive extracts could be tested in combination with current TB drugs and establish if there is improved efficacy and/or decreased toxicity.

Future experiments could also involve bacteriostatic assays against other clinically important organisms such as Streptococcus pneummoniae and Pseudomonas aeruginosa. As Rongoa Māori was an effective form of plant selection it could be used as a starting point for studying the bioactivity of native plants against other bacteria. With many unique plants that were used in Rongoa Māori the potential medicinal value of NZ flora warrants further investigation. 
In conclusion, with the use of Rongoa Māori this study identified seven native plant species with antimycobacterial activity, two of which contained antibacterial properties. In particular, the antimycobacterial activity of the bark extract of Pukatea justified its traditional use in Māori medicine. Overall, the native bioactive extracts in this research could be of an interest in drug discovery and offer an excellent source of potential novel anti-tubercular compounds. 


\section{REFERENCES}

1. WHO: Tuberculosis fact sheet No. 104. Fact sheets on tuberculosis: World Health

Organization;

(2010). [http://www.who.int/mediacentre/factsheets/fs104/en/index.html]

2. Manchester K: Tuberculosis and Leprosy in Antiquity: An Interpretation. Medical History (1984), 28:162-173.

3. Morse D: Prehistoric tuberculosis in America. The American Review of Respiratory Disease (1961), 83:489-504.

4. Black JB: Microbiology: Principles and Explorations, 5th edn: John Wiley \& Sons; (2002).

5. Hershkovitz I, Donoghue HD, Minnikin DE, Besra GS, Lee OY-C, Gernaey AM, Galili E, Eshed V, Greenblatt CL, Lemma E, Bar-Gal GK, Spigelman M: Detection and Molecular Characterization of 9000-Year-Old Mycobacterium tuberculosis from a Neolithic Settlement in the Eastern Mediterranean. Public Library of Science ONE (2008), 3.

6. Pounds NJG: An Economic History of Medieval Europe. London: Longman; (1974).

7. Cockburn A: The Evolution and Eradication of Infectious Diseases. Baltimore: Johns Hopkins Press; (1963).

8. Kaufmann SHE: A short history of Robert Koch's fight against tuberculosis: Those who do not remember the past are condemned to repeat it. Tuberculosis (2003), 83(1-3):86-90.

9. Mitchell R, Kumar V, Fausto N, Abbas A: Pocket companion to Robbins and Cotran pathologic basis of disease, 6th edn. Philadelphia: Saunders Company; (1999).

10. Ulrichs T, Kaufmann SHE: Mycobacterial persistence and Immunity. Frontiers in Bioscience (2002), 7:458-469.

11. Golden MP, Vikram HR: Extrapulmonary Tuberculosis: An Overview. American Family Physician (2005), 72(9).

12. CDC: Morbidity and Mortality Weekly Report (MMWR). Atlanta; Centers for Disease Control and Prevention (1999).

13. WHO: 10 facts about tuberculosis. Fact sheets on tuberculosis: World Health Organization; (2010). [http://www.who.int/features/factfiles/tb_facts/en/index.html]

14. WHO: 2009 Update Tuberculosis Facts. Fact sheets on tuberculosis: World Health Organization; (2010). [http://www.who.int/tb/publications/2009/factsheet_tb_2009update_dec09.p df]

15. WHO: Tuberculosis: MDR-TB \& XDR-TB 2010 report fact sheet. Geneva; World Health Organization (2010). [http://www.who.int/tb/features_archive/world_tb_day_2010/mdrfactsheet15 mar10_19h00.pdf]

16. Grange JM: The global burden of tuberculosis. In: Tuberculosis: An Interdisciplinary Approach. Singapore Imperial College Press; (1999): 677687.

17. WHO: World Health Organization Report 2009, Global tuberculosis control: epidemiology, strategy, financing. Geneva; World Health Organization (2009).

[http://www.who.int/tb/publications/global_report/2009/pdf/full_report.pdf]

18. WHO: TB/HIV fact sheet 2009; World Health Organization (2009). [http://www.who.int/tb/challenges/hiv/factsheet_hivtb_2009update.pdf] 
19. WHO: WHO declares tuberculosis a global emergency. Social and Preventive Medicine (1993), 38(4):251-252.

20. Lim E, Tisch C, Williman J, Heffernan H: Tuberculosis in New Zealand: Annual Report 2008.; Environmental Science and Research Limited (2009).

21. Das D, Baker M, Venugopal K, McAllister S: Why the tuberculosis incidence rate is not falling in New Zealand. The New Zealand medical journal (2006), 119(1243):1-11.

22. Malley G: Evolution of chemotherapy in Tuberculosis. American Medical Association Archives of Internal Medicine (1954), 93:967-976.

23. Waksman SA: Streptomycin: Background, Isolation, Properties, and Utilization. Science (1953), 118(3062):259-266.

24. Honore N, Cole ST: Streptomycin resistance in mycobacteria. Antimicrobial Agents and Chemotherapy (1994), 38:238-242.

25. Bonah C: The 'experimental stable' of the BCG vaccine: safety, efficacy, proof, and standards, 1921-1933. Studies in History and Philosophy of Science Part C: Studies in History and Philosophy of Biological and Biomedical Sciences (2005), 36(4):696-721.

26. Calmette A, Guerin C, Weill-Halle B: Essais d'immunisation contre l'infection tuberculeuse. Revue de la Tuberculose (1924), 5:481-491.

27. Thompson D: Mass Immunization in the Control of Infectious Disease. British Medical Journal (1966), August(427-433).

28. Global Alliance for TB drug development: Rifampin. Tuberculosis (Edinburgh, Scotland) (2008), 88(2):151-154.

29. Global Alliance for TB drug development: Isoniazid. Tuberculosis (Edinburgh, Scotland) (2008), 88(2):112-116.

30. Global Alliance for TB drug development: Pyrazinamide. Tuberculosis (Edinburgh, Scotland) (2008), 88(2):141-144.

31. Gomez JE, McKinney JD: M. tuberculosis persistence, latency, and drug tolerance. Tuberculosis (2004), 84(1-2):29-44.

32. WHO: Guidelines for Drug Susceptibility testing for Second-Line AntiTuberculosis Drugs for DOTS-Plus. Geneva; World Health Organization (2001).

33. Global Alliance for TB drug development: Capreomycin. Tuberculosis (Edinburgh, Scotland) (2008), 88(2):89-91.

34. Global Allliance for TB drug development: Cycloserine. Tuberculosis (Edinburgh, Scotland) (2008), 88(2):100-101.

35. Global Allliance for TB drug development: Ethambutol. Tuberculosis (Edinburgh, Scotland) (2008), 88(2):102-105.

36. Global Alliance for TB drug development: Kanamycin. Tuberculosis (Edinburgh, Scotland) (2008), 88(2):117-118.

37. Global Alliance for TB drug development: Streptomycin. Tuberculosis (Edinburgh, Scotland) (2008), 88(2):162-163.

38. WHO: Pursue high-quality DOTS expansion and enhancement. Tuberculosis (TB) (2010). [http://www.who.int/tb/dots/en/]

39. Petrini B, Hoffner S: Drug-resistant and multidrug-resistant tubercle bacilli. International Journal of Antimicrobial Agents (1999), 13(2):93-97.

40. Porter J, McAdam K: Drug Supply: meeting a global need. In: Tuberculosis: Back to the future. Wiley \& Sons Ltd; (1994): 123-143.

41. WHO: Multidrug and extensively drug-resistant TB (M/XDR-TB): 2010 Global report on surveillance and response. Geneva; World Health Organization

[http://whqlibdoc.who.int/publications/2010/9789241599191_eng.pdf]

42. Telenti $A$, Iseman $M$ : Drug-resistant tuberculosis: what do we do now? Drugs (2000), 59(2):171-179. 
43. Murray P, Rosenthal K, Pfaller M: Medical Microbiology., 5th edn. New York: Elsevier Press; (2005).

44. Gillespie SH: Evolution of Drug Resistance in Mycobacterium tuberculosis: Clinical and Molecular Perspective. Antimicrobial Agents and Chemotherapy (2002), 46(2):267-274.

45. Ramaswamy SV, Reich R, Dou S-J, Jasperse L, Pan X, Wanger A, Quitugua T, Graviss EA: Single Nucleotide Polymorphisms in Genes Associated with Isoniazid Resistance in Mycobacterium tuberculosis. Antimicrobial Agents and Chemotherapy (2003), 47(4):1241-1250.

46. Pablos-Mendez A, Raviglione MC, Laszlo A, Binkin N, Rieder HL, Bustreo F, Cohn DL, Lambregts-van Weezenbeek CSB, Kim SJ, Chaulet P, Nunn $\mathrm{P}$, Tuberculosis TWHO-IUa, Lung Disease Working Group on AntiTuberculosis Drug Resistance Surveillance: Global Surveillance for Antituberculosis-Drug Resistance, 1994-1997. The New England Journal of Medicine (1998), 338(23):1641-1649.

47. World Health Organisation and the Stop TB Partnership: The Global Plan to Stop TB 2006-2015: Progress Report 2006-2008. Geneva; World Health Organization (2009).

[http://www.stoptb.org/assets/documents/global/plan/The_global_plan_prog ress_report1.pdf]

48. Dye C, Espinal MA, Watt CJ, Mbiaga C, Williams BG: Worldwide incidence of multidrug-resistant tuberculosis. Journal of Infectious Diseases (2002), 185(8):1197-1202.

49. McRae J, Yang Q, Crawford R, Palombo E: Review of the methods used for isolating pharmaceutical lead compounds from traditional medicinal plants. The Environmentalist (2007), 27(1):165-174.

50. Lesney M: Nature's Pharmaceuticals-Natural Products from Plants Remain at the Core of Modern Medicinal Chemistry. Today's Chemist at Work (2004)(July):27-32.

51. Gurib-Fakim A: Medicinal plants: Traditions of yesterday and drugs of tomorrow. Molecular Aspects of Medicine (2006), 27(1):1-93.

52. Solecki RS: Shanidar IV, a Neanderthal Flower Burial in Northern Iraq. Science (1975), 190(4217):880-881.

53. Scheindlin S: Ephedra: Once a Boon, Now a Bane. Molecular Interventions (2003), 3(7):358-360.

54. Massengill SE (ed.): A sketch of medicine and pharmacy and a view of its progress by the Massengill family from the fifteenth to the twentieth century. Bristol: S. E. Massengill Company (1920).

55. Heinrich M, Barnes J, Gibbons S, Williamson EM (eds.): Fundamentals of pharmacognosy and phytotherapy. Elsevier Science Limited; (2004).

56. Cohen SG: Asthma in Antiquity: The Ebers Papyrus. Allergy Proceedings (1992), 13(3):147-154.

57. Said HM: Hamdard Pharmacopoeia of Eastern Medicine. The Journal of Clinical Pharmacology and New Drugs (1971), 11:239.

58. Wakim KG: Arabic Medicine in Literature. Bulletin of the Medical Library Association (1944), 32(1):96-104.

59. Al-Sharrah YA: The Arab Tradition of Medical Education and its Relationship with the European Tradition. Prospects (2003), 33(4):413-425.

60. Scott G, Springfield EP, Coldrey N: A Pharmacognostical Study of 26 South African Plant Species Used as Traditional Medicines. Pharmaceutical Biology (2004), 42(3):186 - 213.

61. Bamuamba K, Gammon DW, Meyers P, Dijoux-Franca M-G, Scott G: Antimycobacterial activity of five plant species used as traditional medicines in the Western Cape Province (South Africa). Journal of Ethnopharmacology (2008), 117(2):385-390. 
62. Tabuti JRS, Kukunda CB, Waako PJ: Medicinal plants used by traditional medicine practitioners in the treatment of tuberculosis and related ailments in Uganda. Journal of Ethnopharmacology (2010), 127:130-136.

63. Eldeen IMS, van Staden J: Antimycobacterial activity of some trees used in South African traditional medicine. South African Journal of Botany (2007), 73:248-251.

64. Barrows LR, Powan E, Pond CD, Matainaho T: Anti-TB activity of Evodia elleryana bark extract. Fitoterapia (2007), 78(3):250-252.

65. Adams M, Wube AA, Bucar F, Bauer R, Kunert O, Haslinger E: Quinolone alkaloids from Evodia rutaecarpa: a potent new group of antimycobacterial compounds. International Journal of Antimicrobial Agents (2005), 26(3):262-264.

66. Suffredini IB, Sader HS, Gonçalves AG, Reis AO, Gales AC, Varella AD, Younes RN: Screening of antibacterial extracts from plants native to the Brazilian Amazon Rain Forest and Atlantic Forest. Brazilian Journal of Medical and Biological Research (2004), 37:379-384.

67. Carneiro ALB, Teixeira MFS, Oliveira VMAd, Fernandes OCC, Cauper GSdB, Pohlit AM: Screening of Amazonian plants from the Adolpho Ducke forest reserve, Manaus, state of Amazonas, Brazil, for antimicrobial activity. Memórias do Instituto Oswaldo Cruz (2008), 103:31-38.

68. Jimenez-Arellanes A, Meckes M, Ramirez R, Torres J, Luna-Herrera J: Activity against multidrug-resistant Mycobacterium tuberculosis in Mexican plants used to treat respiratory diseases. Phytotherapy Research (2003), 17(8):903-908.

69. Jiménez-Arellanes $A$, Meckes $M$, Torres $J$, Luna-Herrera J: Antimycobacterial triterpenoids from Lantana hispida (Verbenaceae). Journal of Ethnopharmacology (2007), 111(2):202-205.

70. Molina-Salinas GM, Ramos-Guerra MC, Vargas-Villarreal J, MataCárdenas BD, Becerril-Montes $\mathrm{P}$, Said-Fernández S: Bactericidal Activity of Organic Extracts from Flourensia cernua DC against Strains of Mycobacterium tuberculosis. Archives of Medical Research (2006), 37(1):45-49.

71. Camacho-Corona MdR, Ramírez-Cabrera MA, Santiago OG, GarzaGonzález E, Palacios IdP, Luna-Herrera J: Activity against drug resistanttuberculosis strains of plants used in Mexican traditional medicine to treat tuberculosis and other respiratory diseases. Phytotherapy Research (2008), 22(1):82-85.

72. Mackowiak PA: Brief History of Antipyretic Therapy. Clinical Infectious Diseases (2000), 31:S154-S156.

73. Leroux H: Discovery of salicine. Chinese Medical Journal (1830), 6:341.

74. Rinsema TJ: One hundread years of Aspirin. Medical History (1999), 43:502-507.

75. Rojas R, Caviedes L, Aponte JC, Vaisberg AJ, Lewis WH, Lamas G, Sarasara C, Gilman RH, Hammond GB: Aegicerin, the First Oleanane Triterpene with Wide-Ranging Antimycobacterial Activity, Isolated from Clavija procera. Journal of Natural Products (2006), 69(5):845-846.

76. Limsuwan S, Trip EN, Kouwen TRHM, Piersma S, Hiranrat A, Mahabusarakam W, Voravuthikunchai SP, van Dijl JM, Kayser O: Rhodomyrtone: A new candidate as natural antibacterial drug from Rhodomyrtus tomentosa. Phytomedicine (2009), 16(6-7):645-651.

77. Kwan C-Y: Plant-derived drugs acting on cellular $\mathrm{Ca}^{2+}$ mobilization in vascular smooth muscle: Tetramethylpyrazine and tetrandrine. Stem Cells (1994), 12(1):64-67. 
78. Balandrin MF, Kinghorn AD, Farnsworth NR: Plant-Derived Natural Products in Drug Discovery and Development. In: Human Medicinal Agents from Plants. Washington, DC: American Chemical Society; (1993): 2-12.

79. Rowinsky EK, Donehower RC: Paclitaxel (Taxol). New England Journal of Medicine (1995), 332(15):1004-1014.

80. Martin J, Compston N: Vincristine sulphate in the treatment of lymphoma and leukaemia. The Lancet (1963), 282(7317):1080-1083.

81. Wall ME, Wani MC, Cook CE, Palmer KH, McPhail AT, Sim GA: Plant Antitumor Agents. The Isolation and Structure of Camptothecin, a Novel Alkaloidal Leukemia and Tumor Inhibitor from Camptotheca acuminata. Journal of the American Chemical Society (1966), 88(16):3888-3890.

82. Mitscher LA, Baker W: Tuberculosis: A search for novel therapy starting with natural products. Medicinal Research Reviews (1998), 18(6):363-374.

83. Rastogi N, Abaul J, Goh KS, Devallois A, Philogène E, Bourgeois P: Antimycobacterial activity of chemically defined natural substances from the Caribbean flora in Guadeloupe. FEMS Immunology \& Medical Microbiology (1998), 20(4):267-273.

84. Mata R, Morales I, Perez O, Rivero-Cruz I, Acevedo L, Enriquez-Mendoza I, Bye R, Franzblau S, Timmermann B: Antimycobacterial Compounds from Piper sanctum. Journal of Natural Products (2004), 67(12):1961-1968.

85. Swain T: Secondary Compounds as Protective Agents. Annual Review of Plant Physiology (1977), 28(1):479-501.

86. Fellows L, Scofield A (eds.): Chemical Diversity In Plants. New York: Cambridge University Press; (1995).

87. McChesney James D: Biological and Chemical Diversity and the Search for New Pharmaceuticals and Other Bioactive Natural Products. In: Human Medicinal Agents from Plants. Washington, DC: American Chemical Society; (1993): 38-47.

88. Cowan MM: Plant Products as Antimicrobial Agents. Clinical Microbiology Reviews (1999), 12(4):564-582.

89. Akihisa T, Franzblau SG, Ukiya M, Okuda H, Zhang F, Yasukawa K, Suzuki T, Kimura Y: Antitubercular activity of triterpenoids from Asteraceae flowers. Biological \& pharmaceutical bulletin (2005), 28(1):158-160.

90. Gentry EJ, Jampani HB, Keshavarz-Shokri A, Morton MD, Vander Velde D, Telikepalli H, Mitscher LA, Shawar R, Humble D, Baker W: Antitubercular Natural Products: Berberine from the Roots of Commercial Hydrastis canadensis Powder. Isolation of Inactive 8-Oxotetrahydrothalifendine, Canadine, $\beta$-Hydrastine, and Two New Quinic Acid Esters, Hycandinic Acid Esters-1 and -2. Journal of Natural Products (1998), 61(10):1187-1193.

91. Mativandlela SPN, Muthivhi T, Kikuchi H, Oshima Y, Hamilton C, Hussein AA, van der Walt ML, Houghton PJ, Lall N: Antimycobacterial Flavonoids from the Leaf Extract of Galenia africana. Journal of Natural Products (2009), 72(12):2169-2171.

92. Cooper RA, Millener PR: The New Zealand biota: Historical background and new research. Trends in Ecology \& Evolution (1993), 8(12):429-433.

93. McChesney James D: Biological and Chemical Diversity and the Search for New Pharmaceuticals and Other Bioactive Natural Products. In: Human Medicinal Agents from Plants. Washington, DC: American Chemical Society; (1993): 38-47.

94. DOC: Conservation areas statistics. Maps and Statistics: Department of Conservation; (2010). [http://www.doc.govt.nz/about-doc/role/maps-andstatistics/protected-area-statistics/conservation-areas/]

95. Wilmshurst JM, Anderson AJ, Higham TFG, Worthy TH: Dating the late prehistoric dispersal of Polynesians to New Zealand using the commensal 
Pacific rat. Proceedings of the National Academy of Sciences (2008), 105(22):7676-7680.

96. Riley M: Maori Healing and Herbal: New Zealand Ethnobotanical Sourcebook. Paraparaumu: Viking Sevenseas N.Z. Ltd; (1994).

97. Goldie WH: Maori Medical Lore. In: Transactions and Proceedings of the New Zealand Institute; (1904) vol. 37: 1-120.

98. Brooker SG, Cambie RC, Cooper RC: New Zealand Medicinal Plants. Auckland: Heinemann publishers; (1981).

99. Macdonald C: Medicines of the maori. Auckland: Collins; (1974).

100. Parsons C: Healing practices of the south pacific: University of Hawaii press; (1985).

101. Newton SM, Lau C, Wright CW: A review of antimycobacterial natural products. Phytotherapy Research (2000), 14(5):303-322.

102. Larsen L, Benn MH, Parvez M, Perry NB: A cytotoxic triketonephloroglucinol-bullatenone hybrid from Lophomyrtus bullata. The Royal Society of Chemistry (2005), 3:3236-3241.

103. McCallion RF, Cole AL, Walker JRL, Blunt JW, Munro MHG: Antibiotic compounds from New Zealand plants, II: polygodial, an anti-Candida agent from Pseudowintera colorata. Planta Medica (1982), 44:134-138.

104. Lis-Balchin M, Deans S, Hart S: Bioactivity of New Zealand Medicinal Plant Essential Oils.; International Society for Horticultural Science (1996).

105. Lorimer SD, Perry NB, Tangney RS: An Antifungal Bibenzyl from the New Zealand Liverwort, Plagiochila stephensoniana. Bioactivity-Directed Isolation, Synthesis, and Analysis. Journal of Natural Products (1993), 56(9):1444-1450.

106. Miller C, Nisa S, Dempsey S, Jack C, O'Toole R: Modifying culture conditions in chemical library screening identifies alternative inhibitors of mycobacteria. Antimicrobial Agents Chemotherapy (2009), 12:5279-5283.

107. Perehinec T, Qazi S, Gaddipati S, Salisbury V, Rees C, Hill P: Construction and evaluation of multisite recombinatorial (Gateway) cloning vectors for Gram-positive bacteria. BMC Molecular Biology (2007), 8(1):80.

108. Kraemer G, landolo J: High-frequency transformation of Staphylococcus aureus by electroporation. Current Microbiology (1990), 21(6):373-376.

109. Earl E, Altaf M, Murikoli R, Swift S, O'Toole R: Native New Zealand plants with inhibitory activity towards Mycobacterium tuberculosis. BMC Complementary and Alternative Medicine (2010), 10(1):25.

110. O'Toole R, Von Hofsten J, Rosqvist R, Olsson PE, Wolf-Watz H: Visualisation of zebrafish infection by GFP-labelled Vibrio anguillarum. Microbial pathogenesis (2004), 37(1):41-46

111. Jonas WB: Mosby's Dictionary of Complementary and Alternative Medicine. St Louis: Elsevier Health Sciences; (2005).

112. Brown-Elliott B, Wallace R: Clinical and Taxonomic Status of Pathogenic Nonpigmented or Late-Pigmenting Rapidly Growing Mycobacteria. Clinical Microbiology Reviews (2002), 15:716-746.

113. Reyrat J-M, Kahn D: Mycobacterium smegmatis: an absurd model for tuberculosis? Trends in Microbiology (2001), 9(10):472-473.

114. Inouye S, Tsuji FI: Aequorea green fluorescent protein: Expression of the gene and fluorescence characteristics of the recombinant protein. FEBS Letters (1994), 341(2-3):277-280.

115. Singh M, Singh N, Khare PB, Rawat AKS: Antimicrobial activity of some important Adiantum species used traditionally in indigenous systems of medicine. Journal of Ethnopharmacology (2008), 115(2):327-329.

116. Ofman DJ, Markham KR, Vilain C, Molloy BPJ: Flavonoid profiles of New Zealand kauri and other species of Agathis. Phytochemistry (1995), 38(5):1223-1228. 
117. Taylor R: A leaf from the natural history of New Zealand. (1848).

118. Lai H, Lim Y, Tan S: Antioxidative, tyrosinase inhibiting and antibacterial activities of leaf extracts from medicinal ferns. Bioscience, biotechnology, and biochemistry (2009), 73(6):1362-1366.

119. Jantová S, Nagy M, Ruzeková L, Grancai D: Antibacterial activity of plant extracts from the families Fabaceae, Oleaceae, Philadelphaceae, Rosaceae and Staphyleaceae. Phytotherapy Research (2000), 14(8):601603.

120. Katerere DR, Eloff JN: Antibacterial and antioxidant activity of Sutherlandia frutescens (Fabaceae), a reputed Anti-HIV/AIDS phytomedicine. Phytotherapy Research (2005), 19(9):779-781.

121. Brooker SG, Cooper RC: New Zealand Medicinal Plants. Auckland: Unity Press; (1962).

122. Martin M: He Pukapuka Whakaata Tikanga Mo Nga Rongoa Mo Nga Kai. Auckland: Henry Hill Publishers; (1869).

123. Bloor SJ: An antimicrobial kaempferol-diacyl-rhamnoside from Pentachondra pumila. Phytochemistry (1995), 38(4):1033-1035.

124. Bown D: Encyclopaedia of Herbs and their Uses. London: Dorling Kindersley; (1995).

125. Moerman D: Native American Ethnobotany. Oregon: Timber Press; (1998).

126. Dawson J: Root Parasites. In: Victoria University Press; (1988).

127. Asakawa Y: Biologically active compounds from bryophytes. Pure and applied chemistry (2007), 79(4):557-580.

128. Parsons C: Healing practices of the south pacific.: University of Hawaii press; (1985).

129. Brussell D: Araliaceae species used for culinary and medicinal purposes in Niigata-ken, Japan. Economic Botany (2004), 58(4):736-739.

130. Snogan E, Vahirua-Lechat I, Ho R, Bertho G, Girault J, Ortiga S, Maria A, Lafont R: Ecdysteroids from the medicinal fern Microsorum scolopendria (Burm. f.). Phytochemical Analysis (2007), 18:441-450.

131. Hillis WE, Inoue T: The polyphenols of Nothofagus species--II: The heartwood of Nothofagus fusca. Phytochemistry (1967), 6(1):59-67.

132. Hassan SW, Umar RA, Dabai YU, Ebbo AA, Faruk UZ: Antibacterial, Phytochemical and Toxicity Studies of Pteridium aquilinum L. (Dennstaedtiaceae) in Rabbits. Journal of Pharmacology and Toxicology (2007), 2(2):168-175.

133. Muir AD, Cole ALJ, Walker JRL: Falcarindiol, an Anti-dermatophyte Agent from Schefflera digitata. Planta Medica (1982), 44(3):129-133.

134. Kavalali G: The chemical and pharmacological aspects of Urtica. In: Urtica. CRC Press; (2003).

135. Hostettmann $\mathrm{K}$, Wolfender $\mathrm{J}-\mathrm{L}$ : The search for biologically active secondary metabolites. Pesticide Science (1997), 51(4):471-482.

136. Parekh J, Chanda S: In vitro antibacterial activity of the crude methanol extract of Woodfordia fruticosa Kurz. flower (Lythraceae). Brazilian Journal of Microbiology (2007), 38:204-207.

137. Verastegui MA, Sanchez CA, Heredia NL, Garcia-Alvarado JS: Antimicrobial activity of extracts of three major plants from the Chihuahuan desert. Journal of Ethnopharmacology (1996), 52:175 - 177.

138. McNeil M, Darvill AG, Fry SC, Albersheim P: Structure and Function of the Primary Cell Walls of Plants. Annual Review of Biochemistry (1984), 53(1):625-663.

139. Smeulders MJ, Keer J, Speight RA, Williams HD: Adaptation of Mycobacterium smegmatis to Stationary Phase. Journal of Bacteriology (1999), 181(1):270-283. 
140. Garnier T, Eiglmeier K, Camus J-C, Medina N, Mansoor H, Pryor M, Duthoy S, Grondin S, Lacroix C, Monsempe C, Simon S, Harris B, Atkin R, Doggett J, Mayes R, Keating L, Wheeler PR, Parkhill J, Barrell BG, Cole ST et al: The complete genome sequence of Mycobacterium bovis. Proceedings of the National Academy of Sciences of the United States of America (2003), 100(13):7877-7882.

141. Carter $\mathrm{CH}$, Gasper AJ, Leise JM: Resazurin staining of bacterial colonies on membrane filters. Frederick; 1955).

142. Anoopkumar-Dukie S, Carey JB, Conere T, O'Sullivan E, van Pelt FN, Allshire A: Resazurin assay of radiation response in cultured cells. British Journal of Radiology (2005), 78(934):945-947.

143. Bonacorsi S, Bingen E: Molecular epidemiology of Escherichia coli causing neonatal meningitis. International Journal of Medical Microbiology (2005), 295(6-7):373-381.

144. Valencia IC, Kerdel FA: Severe Staphylococcal Cutaneous Infections and Toxic Shock Syndrome. In: Life-Threatening Dermatoses and Emergencies in Dermatology. (2009): 67-78.

145. Jain A, Daum RS: Staphylococcal Infections in Children: Part 1. Pediatrics in Review (1999), 20(6):183-191.

146. Reiss MA: Toxic shock syndrome. Primary Care Update for OB/GYNS, 7(3):85-90.

147. Enright MC, Robinson DA, Randle G, Feil EJ, Grundmann H, Spratt BG: The evolutionary history of methicillin-resistant Staphylococcus aureus (MRSA). Proceedings of the National Academy of Sciences of the United States of America (2002), 99(11):7687-7692.

148. Fadheel ZH, Perry HE, Henderson RA: Comparison of methicillin-resistant Staphylococcus aureus (MRSA) carriage rate in the general population with the health-worker population. New Zealand Institute of Medical Laboratory Science (2008), 62:4-6.

149. Fu LM, Fu-Liu CS: Genome Comparison of Mycobacterium tuberculosis and Other Bacteria. OMICS: A Journal of Integrative Biology (2002), 6(2):199-206.

150. Pauli GF, Case RJ, Inui T, Wang Y, Cho S, Fischer NH, Franzblau SG: New perspectives on natural products in TB drug research. Life Sciences (2005), 78(5):485-494.

151. Wassilieff M: Tall broadleaf trees - Forest giants.; (2009).

152. Fogg WS: The Pharmacological action of Pukateine. Journal of Pharmacology and Experimental Therapeutics (1935), 54(2):167-187.

153. Dajas-Bailador FA, Asencio M, Bonilla C, Scorza MC, Echeverry C, ReyesParada M, Silveira R, Protais P, Russell G, Cassels BK, Dajas F: Dopaminergic pharmacology and antioxidant properties of pukateine, a natural product lead for the design of agents increasing dopamine neurotransmission. General Pharmacology (1999), 32(3):373-379.

154. Valiente $M$, D'Ocon $P$, Noguera MA, Cassels BK, Lugnier C, Ivorra MD: Vascular activity of (-)-anonaine, (-)-roemerine and (-)-pukateine, three natural $6 \mathrm{a}(\mathrm{R})$-1,2-methylenedioxyaporphines with different affinities for a1adrenoceptor subtypes. Planta Medica (2004), 70(7):603-609.

155. Woollard JMR, Perry NB, Weavers RT, van Klink JW: Bullatenone, 1,3dione and sesquiterpene chemotypes of Lophomyrtus species. Phytochemistry (2008), 69(6):1313-1318.

156. Larsen L, Benn MH, Parvez M, Perry NB: A cytotoxic triketonephloroglucinol-bullatenone hybrid from Lophomyrtus bullata. The Royal Society of Chemistry (2005), 3:3236-3241.

157. Sugimura T, Koguro K, Tai A: Total syntheses of (+)-ipomeamarone and ()-ngaione. Tetrahedron Letters (1993), 34(3):509-512. 
158. Taniguchi M, Yano Y, Tada E, Ikenishi K, Oi S, Haraguchi H, Hashimoto K, Kubo I: Mode of Action of Polygodial, an Antifungal Sesquiterpene Dialdehyde. Agricultural and biological chemistry (1988), 52(6):1409-1414.

159. De Nobili M, Chen Y: Size Exclusion Chromatography of Humic Substances: Limits, Perspectives and Prospectives. Soil Science (1999), 164(11):825-833.

160. Muller MB, Schmitt D, Frimmel FH: Fractionation of Natural Organic Matter by Size Exclusion Chromatography-Properties and Stability of Fractions. Environmental Science \& Technology (2000), 34(23):4867-4872.

161. Sudderth RB, Kordosky GA (eds.): Some Practical Considerations in the Evalaution and Selection of Solvent Extraction Reagents: Malhotra and Riggs; (1986).

162. Webb RG: Solvent Extraction of Organic Water Pollutants. International Journal of Environmental Analytical Chemistry (1978), 5(3):239 - 252.

163. Monago CC, Alumanah EO: Antidiabetic Effect of Chloroform -Methanol Extract of Abrus Precatorius Linn Seed in Alloxan Diabetic Rabbit. Journal of Applied Sciences \& Environmental Management (2005), 9(1):85-88.

164. Hatta T: Le Chatelier principle. The New Palgrave: A Dictionary of Economics (1987), 9:155-157.

165. Edwards EJ, Cobb AH: Improved High-Performance Liquid Chromatographic Method for the Analysis of Potato (Solanum tuberosum) Glycoalkaloids. Journal of Agricultural and Food Chemistry (1996), 44(9):2705-2709.

166. Graham TL: A Rapid, High Resolution High Performance Liquid Chromatography Profiling Procedure for Plant and Microbial Aromatic Secondary Metabolites. Plant Physiology (1991), 95(2):584-593.

167. Hudson A, Imamura T, Gutteridge W, Kanyok T, Nunn P: The current antiTB drug research and development pipeline.; World Health Organization (2003).

168. Ltd FHR: Kolorex - natural Candida support. (2009). [http://www.kolorex.com/index.html]

169. Saklani A, Kutty SK: Plant-derived compounds in clinical trials. Drug Discovery Today (2008), 13(3-4):161-171.

170. Arjanova OV, Prihoda ND, Yurchenko LV, Sokolenko NI, Vihrova LA, Pylypchuk VS, Frolov VM, Kutsyna GA: Enhancement of efficacy of tuberculosis drugs with Immunoxel (Dzherelo) in HIV-infected patients with active pulmonary tuberculosis. Immunotherapy (2009), 1(4):549-556.

171. Nikolaeva LG, Maystat TV, Volyanskii YL, Pylypchuk VS, Frolov VM, Kutsyna GA: Effect of Immunomodulating Adjuvant Dzherelo (Immunoxel) in HIV Infected Patients Receiving Standard Antiretroviral Therapy. The Open Virology Journal (2009), 3:31-36.

172. Zaitzeva SI, Matveeva SL, Gerasimov TG, Pashkov YN, Butov DA, Pylypchuk VS, Frolov VM, Kutsyna GA: Efficacy and Safety of Phytoconcentrate Dzherelo (Immunoxel) in Treatment of Patients with Multi-Drug Resistant TB (MDR-TB) in Comparison to Standard Chemotherapy. Research Journal of Medical Sciences (2009), 3(2):36-41.

173. Nikolaeva LG, Maystat TV, Pylypchuk VS, Volyanskii YL, Masyuk LA, Kutsyna GA: Effect of oral immunomodulator Dzherelo in TB/HIV coinfected patients receiving anti-tuberculosis therapy under DOTS. International Immunopharmacology (2008), 8(6):845-851. 


\section{APPENDICES}

Appendix 1: Research article in BMC Complementary and Alternative Medicine

Results from the initial screen of the plant extracts against $M$. smegmatis (Section 3.2.6) and the screening against clinically-relevant species (Section 4.2.1) were peer-reviewed and published in the journal BMC Complementary and Alternative Medicine (2010), 10(1):25. Below is the research article from the journal. 
Appendices

\title{
Native New Zealand plants with inhibitory activity towards Mycobacterium tuberculosis
}

\author{
Emma A Earl'1, Mudassar Altaf1', Rekha V Murikoli', Simon Swift² and Ronan O'Toole ${ }^{* 1}$
}

\begin{abstract}
Background: Plants have long been investigated as a source of antibiotics and other bioactives for the treatment of human disease. New Zealand contains a diverse and unique flora, however, few of its endemic plants have been used to treat tuberculosis. One plant, Laurelia novae-zelandiae, was reportedly used by indigenous Maori for the treatment of tubercular lesions.

Methods: Laurelia novae-zelandiae and 44 other native plants were tested for direct anti-bacterial activity. Plants were extracted with different solvents and extracts screened for inhibition of the surrogate species, Mycobacterium smegmatis. Active plant samples were then tested for bacteriostatic activity towards M. tuberculosis and other clinicallyimportant species.

Results: Extracts of six native plants were active against $M$. smegmatis. Many of these were also inhibitory towards $M$. tuberculosis including Laurelia novae-zelandiae (Pukatea). M. excelsa (Pohutukawa) was the only plant extract tested that was active against Staphylococcus aureus.

Conclusions: Our data provide support for the traditional use of Pukatea in treating tuberculosis. In addition, our analyses indicate that other native plant species possess antibiotic activity.
\end{abstract}

\section{Background}

Tuberculosis (TB) is the leading cause of death due to a single infectious organism [1]. In 2007, 1.78 million people died from the disease and an estimated 9.27 million new cases were recorded worldwide [2]. TB requires a lengthy treatment period of six months with the first-line drugs rifampicin, isoniazid, ethambutol and pyrazinamide [3]. The availability of new drugs that shortened the course of chemotherapy would improve patient adherence and affordability thus, enabling more favourable treatment outcomes. In addition, alternative drugs are needed to counteract the spread of drug resistant TB which threatens global control programmes [4]. MDR$\mathrm{TB}$, resistant to rifampicin and isoniazid, now exceeds 0.5 million cases per year [2] and in some states accounts for up to $22 \%$ of TB cases [2,5]. Extensively-drug resistant (XDR) strains of $M$. tuberculosis, resistant to both firstand second-line drugs, were first reported in the United

*Correspondence: ronan.otoole@vuw.ac.nz

ISchool of Biological Sciences, Victoria University of Wellington, Wellington 6140, New Zealand

Full list of author information is available at the end of the article
State, Latvia and South Korea in 2006 [6] but are now present in 57 countries [7].

The World Health Organisation has advised that new TB drugs are required to treat TB $[8,9]$. While much of the focus has been on screening libraries of synthetic compounds for mycobacterial inhibitors, plants have often provided a source of anti-bacterial compounds. For example, Aegicerin, isolated from Clavija procera, has been shown to have activity against Mycobacterium tuberculosis $\mathrm{H} 37 \mathrm{Rv}$ and MDR-TB strains [10]. Rhodomyrtone, a compound from the Southeast Asian plant Rhodomyrtus tomentosa was found to have potent antibacterial activity against a number of clinically-important Gram-positive species including Enterococcus faecalis, Streptococcus pneumoniae and methicillin-resistant Staphylococcus aureus (MRSA) [11].

In this work, solvent extracts were prepared from 45 native New Zealand plants and screened for activity using Mycobacterium smegmatis. Active samples were then tested against Mycobacterium bovis BCG, M. tuberculosis H37Ra, Escherichia coli and Staphylococcus aureus. A number of plants were identified as containing antiMycobacterium tuberculosis activity and their potential 
Appendices

for generating novel compounds for the treatment of tuberculosis is discussed.

\section{Methods \\ Bacterial strains and plasmids}

The mycobacterial strains used were Mycobacterium smegmatis mc ${ }^{2} 155, M$. bovis BCG (Pasteur) and $M$. tuberculosis H37Ra. M. smegmatis and M. bovis BCG were labelled with GFP through the introduction of the plasmid pSHIGH+hsp 60 by electroporation and selection on media containing $50 \mu \mathrm{g} / \mathrm{ml}$ kanamycin as previously described [12]. GFP-labelled Staphylococcus aureus Newman was constructed as follows: the $f d h$ (formate dehydrogenase) promoter was amplified from $S$. aureus Newman using Phusion ${ }^{\text {Tx }}$ Flash High-Fidelity PCR Master Mix (Finnzymes, Finland) according to the manufacturers' instructions with primers GGGGACAACT TTGTATAGAAAAGTTGgaaggggtaagtgtgataagc and GGGGACTGCTTTTTTGTACAAACTTgtctttaaaataag aagttcattaattgttc, where uppercase represents attB sites for Gateway cloning (Invitrogen) and lower case represents S. aureus DNA. The 275 bp amplified product was cloned into pDONR221 using BP Clonase ${ }^{\mathrm{Tn}}$ II (Invitrogen) and used to transform chemically-competent Escherichia coli TOP 10 (Invitrogen). The insert was sequenced to confirm an error-free amplification. Gateway cloning with LR Clonase ${ }^{\text {TI }}$ II (Invitrogen) combined the $f d h$ promoter with $g f p$, or $g f p l u x A B C D E$, and the rrnBT1T2 terminator in the destination vector pDEST-pUNK1 as described previously [13]. The correct plasmid constructs from bioluminescent/fluorescent LR-reaction transformants of $E$. coli TOP 10 were confirmed by restriction mapping. The plasmids generated were electroporated into S. aureus RN4220 as previously described [14] and then transferred to $S$. aureus Newman by bacteriophage transduction [15]. S. aureus strains containing pDESTpUNK1 derivatives were selected on media containing 30 $\mathrm{g} / \mathrm{ml}$ erythromycin. Escherichia coli $\mathrm{DH} 5 \alpha$ was labelled with GFP using pOT11 [16].

\section{Plant Collection and solvent extraction}

Plant samples were collected from the Karori Wildlife Sanctuary (Zealandia) and the Otari-Wilton Bush Reserve, Wellington; Kaitoke Regional Park, Upper Hutt; and the Nelson region with permission. The native New Zealand plants tested for anti-mycobacterial activity are listed in Table 1. Plant samples were collected fresh, macerated and dried in a desiccator. For each sample, approximately $1 \mathrm{~g}$ of dried plant tissue was placed in a $50 \mathrm{ml}$ conical tube. Sterile distilled water, ethanol or methanol were added to the samples to give a final concentration of $100 \mathrm{mg} / \mathrm{ml}$. The samples were incubated in a water bath at $55^{\circ} \mathrm{C}$ for 1 hour and then stored at $-80^{\circ} \mathrm{C}$. The incubation at $55^{\circ} \mathrm{C}$ was used as Māori heated plant extracts dur- ing the preparation of some traditional medicines. The resulting crude extracts were sterilized using a $0.22 \mu \mathrm{m}$ filter prior to anti-microbial analysis.

Screening plant extracts for bacteriostatic activity towards M. smegmatis

Plant extracts were tested for bacteriostatic activity in a 96 well-plate format assay using $M$. smegmatis mc ${ }^{2} 155$ / pSHIGH+hsp60 as previously described [12]. Optical Density (OD) and GFP fluorescence were used to detect growth inhibition. M. smegmatis was cultured for 24 hours in Luria Broth (LB) supplemented with D-arabinose $(1 \mathrm{mg} / \mathrm{ml})$, Tween $80(0.1 \% \mathrm{v} / \mathrm{v})$ and kanamycin $(50$ $\mu \mathrm{g} / \mathrm{ml})$. Sterile distilled water $(150 \mu \mathrm{L})$ was added to the outer lanes of the 96-well microtiter plates to minimise evaporation. Liquid media $(50 \mu \mathrm{L})$ was added to the remaining wells. The effect of the solvents used on the growth of $M$. smegmatis was tested. Inhibition of $M$. smegmatis growth was observed at concentrations of ethanol and methanol greater than $5 \%(\mathrm{v} / \mathrm{v})$. Plant extracts were added to columns 2 and 3 of the microtitre plates with a starting concentration of $2 \mathrm{mg} / \mathrm{ml}$ corresponding to a solvent concentration of $2 \%(\mathrm{v} / \mathrm{v})$. A two-fold serial dilution was then performed on each extract starting at column 3. M. smegmatis cells were added to rows B-D at a final OD at $600 \mathrm{~nm}\left(\mathrm{OD}_{600}\right)$ of 0.2 . Rows E-G contained media and extract alone, to measure any background optical density or fluorescence associated with the extract. A number of controls were added to ensure assay reliability, including the use of standard anti-tubercular drugs, rifampicin and streptomycin, as positive controls, each starting at a concentration of $100 \mu \mathrm{M}$. All extracts and controls were tested in triplicate. Plates were sealed and incubated at $37^{\circ} \mathrm{C}$ with $200 \mathrm{rpm}$ shaking for 96 hours, after which the plates were read for OD and GFP fluorescence. For active extracts, dose response experiments were performed to validate activity versus $M$. smegmatis.

Bacteriostatic assays for M. bovis, M. tuberculosis, S. aureus and E. coli

M. bovis BCG and M. tuberculosis H37Ra cultures were grown in Middlebrook $7 \mathrm{H} 9$ broth supplemented with $10 \%$ (v/v) OADC $(0.06 \%$ oleic acid, $5 \%$ BSA, $2 \%$ Dextrose, $0.85 \% \mathrm{NaCl})$, glycerol $(0.5 \% \mathrm{v} / \mathrm{v})$ and Tween $80(0.05 \% \mathrm{v} /$ v). A bacteriostatic assay was set up as previously described [12], with cells added to give a final OD ${ }_{600}$ of 0.05 All extracts and controls were tested in triplicate. Plates were sealed and incubated at $37^{\circ} \mathrm{C}$ with $200 \mathrm{rpm}$ shaking for 14 days before the GFP fluorescence and/or OD of the cultures were measured.

GFP-labelled $S$. aureus Newman was cultured in LB containing erythromycin $(30 \mu \mathrm{g} / \mathrm{ml})$ and xylose $(0.5 \% \mathrm{w} /$ v). GFP-labelled $E$. coli $\mathrm{DH} 5 \alpha /$ pOT11 was cultured in LB containing chloramphenicol $(25 \mu \mathrm{g} / \mathrm{ml})$. IPTG $(100 \mu \mathrm{g} /$ 
Appendices

Earl et al. BMC Complementary and Alternative Medicine 2010, 10:25

http://www.biomedcentral.com/1472-6882/10/25

Page 3 of 7

Table 1: Native New Zealand plants screened for activity against $M$. smegmatis.

\begin{tabular}{|c|c|c|}
\hline Plant name (common) & Part & Documented Traditional Medicinal Use \\
\hline $\begin{array}{l}\text { Adiantum raddianum (Delta maidenhair } \\
\text { fern) }\end{array}$ & Leaf & ni \\
\hline Agathis australis (Kauri) & Leaf & ni \\
\hline $\begin{array}{l}\text { Arthropodium cirratum (New Zealand rock } \\
\text { lily) }\end{array}$ & Leaf & Ulcers [29] \\
\hline $\begin{array}{l}\text { Asplenium bulbiferum (Hen and chicken } \\
\text { fern) }\end{array}$ & Leaf & ni \\
\hline Beilschmiedia tawa (Tawa) & Leaf & Sore throat, colds, cough [22] \\
\hline Blechnum fluviatile (Kiwikiwi) & Leaf & Sore tongue and mouth [30] \\
\hline Brachyglottis repanda (Rangiora) & Leaf & Wounds, ulcers and boils [30] \\
\hline Carpodetus serratus (Marble leaf) & Leaf & ni \\
\hline Clianthus puniceus (Kakabeak) & Leaf & ni \\
\hline Cordyline australis (Cabbage tree) & Leaf & Dysentery, diarrhoea and sores [30] \\
\hline Cortaderia toetoe (Toetoe) & Shoot & Diarrhoea, bladder complaints $[23,31]$ \\
\hline Cyathea dealbata (Ponga) & Fronds & Treat boils [32] \\
\hline Dacrydium cupressinum (Rimu) & Leaf & Treat sores [22] \\
\hline Dracophyllum longifolium (Inanga) & Leaf & ni \\
\hline Dodonaea viscosa (Ake ake) & Leaf & Treat sore throats and skin irritations [33] \\
\hline Dysoxylum spectabile (Kohekohe) & Leaf & Relieve coughing, colds and fevers [33] \\
\hline \multirow[t]{2}{*}{ Exocarpus bidwilli } & Leaf & ni \\
\hline & Seed & ni \\
\hline \multirow[t]{2}{*}{ Hebe stricta (Koromiko) } & Leaf & $\begin{array}{l}\text { Skin problems, ulcers, diarrhoea, dysentery, kidney and bladder complaints } \\
\text { [33] }\end{array}$ \\
\hline & Flower & ni \\
\hline Hymenophyton flabellatum (Liverwort) & Leaf & ni \\
\hline Knightia excelsa (Rewarewa) & Leaf & Relieve coughing [22] \\
\hline Kunzea ericoides (Kanuka) & Leaf & Relieve pain, headaches and coughs [22] \\
\hline \multirow[t]{3}{*}{ Laurelia novae-zelandiae (Pukatea) } & $\begin{array}{l}\text { Inner } \\
\text { bark }\end{array}$ & Sores, ulcers, toothache and tuberculosis $[23,30,32]$ \\
\hline & Bark & Treat sores, skin conditions, venereal disease [29] \\
\hline & Leaf & Toothache [22] \\
\hline \multirow[t]{2}{*}{ Leptospermum scoparium (Manuka) } & Leaf & Colds, pains, urinary troubles [30] \\
\hline & Flower & ni \\
\hline Lophomyrtus bullata (Ramarama) & Leaf & Treat bruises [22] \\
\hline Macropiper excelsum (Kawakawa) & Leaf & Rheumatism, arthritis, diuretic, bruises and chest difficulties $[32,34]$ \\
\hline Melicytos ramiflorus (Mahoe) & Leaf & Treat rheumatism and stomach wounds [30] \\
\hline Meryta sinclairii (Puka) & Leaf & ni \\
\hline \multirow[t]{2}{*}{ Metrosideros excelsa (Pohutukawa) } & Leaf & ni \\
\hline & Flower & Sore throats $[23,30]$ \\
\hline Metrosideros robusta (Northern Rata) & Leaf & ni \\
\hline Metrosideros umbellata (Southern Rata) & Leaf & ni \\
\hline \multirow[t]{2}{*}{ Myoporum laetum (Ngaio) } & Leaf & Bruises and infected wounds [30] \\
\hline & Leaf & Bruises and wounds \\
\hline Nothofagus fusca (Red beech) & Leaf & $n i$ \\
\hline Paesia scaberula (Lace fern) & Leaf & $n i$ \\
\hline
\end{tabular}


Appendices

Earl et al. BMC Complementary and Alternative Medicine 2010, 10:25

Page 4 of 7 http://www.biomedcentral.com/1472-6882/10/25

Table 1: Native New Zealand plants screened for activity against $M$. smegmatis. (Continued)

\begin{tabular}{lll}
\hline Phormium tenax (New Zealand flax) & Leaf & Treat cuts and constipation [28] \\
Pittosporum tenuifolium (Kohuhu) & Leaf & Eczema and other skin diseases, fever and chills [22] \\
Plagiochila stephensoniana (Liverwort) & Leaf & $n i$ \\
Pseudopanax arboreus (Five finger) & Leaf & $n i$ \\
Pseudopanax crassifolius (Lancewood) & Leaf & $n i$ \\
Pteridium esculentum (Bracken) & Leaf & Antiseptic, treats sores [33] \\
Rubus cissoides (Bush lawyer) & Leaf & Chest congestion, coughs and sore throats [30] \\
Schefflera digitata (Seven finger) & Leaf & $n i$ \\
Sophora microphylla (Kowhai) & Leaf & Wounds, back, abdominal and internal pains [32] \\
Urtica ferox (Stinging nettle) & Leaf & ni \\
Vitex lucens (Puriri) & Leaf & Backache, ulcers, and sore throats [30] \\
Weinmannia racemosa (Kamahi) & Leaf & ni \\
\hline
\end{tabular}

ni= no information available.

ml) was added to induce GFP expression. The bacteriostatic assay for $S$. aureus and $E$. coli were performed as per the $M$. smegmatis bacteriostatic assay method except cultures were incubated for 24 hours at $37^{\circ} \mathrm{C}$ with 200 rpm shaking post addition of extracts.

\section{Determination of inhibitory concentrations of plant extracts}

A Perkin Elmer Envision 2102 multilabel plate reader and the Wallace Envision Manager 1.12 software program were used to measure the OD and GFP signals of the microtitre plate cultures. OD was measured at $600 \mathrm{~nm}$. GFP fluorescence was detected using excitation and emission wavelengths of $485 \mathrm{~nm}$ and $510 \mathrm{~nm}$, respectively. 12-point scans were performed on each well to minimise intra-well variation. The intrinsic absorbance and fluorescence readings of extracts alone were measured to account for background signal and subtracted from the readings for the test samples. Data were normalised by expressing the absorbance and fluorescence values as a percentage of a no-drug negative control. Doseresponse curves were plotted using SigmaPlot (version $10.0)$ and minimum inhibitory concentration (MIC) and $50 \%$ inhibitory concentration (IC ${ }_{50}$ ) values were calculated.

\section{Results}

\section{Activity of plant extracts towards M. smegmatis}

45 plants native to New Zealand (Table 1) were extracted with water, ethanol and methanol and the extracts were tested for their ability to inhibit the growth of the fastgrowing species, M. smegmatis. Extracts from 6 plants species, Laurelia novae-zelandiae, Lophomyrtus bullata, Metrosideros excelsa, Myoporum laetum, Pittosporum tenuifolium and Pseudopanax crassifolius showed inhibi- tion towards M. smegmatis (Table 2). Dose-response experiments were performed on the active extracts and their MIC and $\mathrm{IC}_{50}$ values were determined. The most active extract was derived from $L$. novae-zelandiae (Pukatea). The bark of $L$. novae-zelandiae generated an $\mathrm{IC}_{50}$ value of $0.02 \mathrm{mg} / \mathrm{ml}$, respectively while the cambium had an IC ${ }_{50}$ of $0.25 \mathrm{mg} / \mathrm{ml}$ (Table 3). Significant activity was also observed with respect to the leaf, $\mathrm{IC}_{50}$ of 0.11 $\mathrm{mg} / \mathrm{ml}$, and flower, $\mathrm{IC}_{50}$ of $0.41 \mathrm{mg} / \mathrm{ml}$, of M. excelsa. The leaf of $P$. tenuifolium was less active with an $\mathrm{IC}_{50}$ value of $0.78 \mathrm{mg} / \mathrm{ml}$ (Table 3).

Antibacterial activity of plant extracts towards clinicallyrelevant species

The extracts of $L$. novae-zelandiae, L. bullata, M. excelsa, $M$. laetum, P. tenuifolium and P. crassifolius were tested against $M$. bovis BCG and M. tuberculosis H37Ra. The leaf of $P$. tenuifolium was the most active extract with respect to $M$. tuberculosis with an IC ${ }_{50}$ of $0.51 \mathrm{mg} / \mathrm{ml}$ (Table 3). The bark taken from L. novae-zelandiae had an $\mathrm{IC}_{50}$ of $0.54 \mathrm{mg} / \mathrm{ml}$ against $M$. bovis and an IC 50 of 2.39 $\mathrm{mg} / \mathrm{ml}$ against $M$. tuberculosis (Table 3). The cambium of L. novae-zelandiae was similarly active against both $M$. bovis and M. tuberculosis. The leaf extract from M. laetum was not active against $M$. tuberculosis. To examine the specificity of the anti-bacterial activity of the plant extracts, the extracts were also tested against $S$. aureus and $E$. coli. The leaf of $M$. excelsa which was active against $M$. smegmatis and to a lesser extent, $M$. tuberculosis, also displayed antibacterial activity towards $S$. aureus with an IC ${ }_{50}$ of $1.17 \mathrm{mg} / \mathrm{ml}$. None of the extracts tested exhibited anti-bacterial activity towards $E$. coli up to the $10 \mathrm{mg} / \mathrm{ml}$ concentration tested. 
Appendices

Earl et al. BMC Complementary and Alternative Medicine 2010, 10:25

http://www.biomedcentral.com/1472-6882/10/25

Page 5 of 7

Table 2: Anti-bacterial activity of plant extracts towards M. smegmatis $\mathbf{m c}^{2} 155$.

\begin{tabular}{|c|c|c|c|c|c|c|}
\hline \multirow[t]{2}{*}{ Plant species } & \multirow[t]{2}{*}{ Common Name } & \multirow[t]{2}{*}{ Part } & \multirow[t]{2}{*}{ Sample ocation } & \multicolumn{3}{|c|}{ Extract } \\
\hline & & & & Aqueous & Ethanol & Methanol \\
\hline \multirow[t]{2}{*}{ Laurelia novae-zelandiae } & Pukatea & Bark & Otari-Wilton & + & - & - \\
\hline & & Cambium & Otari-Wilton & - & - & + \\
\hline Lophomyrtus bullata & Ramarama & Leaf & Otari-Wilton & - & - & + \\
\hline \multirow[t]{2}{*}{ Metrosideros excelsa } & Pohutukawa & Leaf & Ngaio & - & - & + \\
\hline & & Flower & Ngaio & - & + & - \\
\hline Myoporum laetum & Ngaio & Leaf & Ngaio & + & - & - \\
\hline Pittosporum tenuifolium & Kohuhu & Leaf & Ngaio & - & + & - \\
\hline Pseudopanax crassifolius & Lancewood & Leaf & Otari-Wilton & - & - & + \\
\hline
\end{tabular}

\section{Discussion}

Plants and their extracts have been used by indigenous peoples for the treatment of infectious diseases such as tuberculosis since long before the discovery of antibiotics. A recent study determined that more than 80 plant species have been used by traditional medical practitioners in Uganda to treat tuberculosis [17]. Another study characterised leaf, bark and root material from trees used as traditional anti-tubercular medicines in South Africa. Direct bacteriostatic activity towards Mycobacterium aurum was identified for Acacia nilotica and Combretum kraussii at concentrations ranging from 1.56 to $0.195 \mathrm{mg} /$ $\mathrm{ml}$ [18]. A survey of the ethnobotanical literature was used to select plants used by traditional healers in Mexico to test for activity towards $M$. tuberculosis. Extracts of Citrus aurantifolia, C. sinensis and Olea europaea were found to be active against both drug-susceptible and drug-resistant strains of virulent $M$. tuberculosis with minimum inhibitory concentrations of between 0.1 and $0.025 \mathrm{mg} / \mathrm{ml}$ [19]. Although, the New Zealand shrub Lophomyrtus bullata (Ramarama) has been identified as having activity towards Bacillus subtilis [20], to current knowledge, Pukatea or other New Zealand plants have not been assayed for activity against mycobacteria [21].

In New Zealand, the bark of Laurelia novae-zelandiae (Pukatea) (Figure 1A) was used by Māori in a number of medicinal remedies but it was especially noted for its use against tubercular lesions $[22,23]$. The pulp of the cambium was boiled in water and the resulting liquid used for treating tubercular ulcers. The timber of Pukatea was also used by Māori to create figureheads for canoes [24]. Pukatea is generally found in lowland forests in the North

Table 3: MIC and IC ${ }_{50}$ values of active plant extracts with respect to $M$. smegmatis and clinically-relevant bacterial species.

\begin{tabular}{|c|c|c|c|c|c|c|c|c|c|}
\hline \multirow[t]{3}{*}{ Plant } & \multirow[t]{3}{*}{ Part } & \multicolumn{2}{|c|}{ M. smegmatis } & \multicolumn{2}{|c|}{ M. bovis } & \multicolumn{2}{|c|}{ M. tuberculosis } & \multicolumn{2}{|c|}{ S. aureus } \\
\hline & & \multicolumn{2}{|c|}{$\mathrm{mg} / \mathrm{ml}$} & \multicolumn{2}{|c|}{$\mathrm{mg} / \mathrm{ml}$} & \multicolumn{2}{|c|}{$\mathrm{mg} / \mathrm{ml}$} & \multicolumn{2}{|c|}{$\mathrm{mg} / \mathrm{ml}$} \\
\hline & & MIC & $\mathrm{IC}_{50}$ & MIC & $\mathrm{IC}_{50}$ & MIC & $I_{50}$ & MIC & $I_{50}$ \\
\hline \multirow[t]{2}{*}{ L. novae-zelandiae } & Bark & 0.04 & $0.02 \pm 0.01$ & 1.50 & $0.54 \pm 0.03$ & 4.16 & $2.39 \pm 0.33$ & $>10$ & $>10$ \\
\hline & Cambium & 0.50 & $0.25 \pm 0.01$ & 2.50 & $1.63 \pm 0.21$ & 3.75 & $1.86 \pm 0.22$ & $>10$ & $>10$ \\
\hline L. bullata & Leaf & 1.00 & $0.31 \pm 0.15$ & 3.12 & $2.59 \pm 0.43$ & 6.51 & $5.59 \pm 0.32$ & $>10$ & $>10$ \\
\hline \multirow[t]{2}{*}{ M. excelsa } & Leaf & 0.63 & $0.11 \pm 0.06$ & 8.35 & $6.95 \pm 3.07$ & $>10$ & $4.83 \pm 0.43$ & 2.20 & $1.17 \pm 0.39$ \\
\hline & Flower & 0.63 & $0.41 \pm 0.06$ & 3.13 & $1.12 \pm 0.12$ & 4.18 & $2.19 \pm 0.76$ & $>10$ & $>10$ \\
\hline M. laetum & Leaf & 0.63 & $0.34 \pm 0.02$ & $>10$ & $>10$ & $>10$ & $>10$ & $>10$ & $>10$ \\
\hline P. tenuifolium & Leaf & 2.00 & $0.78 \pm 0.34$ & $>10$ & $5.37 \pm 1.35$ & 1.25 & $0.51 \pm 0.11$ & $>10$ & $>10$ \\
\hline P. crassifolius & Leaf & 0.63 & $0.31 \pm 0.01$ & 6.25 & $4.08 \pm 1.76$ & 3.58 & $1.74 \pm 0.18$ & $>10$ & $>10$ \\
\hline
\end{tabular}

MIC, minimum inhibitory concentration. $I C_{50}, 50 \%$ inhibitory concentration. 
Appendices

Earl et al. BMC Complementary and Alternative Medicine 2010, 10:25 http://www.biomedcentral.com/1472-6882/10/25

Island and the northern areas of the South Island [25]. It can grow up to 35 metres and produces plank buttresses (Figure 1B) to support the tree's growth in swamp or shallow-soil areas [25]. Pukatea has so-called 'toothed' leaves (Figure 1C) and produces small flowers [25].

In this work, we characterised Pukatea and 44 other native plants for activity towards $M$. smegmatis. Extracts from six New Zealand plants were found to have activity against $M$. smegmatis. Bark and cambium samples from Pukatea were the most active against $M$. smegmatis (Table 3). Furthermore, the bark and cambium extracts were also active against $M$. tuberculosis. The direct antimycobacterial activity of the Pukatea extract therefore correlates with the use of this plant by Māori to treat tubercular lesions. This strengthens the possibility that the bark of Pukatea contains previously-unknown antitubercular compound(s). In Māori medicine, M. excelsa was used in the treatment of sore throats. Although the traditional use of $M$. excelsa does not include the treatment of tuberculosis, extracts from M. excelsa were nevertheless active against $M$. smegmatis and $M$. tuberculosis. Similarly, the leaf of $P$. tenuifolium, used by Māori to treat skin infections, was active against $M$. smegmatis and $M$. tuberculosis. The anti-mycobacterial activities that were detected for $M$. excelsa and $P$. tenuifolium extracts could relate to their traditional use in anti-infec-

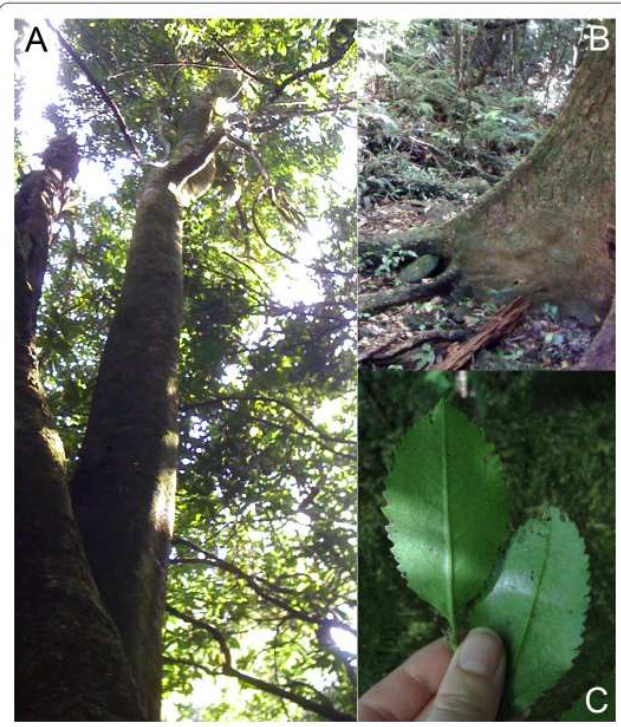

Figure 1 Images of Laurelia novae-zelandiae (Pukatea) specimen located at Otari-Wilton Bush, Wellington. A, branchless trunk and canopy of Pukatea. B, plank buttress of Pukatea. C, examples of "toothed" leaves of Pukatea. tive therapy. Of the extracts shown to have anti-mycobacterial activity, only the $M$. excelsa leaf extract displayed activity against $S$. aureus. Interestingly, none of the plant species tested exhibited antibacterial activity towards $E$. coli. It should be noted that the MIC and IC ${ }_{50}$ values of the extracts in the different mycobacteria (Table 3) will be subject to variation due to species differences, the type of growth medium used, and the assay incubation time.

There is growing interest in identifying the compounds responsible for the anti-mycobacterial activity of traditional medicines and developing them as potential new tuberculosis drugs. Although the chemical basis for the anti-tubercular activity of Pukatea needs to be elucidated, earlier chemical studies identified a novel alkaloid, pukateine, from the bark of Pukatea. Pukateine is an analgesic which acts as a $\mathrm{D}_{2}$ dopamine receptor agonist and $\alpha 1$ adrenergic receptor antagonist [26,27]. A number of the other plant extracts found to have activity against mycobacteria have also been analysed chemically. The flower of $M$. excelsa contains ellagic acid which is a polyphenol antioxidant [28]. Bullatenone, discovered in $L$. bullata (Ramarama), is an antiseptic [28]. Chemical derivatives of bullatenone have been found to have antimicrobial properties against Bacillus subtilis [20]. Ngaione, a hepatotoxic sesquiterpene, found in the leaves of M. laetum (Ngaio) has been used in the treatment of athletes foot [28]. It is possible that compounds such as pukateine, ellagic acid, bullatenone or ngaione may contribute to the anti-bacterial activity of their plant extracts. These compounds offer a starting point for future studies to characterise the chemical basis of the anti-bacterial activity of $L$. novae-zelandiae, $M$. excelsa, L. bullata and M.laetum. They may also assist in identifying ways to improve the efficiency of the extraction of anti-mycobacterial activity from the plant samples and hence, provide extracts with lower MIC values towards M. tuberculosis. Such extracts will be integral to any bioassay-guided purification of active compounds.

\section{Conclusions}

It is estimated that less than $10 \%$ of the Earth's higher plant species have been analysed for any kind of bioactivity [18]. There is a need for more research to be conducted on plants that have been traditionally used by indigenous peoples to treat tuberculosis, for the identification of new anti-tubercular drugs. New Zealand has a diverse flora which potentially offers many unique bioactive compounds. Drawing on knowledge from traditional medicine, we have identified a number of native plants which contain activity against $M$. tuberculosis. Determining the chemical species responsible for this activity will be the subject of further studies.

Competing interests

The authors declare that they have no competing interests. 
Appendices

Authors' contribution

EAE collected the plant samples, performed the solvent extractions and antibacterial assays with M. smegmatis, E. coli and S. aureus. MA perfomed the antibacterial assays in the slow-growing mycobacteria, M. bovis BCG and $M$. tuberculosis H37Ra. RVM assisted in testing the potency of the plant extracts. SS constructed the GFP-labelled S. aureus. RO'T conceived and funded the study, and planned and supervised the experimental work. All authors have read and approved the final manuscript.

\section{Acknowledgements}

We gratefully acknowledge the support of the Health Research Council of New Zealand (grant number 07/379), the Wellington Medical Research Foundation (grant no. 2009/184), and the University Research Fund, Victoria University of Wellington (grant no. 26211/1496). MA is supported by a Victoria University of Wellington PhD scholarship. We would like to thank Kathryn J O'Toole for assistance with plant species identification. We would like to thank Karori Wildlife Sanctuary (Zealandia), Otari-Wilton Bush Reserve and Kaitoke Regional Park for enabling collection of plant samples.

\section{Author Details}

1School of Biological Sciences, Victoria University of Wellington, Wellington 6140, New Zealand and 2Department of Molecular Medicine \& Pathology, School of Medical Sciences, University of Auckland, Private Bag 92019, Auckland 1142, New Zealand

Received: 18 March 2010 Accepted: 10 June 2010 Published: 10 June 2010

References

1. National Institute of Allergy and Infectious Diseases $\mathrm{NloH}$ : Understanding Microbes in Sickness and in Health. 2006 [http://www3.niaid.nih.gov/ topics/microbes/PDF/microbesbook.pdf].

2. WHO: World Health Organization Report 2009, Global tuberculosis control: epidemiology, strategy, financing. 2009 [http://www.who.int/ tb/publications/global report/2009/pdf/full reportpdff. World Health Organization

3. Wade MM, Zhang Y: Mechanisms of drug resistance in Mycobacterium tuberculosis. Frontiers in Bioscience 2004, 9:975-994.

4. WHO: World Health Organisation and the Stop TB Partnership. Building on and enhancing DOTS to meet the TB-related Millennium Development Goals. 2006.

5. IUATLD: Anti-tuberculosis drug resistance in the world, report no. 4 2008 [http://www.who.int/tb/features archive/ drsreport launch_26feb08/en/index.html]. International Union Against Tuberculosis and Lung Disease

6. CDC: Centers for Disease Control and Prevention. Emergence of Mycobacterium tuberculosis with extensive resistance to second-line drugs worldwide, 2000-2004. Morbidity and Mortality Weekly Report 2006, 55:301-305.

7. WHO: Countries that had reported at least one XDR-TB case by September 2009. 2009 [http://www.who.int/tb/challenges/xd/ xdr map sep09.pdff

8. WHO: Global Plan to Stop TB. World Health Organisation and the Stop TB Partnership 2006

9. Dye C, Espinal MA, Watt CJ, Mbiaga C, Williams BG: Worldwide incidence of multidrug-resistant tuberculosis. Journal of Infectious Diseases 2002 185(8):1197-1202

10. Rojas R, Caviedes L, Aponte JC, Vaisberg AJ, Lewis WH, Lamas G, Sarasara C, Gilman RH, Hammond GB: Aegicerin, the First Oleanane Triterpene with Wide-Ranging Antimycobacterial Activity, Isolated from Clavija procera. Journal of Natural Products 2006, 69(5):845-846.

11. Limsuwan S, Trip EN, Kouwen TRHM Piersma S. Hiranrat A Mahabusarakam W, Voravuthikunchai SP, van Dijl JM, Kayser O: Rhodomyrtone: A new candidate as natural antibacterial drug from Rhodomyrtus tomentosa. Phytomedicine 2009, 16(6-7):645-651.

12. Miller $\mathrm{CH}$, Nisa S, Dempsey S, Jack C, O'Toole R: Modifying culture conditions in chemical library screening identifies alternative inhibitors of mycobacteria. Antimicrobial Agents and Chemotherapy 2009, 53(12):5279-5283.

13. Perehinec TM, Qazi SN, Gaddipati SR, Salisbury V, Rees CE, Hill PJ: Construction and evaluation of multisite recombinatorial (Gateway) cloning vectors for Gram-positive bacteria. BMC Molecular Biology 2007,

14. Kraemer GR, landolo Jj: High-frequency transformation of Staphylococcus aureus by electroporation. Current Microbiology 1990, 21(6):373-376.

15. Novick RP: Genetic systems in Staphylococci. Methods in Enzymology 1991, 204:587-636

16. O'Toole R, Von Hofsten J, Rosqvist R, Olsson PE, Wolf-Watz H:Visualisation of zebrafish infection by GFP-labelled Vibrio anguillarum. Microbial Pathogenesis 2004, 37(1):41-46.

17. Tabuti JRS, Kukunda CB, Waako PJ: Medicinal plants used by traditional medicine practitioners in the treatment of tuberculosis and related ailments in Uganda. Journal of ethnopharmacology 2010, 127:130-136.

18. Eldeen IMS, van Staden J: Antimycobacterial activity of some trees used in South African traditional medicine. South African Journal of Botany 2007, 73:248-251.

19. Camacho-Corona Mdel R, Ramirez-Cabrera MA, Santiago OG, GarzaGonzalez E, Palacios Ide P, Luna-Herrera J: Activity against drug resistanttuberculosis strains of plants used in Mexican traditional medicine to treat tuberculosis and other respiratory diseases. Phytotherapy Research 2008, 22(1):82-85.

20. Larsen L, Benn MH, Parvez M, Perry NB: A cytotoxic triketonephloroglucinol-bullatenone hybrid from Lophomyrtus bullata. The Royal Society of Chemistry 2005, 3:3236-3241.

21. Newton SM, Lau C, Wright CW: A review of antimycobacterial natural products. Phytotherapy Research 2000, 14(5):303-322.

22. Brooker SG, Cambie RC, Cooper RC: New Zealand Medicinal Plants. 2nd edition. Auckland Reed Publishing (NZ) Ltd; 1987.

23. Goldie WH: Maori Medical Lore. Transactions of the New Zealand Institute. Auckland Southern Reprints:" 1998.

24. Clarke A: Botanist's records of medicinal plants uses. In The great sacred forest of Tane Auckland. Reed Publishing; 2007:322.

25. Wassilieff M: Tall broadleaf trees - Forest giants. Te Ara - the Encyclopedia of New Zealand 2009 .

26. Dajas-Bailador FA, Asencio M, Bonilla C, Scorza MC, Echeverry C, ReyesParada M, Silveira R, Protais P, Russell G, Cassels BK, et al.: Dopaminergic pharmacology and antioxidant properties of pukateine, a natural product lead for the design of agents increasing dopamine neurotransmission. General Pharmacology 1999, 32(3):373-379

27. Valiente $M, D^{\prime} O$ con $P$, Noguera MA, Cassels BK, Lugnier C, Ivorra MD: Vascular activity of (-)-anonaine, (-)-roemerine and (-)-pukateine, three

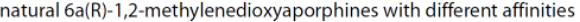
for alpha1-adrenoceptor subtypes. Planta Medica 2004, 70(7):603-609.

28. Brooker SG, Cambie RC, Cooper RC: New Zealand Medicinal Plants. Auckland Heinemann publishers; 1981

29. Taylor R: A leaf from the natural history of New Zealand. 1848

30. Brooker SG, Cooper RC: New Zealand Medicinal Plants. Economic Botany 1962, 15(1):1-10

31. Martin M: He Pukapuka Whakaata Tikanga Mo Nga Rongoa Mo Nga Kai. Auckland Henry Hill Publishers; 1869.

32. Macdonald C: Medicines of the maori. Auckland Collins; 1974

33. Riley M: Maori Healing and Herbal: New Zealand Ethnobotanical Sourcebook. Paraparaumu Viking Sevenseas N.Z. Ltd; 1994.

34. Parsons C: Healing practices of the south pacific. University of Hawaii press; 1985.

Pre-publication history

The pre-publication history for this paper can be accessed here http://wwwbiomedcentral.com/1472-6882/10/25/prepub

doi: $10.1186 / 1472-6882-10-25$

Cite this article as: Earl et al., Native New Zealand plants with inhibitory activity towards Mycobacterium tuberculosis BMC Complementary and Alternative Medicine 2010, 10:2 
Appendix 2: Bacteriostatic inhibition curves of extracts with activity against $M$. smegmatis

Dose-response experiments were performed on the active extracts that were found to have $\geq 90 \%$ inhibition in the initial screen against $M$. smegmatis. Figure A.2 depicts the bacteriostatic curves for the active extracts from L. bullata, $M$. excelsa, M. laetum, $P$. tenuifolium, $P$. crassifolius and P. colorata species.
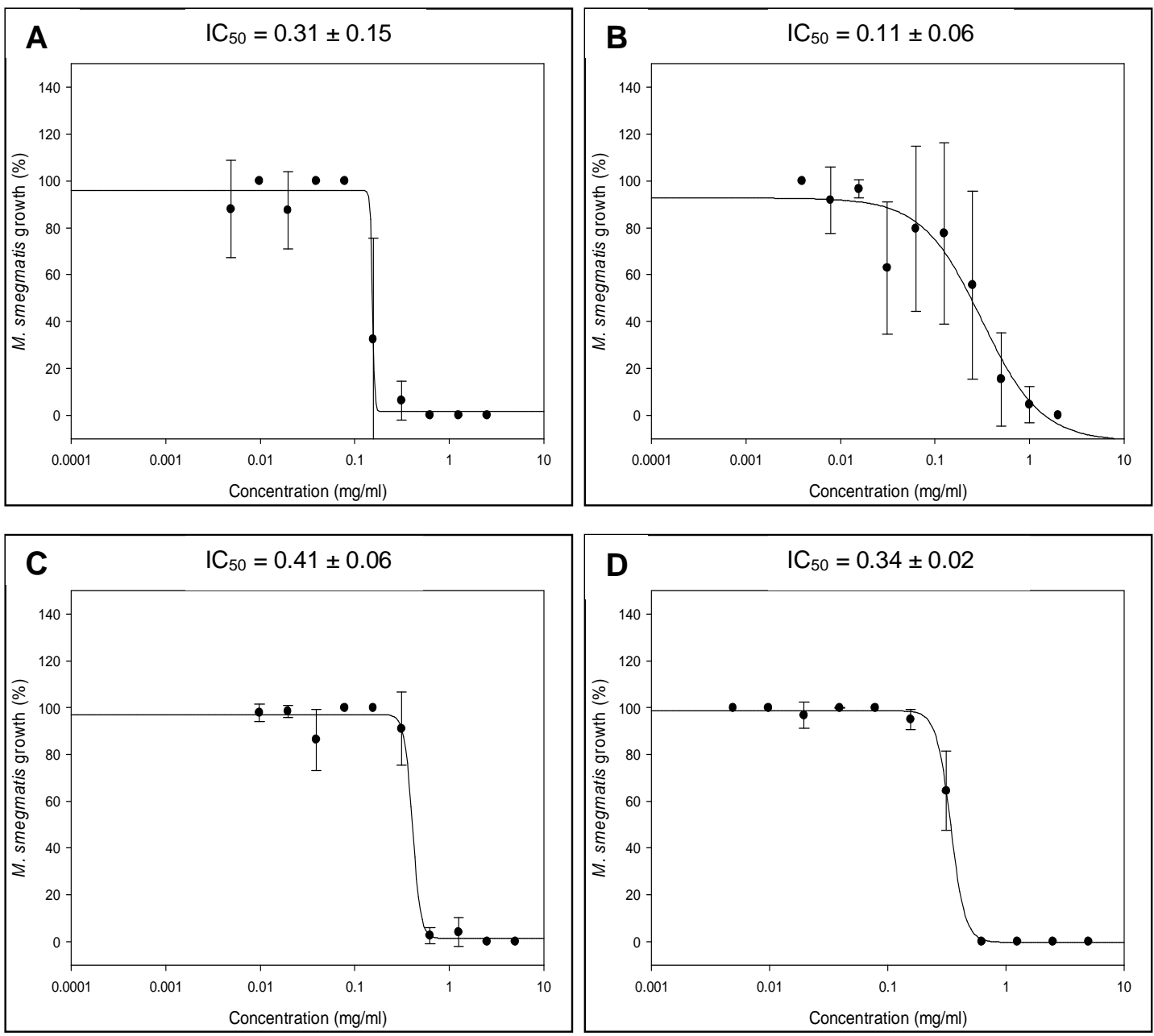

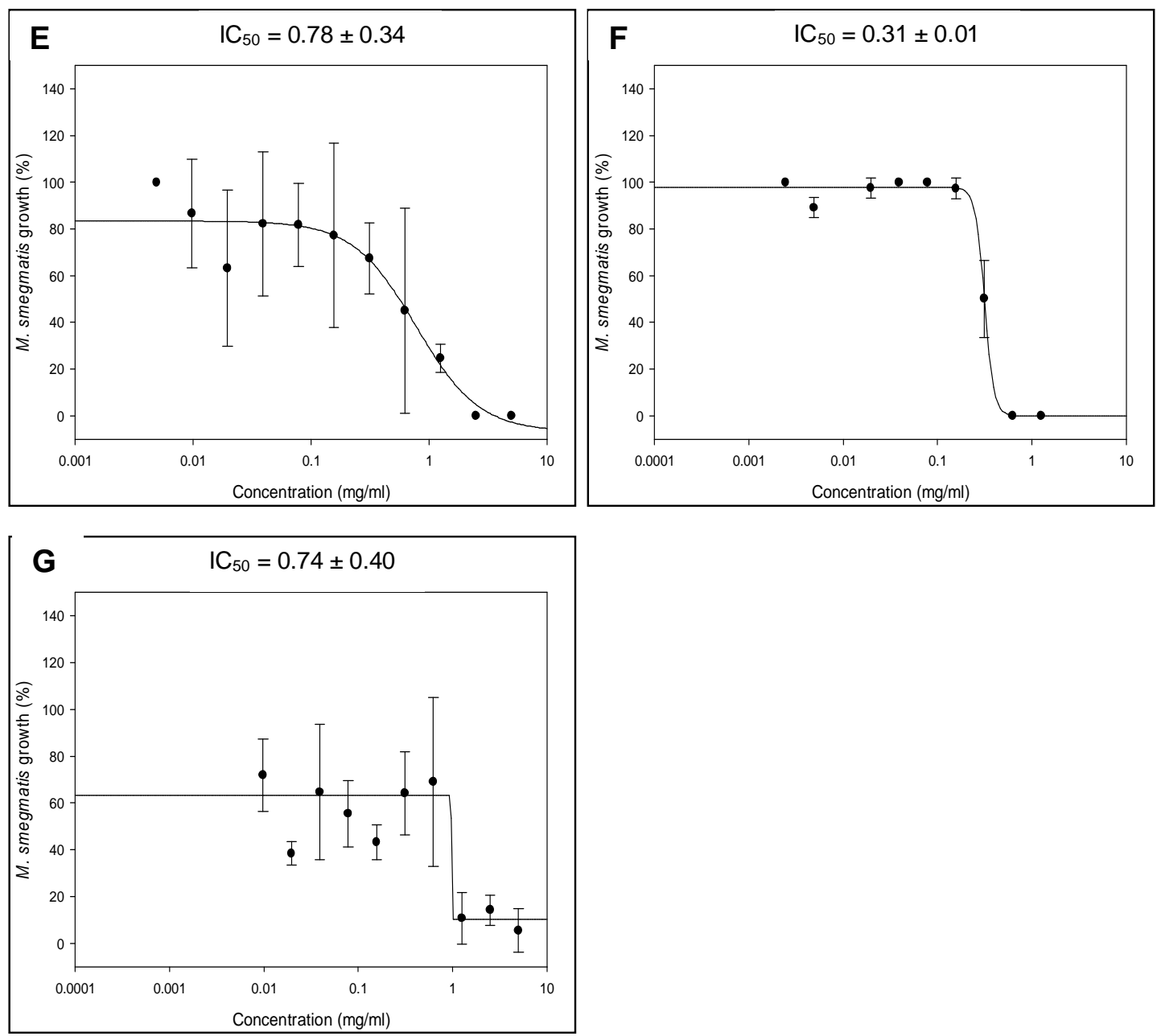

Figure A.2. Bacteriostatic inhibition curves of active extracts against $\boldsymbol{M}$. smegmatis. A) $\mathrm{MeOH}$ leaf extract $L$. bullata, B) $\mathrm{MeOH}$ leaf extract of $M$. excelsa, C) $\mathrm{EtOH}$ flower extract of $M$. excelsa, D) AQ leaf extract of $M$. laetum, E) $\mathrm{EtOH}$ leaf extract of $P$. tenuifolium, $\mathbf{F}$ ) EtOH leaf extract of $P$. crassifolius, $\mathbf{G}) \mathrm{MeOH}$ leaf extract of $P$. colorata. Values are based on GFP results. $100 \%$ represents complete growth of $M$. smegmatis cells compared to the untreated control. Error bars denote standard deviation between triplicate values. 